Prepared for the U.S. Department of Energy

under Contract DE-AC05-76RL01830

\title{
Characterization of U-Mo Foils for AFIP-7
}

DJ Edwards

RM Ermi

AL Schemer-Kohrn

November 2012

\author{
NR Overman
}

$\mathrm{CH}$ Henager Jr

D Burkes

DJ Senor

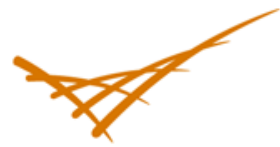

Pacific Northwest

NATIONAL LABORATORY

Proudly Operated by Battelle Since 1965 



\title{
DISCLAIMER
}

This report was prepared as an account of work sponsored by an agency of the United States Government. Neither the United States Government nor any agency thereof, nor Battelle Memorial Institute, nor any of their employees, makes any warranty, express or implied, or assumes any legal liability or responsibility for the accuracy, completeness, or usefulness of any information, apparatus, product, or process disclosed, or represents that its use would not infringe privately owned rights. Reference herein to any specific commercial product, process, or service by trade name, trademark, manufacturer, or otherwise does not necessarily constitute or imply its endorsement, recommendation, or favoring by the United States Government or any agency thereof, or Battelle Memorial Institute. The views and opinions of authors expressed herein do not necessarily state or reflect those of the United States Government or any agency thereof.

\author{
PACIFIC NORTHWEST NATIONAL LABORATORY \\ operated by \\ BATTELLE \\ for the \\ UNITED STATES DEPARTMENT OF ENERGY \\ under Contract DE-AC05-76RL01830
}

Printed in the United States of America
Available to DOE and DOE contractors from the Office of Scientific and Technical Information,
P.O. Box 62, Oak Ridge, TN 37831-0062;
ph: (865) 576-8401
fax: $(865)$ 576-5728
email: reports@adonis.osti.gov

\begin{abstract}
Available to the public from the National Technical Information Service, U.S. Department of Commerce, 5285 Port Royal Rd., Springfield, VA 22161 ph: (800) 553-6847 fax: $(703) 605-6900$ email: orders@ntis.fedworld.gov online ordering: http://www.ntis.gov/ordering.htm
\end{abstract}

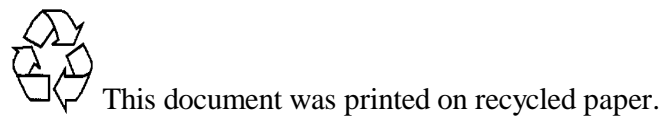


PNNL-21990

\section{Characterization of U-Mo Foils for AFIP-7}

DJ Edwards

RM Emi

AL Schemer-Kohrn

NR Overman
$\mathrm{CH}$ Henager Jr

D Burkes

DJ Senor

November 2012

Prepared for the U.S. Department of Energy under Contract DE-AC05-76RL01830

Pacific Northwest National Laboratory

Richland, Washington 99352 


\section{PNNL-21990}

\section{Characterization of U-Mo Foils for AFIP-7}

Final Report

September 2012

Prepared by

Battelle Pacific Northwest Division

P.O. Box 999

Richland, Washington 99352

Principal Investigators:

Dan Edwards, Ruby Ermi, Alan Schemer-Kohrn,

Nicole Overman, Chuck Henager, Doug Burkes and

Dave Senor

Prepared for

Idaho National Laboratory

RERTR Characterization Lead

Dennis Keiser 
DISCLAIMER OF WARRANTIES AND LIMITATION OF LIABILITIES

THIS REPORT WAS PREPARED BY THE ORGANIZATION(S) NAMED BELOW AS AN ACCOUNT OF WORK SPONSORED OR COSPONSORED BY THE ELECTRIC POWER RESEARCH INSTITUTE, INC. (EPRI). NEITHER EPRI, ANY MEMBER OF EPRI, ANY COSPONSOR, THE ORGANIZATION NAMED BELOW, NOR ANY PERSON ACTING ON BEHALF OF ANY OF THEM:

(A) MAKES ANY WARRANTY OR REPRESENTATION WHATSOEVER, EXPRESS OR IMPLIED, (I) WITH RESPECT TO THE USE OF ANY INFORMATION, APPARATUS, METHOD, PROCESS, OR SIMILAR ITEM DISCLOSED IN THIS REPORT, INCLUDING MERCHANTABILITY AND FITNESS FOR A PARTICULAR PURPOSE, OR (II) THAT SUCH USE DOES NOT INFRINGE ON OR INTERFERE WITH PRIVATELY OWNED RIGHTS, INCLUDING ANY PARTY'S INTELLECTUAL PROPERTY, OR (III) THAT THIS REPORT IS SUITABLE TO ANY PARTICULAR USER'S CIRCUMSTANCE; OR

(B) ASSUMES RESPONSIBILITY FOR ANY DAMAGES OR OTHER LIABILITY WHATSOEVER (INCLUDING ANY CONSEQUENTIAL DAMAGES, EVEN IF EPRI OR ANY EPRI REPRESENTATIVE HAS BEEN ADVISED OF THE POSSIBILITY OF SUCH DAMAGES) RESULTING FROM YOUR SELECTION OR USE OF THIS REPORT OR ANY INFORMATION, APPARATUS, METHOD, PROCESS, OR SIMILAR ITEM DISCLOSED IN THIS REPORT.

ORGANIZATION(S) THAT PREPARED THIS REPORT

Battelle Pacific Northwest Division 


\section{REPORT SUMMARY}

Twelve AFIP in-process foil samples, fabricated by either Y-12 or LANL, were shipped from LANL to PNNL for potential characterization using optical and scanning electron microscopy techniques. Of these twelve, nine different conditions were examined to one degree or another using both techniques. For this report a complete description of the results are provided for one archive foil from each source of material, and one unirradiated piece of a foil of each source that was irradiated in the Advanced Test Reactor. Additional data from two other LANL conditions are summarized in very brief form in an appendix.

The characterization revealed that all four characterized conditions contained a cold worked microstructure to different degrees. The Y-12 foils exhibited a higher degree of cold working compared to the LANL foils, as evidenced by the highly elongated and obscure U-Mo grain structure present in each foil. The longitudinal orientations for both of the Y-12 foils possesses a highly laminar appearance with such a distorted grain structure that it was very difficult to even offer a range of grain sizes. The U-Mo grain structure of the LANL foils, by comparison, consisted of a more easily discernible grain structure with a mix of equiaxed and elongated grains. Both materials have an inhomogenous grain structure in that all of the characterized foils possess abnormally coarse grains.

The zirconium layers of the Y-12 foils exhibit greater undulation in the sense of more periodicity in the wave front, however, the LANL foils were found to have less periodic undulation, but greater shifts in thickness, in some cases producing regions that could be as thick as $35-40 \mu \mathrm{m}$ thick regions to localized regions that tapered down to as low as $6-10 \mu \mathrm{m}$. All foils were found to have fairly uniform surfaces on the exterior zirconium surfaces, and ranged in thickness from 335 to $350 \mu \mathrm{m}$ of total thickness.

Up to four discrete interaction layers were observed in the archive LANL foil, which was consistent over the observed width of the cross-section in both orientations. On the other hand, both of the characterized Y-12 conditions showed a discontinuous interface between the zirconium and U-Mo, that is, a highly non-uniform reaction layer formed in these materials. In localized colonies the four distinct interaction layers could be identified, but outside of these regions the interaction layers consisted of usually just two layers with varying levels of uranium and minor levels of Mo with no discernible precipitation at the nanoscale. The LANL foil sent for irradiation surprisingly had a discontinuous interface, similar to the Y-12 foils but not to the same degree. The presence of Fe contamination was also observed to a limited extent in each foil, but only in the Y-12 foil sent for irradiation were discrete phase regions found that were tentatively identified as an $\mathrm{Zr}_{3} \mathrm{Fe}$ phase based solely upon composition. 


\section{ACKNOWLEDGEMENTS}

The assistance of the following staff at PNNL is greatly appreciated: John Keaveney, Ruby Ermi and Clyde Chamberlin for their help in setting up the facilities to prepare the numerous specimens characterized in this program. The project leaders would also like to acknowledge the efforts of Ruby Ermi and Alan Schemer-Kohrn for their diligent work in preparing and

characterizing the samples, and working beyond normal working schedules to make this project a success. 


\section{Contents}

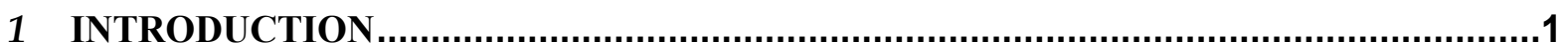

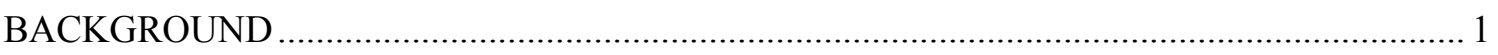

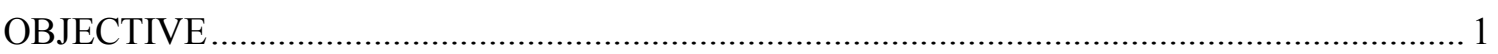

2 MATERIALS AND EXPERIMENTAL PROCEDURE .....................................................

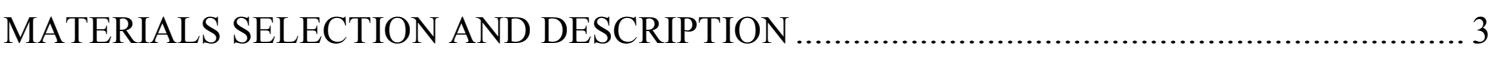

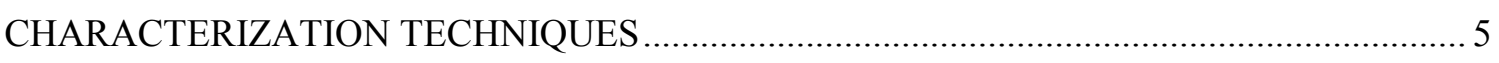

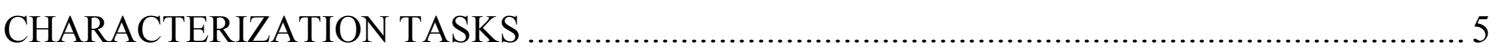

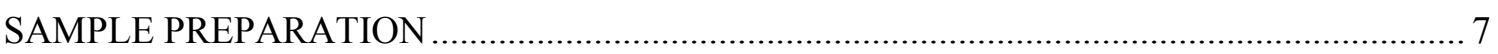

3 CHARACTERIZATION RESULTS: LANL FOIL R1X4 ARCHIVE (63240)

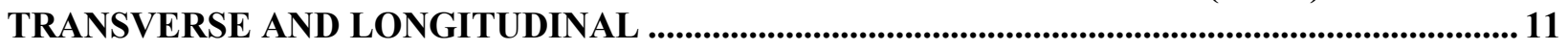

OPTICAL METALLOGRAPHY \& LOW MAGNIFICATION FEG-SEM IMAGING............. 11

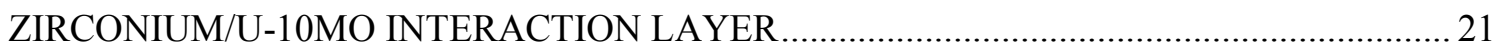

SUMMARY OF RESULTS FOR LANL FOIL R1X4 ARCHIVE........................................... 22

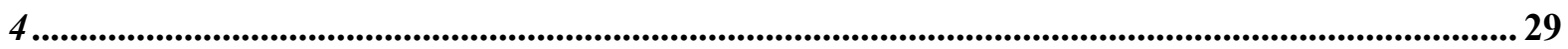

CHARACTERIZATION RESULTS: Y-12 FOIL R9HW ARCHIVE (63233)

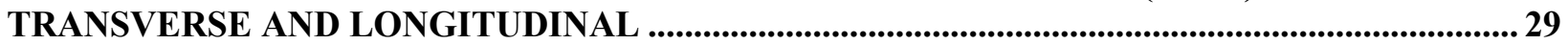

OPTICAL METALLOGRAPHY \& LOW MAGNIFICATION FEG-SEM IMAGING ............. 29

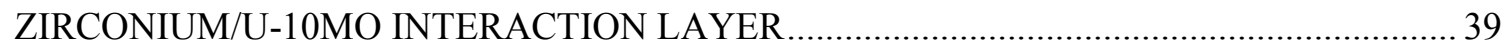

SUMMARY OF RESULTS FOR Y-12 FOIL R9HW ARCHIVE ........................................... 43

5 CHARACTERIZATION RESULTS: Y-12 U-10MO FOIL R9HT (63231)

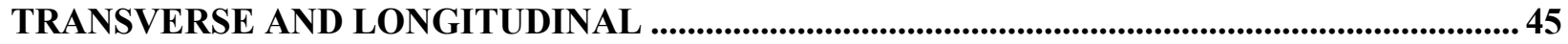

OPTICAL METALLOGRAPHY \& LOW MAGNIFICATION FEG-SEM IMAGING............. 45

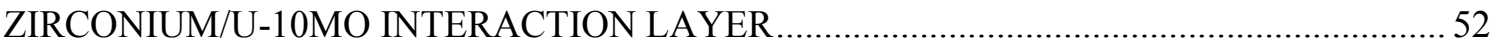

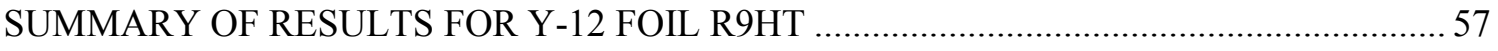

6 CHARACTERIZATION RESULTS: LANL U-10MO FOIL: R1X6 (63238)

TRANSVERSE AND LONGITUDINAL ......................................................................................58

OPTICAL METALLOGRAPHY \& LOW MAGNIFICATION FEG-SEM IMAGING............. 58

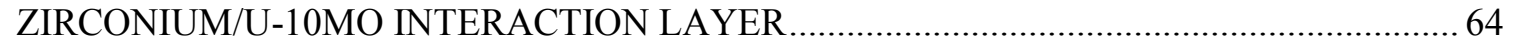

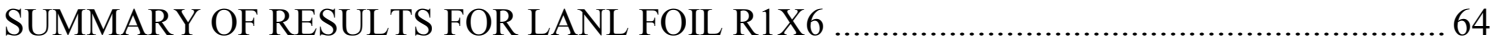




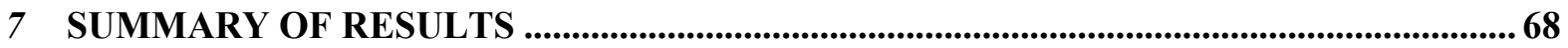

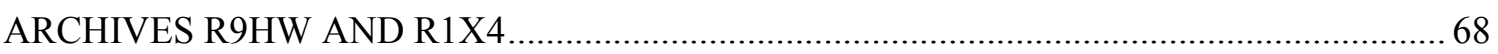

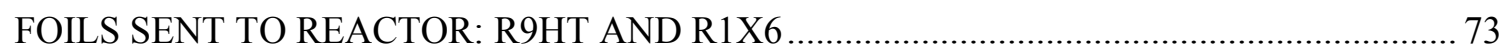

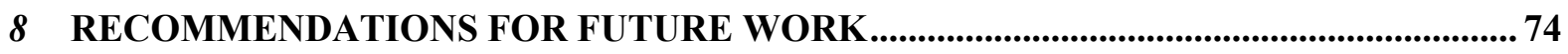

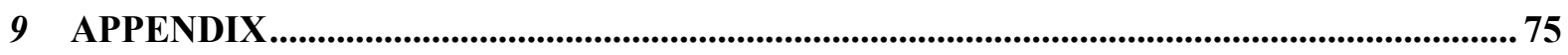




\section{1}

\section{INTRODUCTION}

\section{Background}

The ATR Full-size plate In center flux trap Position (AFIP)-7 experiment was designed to evaluate the performance of aluminum-clad monolithic uranium-molybdenum (U-Mo) fuel plates at a scale prototypic of Advanced Test Reactor (ATR) fuel plates. Foils were fabricated at Los Alamos National Laboratory (LANL) and the Y-12 National Security Complex (Y-12 NSC) for this effort. A number of foils were fabricated that eventually resulted in four fuel plates for irradiation testing in the ATR and two archive fuel plates.

The fuel foils consisted of a monolithic U-10Mo (nominal weight percent) enriched to nominally $19.75 \% \mathrm{U}^{235}$. The fuel meat had a target thickness of $0.013 \mathrm{in}$. with a $0.001 \mathrm{in}$. thick $\mathrm{Zr}$ coating on either side of the foil, resulting in an overall foil target thickness of $0.015 \mathrm{in}$. The foils were fabricated utilizing a two stage rolling process. The first stage involved hot rolling a U-10Mo coupon with two sheets of $\mathrm{Zr}$ foil on either side and hermetically sealed in a carbon steel can to metallurgically bond the $\mathrm{Zr}$ coating to the U-10Mo meat. A cold rolling operation was then performed to improve the homogeneity and uniformity of the fuel foil down to the target thickness. The process utilized to prepare the fuel foils is similar to that described in Reference 1.

\section{Objective}

The AFIP-7 in-process fuel foil characterization was a collaborative effort between Idaho National Laboratory (INL) and Pacific Northwest National Laboratory (PNNL). The specific characterization requirements for this effort were communicated to PNNL on March 2, 2012 [2]. A total of twelve in-process foil samples were shipped from LANL to PNNL. These samples were received at PNNL on May 9, 2012. Multiple sample pieces were provided to facilitate Optical Microscopy (OM) and Scanning Electron Microscopy (SEM). The specific characteristics that were investigated by OM and SEM are addressed in detail in the following section. Three of the 12 foils were duplicates of other foils, leaving a total of nine actual

\footnotetext{
${ }^{1}$ G.A. Moore and M.C. Marshall, “Co-Rolled U10Mo/Zirconium-Barrier-Layer Monolithic Fuel Foil Fabrication Process,” Idaho National Laboratory Report INL/EXT-10-17774 (2010).

2 “AFIP-7 In-Process Fuel Foil Characterization Request”, INL Interoffice Memorandum from D.D. Keiser et al. (INL) to D.E. Burkes (PNNL), dated March 2, 2012. 1
} 
conditions slated for characterization. Three of the foils were fabricated by Y-12, the remaining foils were each fabricated by LANL. 
MATERIALS AND EXPERIMENTAL PROCEDURE

\section{Materials Selection and Description}

The samples were packaged inside of individual small plastic bags, with details listed in each bag regarding the net sample weight, $U$ and $U^{235}$ content and level of enrichment. Each piece had markings indicating the rolling direction, and in some cases the sample ID. An example of the packaging is shown in Figure 1. A list of the samples is provided in Table 1, summarizing the details of each condition with respect to the uranium and $U^{235}$ content, and level of enrichment. The last 4 digits of the Foil ID were used as a shorthand method to label each condition prepared for characterization.

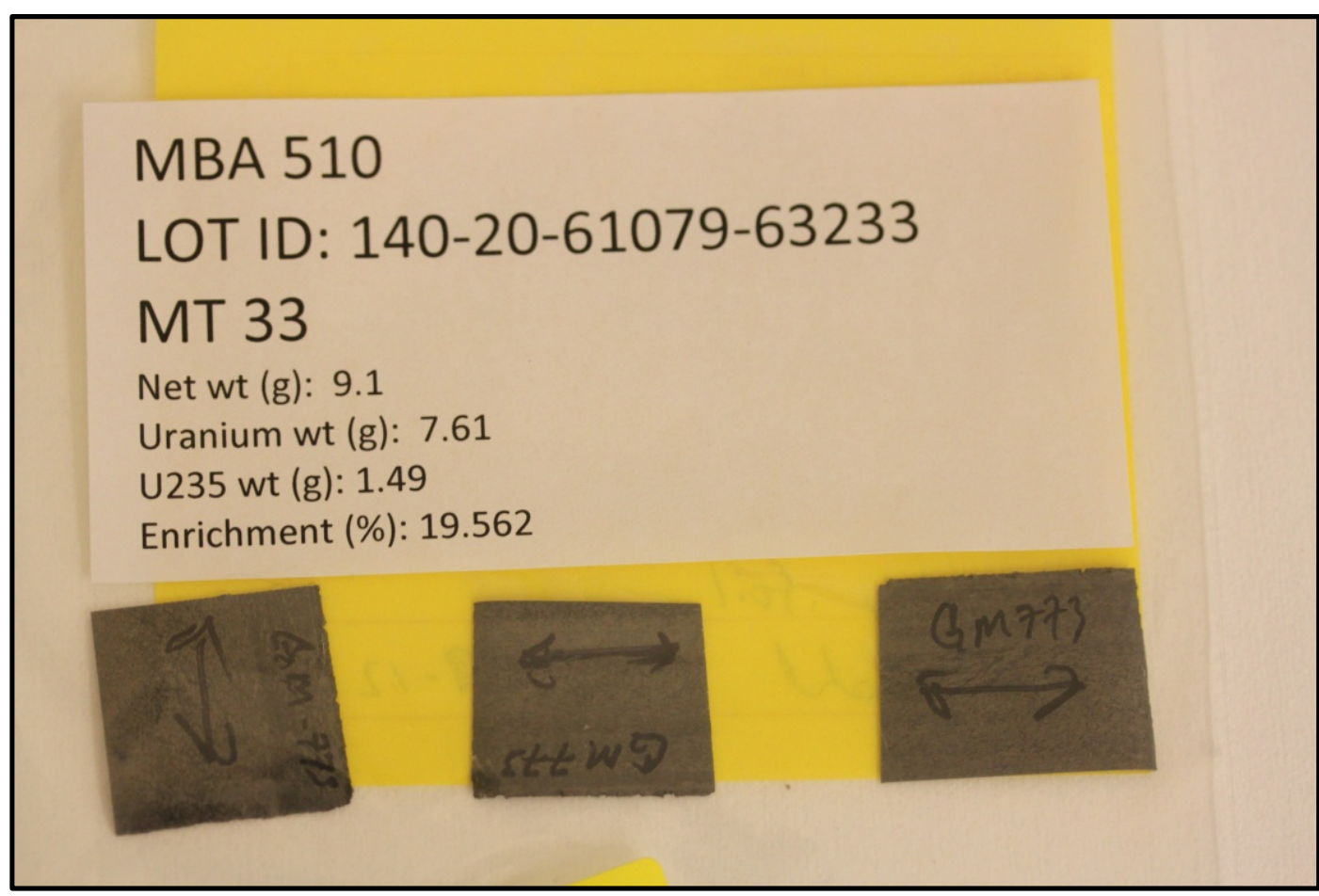

Figure 2-1. An example of the individual pieces included in a single plastic bag for condition GM773, listed in Table 2 as R9HW. 
Table 2-1. List of samples and various codes used to identify each condition.

\begin{tabular}{|c|c|c|c|c|c|c|c|c|c|c|c|c|}
\hline ID & $\begin{array}{l}\text { Safeguards Material } \\
\text { Identification }\end{array}$ & Foil ID & Plate ID & $\begin{array}{c}\text { Sample } \\
\#\end{array}$ & $\begin{array}{l}\text { Unique } \\
\text { ID }\end{array}$ & $\begin{array}{l}\text { BATCH } \\
\text { NUMBER }\end{array}$ & Description & $\begin{array}{l}\text { Net } \\
\text { WT } \\
\text { (g) }\end{array}$ & $\begin{array}{l}\text { U WT } \\
\text { (g) }\end{array}$ & $\begin{array}{l}U^{235} W^{2} T \\
(g)\end{array}$ & $\begin{array}{l}\% \mathrm{U}^{235} \\
\text { Enrich }\end{array}$ & $\begin{array}{l}\text { Pieces } \\
\text { as- } \\
\text { received }\end{array}$ \\
\hline R9HT & $\begin{array}{c}\text { U-Mo Foil } \\
63231 \\
\end{array}$ & $\begin{array}{l}\text { 3E67LA } \\
\text { R9HT }\end{array}$ & $7 Z \mathrm{H}-1$ & GM-771 & $\begin{array}{c}\text { GM-771- } \\
3 \\
\end{array}$ & $\begin{array}{c}140-20- \\
61010-63231 \\
\end{array}$ & $\begin{array}{l}\text { 3E67LAR9HT, Y-12, G. Moore, U- } \\
\text { 10Mo Foil, plate went to reactor }\end{array}$ & 4.740 & 3.967 & 0.77602 & $19.562 \%$ & 3 \\
\hline R9HV & $\begin{array}{l}\text { U-Mo Foil } \\
63232\end{array}$ & $\begin{array}{l}\text { 3E67LA } \\
\text { R9HV }\end{array}$ & & GM-772 & $\begin{array}{c}\text { GM-772- } \\
3 \\
\end{array}$ & $\begin{array}{c}140-20- \\
61078-63232 \\
\end{array}$ & $\begin{array}{l}\text { 3E67LAR9HV, Y-12, G. Moore, U- } \\
\text { 10Mo Foil only }\end{array}$ & 7.490 & 6.259 & 1.22439 & $19.562 \%$ & 3 \\
\hline R9HW & $\begin{array}{c}\text { U-Mo Foil } \\
63233\end{array}$ & $\begin{array}{l}\text { 3E67L } \\
\text { R9HW }\end{array}$ & ARCHIVE & GM-773 & $\begin{array}{c}\text { GM-773- } \\
3\end{array}$ & $\begin{array}{c}140-20- \\
61079-63233 \\
\end{array}$ & $\begin{array}{l}\text { 3E67LAR9HW, Y-12 G. Moore, U- } \\
\text { 10Mo, Y-12 ARCHIVE }\end{array}$ & 9.080 & 7.606 & 1.48789 & $19.562 \%$ & 3 \\
\hline PVME & $\begin{array}{l}\text { U-Mo Foil } \\
63234-0\end{array}$ & $\begin{array}{l}\text { 3G60-CK- } \\
\text { PVME }\end{array}$ & $7 Z \mathrm{H}-2$ & $\begin{array}{l}\text { SAM-11- } \\
25\end{array}$ & BM-809 & $\begin{array}{c}140-20- \\
61091-63234\end{array}$ & $\begin{array}{c}\text { PVME-JK7, from LANL, BM-809, } \\
\text { foil, plate went to reactor }\end{array}$ & 2.8 & 2.4 & 0.474792 & $19.783 \%$ & 1 \\
\hline PVME & $\begin{array}{l}\text { U-Mo Foil } \\
63234-3\end{array}$ & $\begin{array}{l}\text { 3G60-CK- } \\
\text { PVME }\end{array}$ & $7 Z \mathrm{H}-2$ & $\begin{array}{l}\text { SAM-11- } \\
25\end{array}$ & $\begin{array}{c}\text { BM-809- } \\
3\end{array}$ & $\begin{array}{c}140-20- \\
61091-63234\end{array}$ & $\begin{array}{l}\text { PVME-JK8, from LANL, BM-809, } \\
\text { foil, plate went to reactor }\end{array}$ & 3 & 2.6 & 0.514358 & $19.783 \%$ & 1 \\
\hline PVNF & $\begin{array}{c}\text { U-Mo Foil } \\
63234-1\end{array}$ & $\begin{array}{l}\text { 3G60-CK- } \\
\text { PVNF }\end{array}$ & & $\begin{array}{l}\text { SAM-11- } \\
27\end{array}$ & $\begin{array}{c}\text { BM-809- } \\
1 \\
\end{array}$ & $\begin{array}{c}140-20- \\
61091-63234 \\
\end{array}$ & $\begin{array}{l}\text { PVNF-18, from LANL, BM-809, foil } \\
\text { only }\end{array}$ & 2.4 & 2 & 0.39566 & $19.783 \%$ & 1 \\
\hline PVNF & $\begin{array}{l}\text { U-Mo Foil } \\
63234-5\end{array}$ & $\begin{array}{c}\text { 3G60-CK- } \\
\text { PVNF }\end{array}$ & & $\begin{array}{l}\text { SAM-11- } \\
27 \\
\end{array}$ & $\begin{array}{c}\text { BM-809- } \\
5 \\
\end{array}$ & $\begin{array}{c}140-20- \\
61091-63234 \\
\end{array}$ & $\begin{array}{c}\text { PVNF-17, from LANL, BM-809, foil } \\
\text { only }\end{array}$ & 2.7 & 2.3 & 0.455009 & $19.783 \%$ & 1 \\
\hline PVMF & $\begin{array}{l}\text { U-Mo Foil } \\
63234-4\end{array}$ & $\begin{array}{l}\text { 3G60-CK- } \\
\text { PVMF }\end{array}$ & $7 Z \mathrm{H}-4$ & $\begin{array}{l}\text { SAM-11- } \\
26 \\
\end{array}$ & $\begin{array}{c}\text { BM-809- } \\
4 \\
\end{array}$ & $\begin{array}{c}140-20- \\
61091-63234 \\
\end{array}$ & $\begin{array}{l}\text { PVMF-10, from LANL, BM-809, } \\
\text { foil, plate went to reactor }\end{array}$ & 2.7 & 2.3 & 0.455009 & $19.783 \%$ & 1 \\
\hline PVMF & $\begin{array}{l}\text { U-Mo Foil } \\
63234-2\end{array}$ & $\begin{array}{l}\text { 3G60-CK- } \\
\text { PVMF }\end{array}$ & $7 Z \mathrm{H}-4$ & $\begin{array}{l}\text { SAM-11- } \\
26 \\
\end{array}$ & $\begin{array}{c}\text { BM-809- } \\
2 \\
\end{array}$ & $\begin{array}{c}140-20- \\
61091-63234 \\
\end{array}$ & $\begin{array}{c}\text { PVMF-12, from LANL, BM-809, } \\
\text { foil, plate went to reactor }\end{array}$ & 2.3 & 2 & 0.39566 & $19.783 \%$ & 1 \\
\hline R1X9 & $\begin{array}{l}\text { U-Mo Foil } \\
63236\end{array}$ & $\begin{array}{l}\text { 3G60-CK- } \\
\text { R1X9 }\end{array}$ & & $\begin{array}{l}\text { SAM-11- } \\
29\end{array}$ & $\begin{array}{c}\text { BM-809- } \\
6-1\end{array}$ & $\begin{array}{c}140-20- \\
61091-63236\end{array}$ & $\begin{array}{c}\text { 3G60-CK-R1X9-ARCH-1, from } \\
\text { LANL,BM-809, cut } 1 \text { to LANL, foil } \\
\text { only }\end{array}$ & 4.58 & 3.881 & 0.70140168 & $19.881 \%$ & 1 \\
\hline R1X6 & $\begin{array}{l}\text { U-Mo Foil } \\
63238\end{array}$ & $\begin{array}{l}\text { 3G60-CK- } \\
\text { R1X6 }\end{array}$ & $7 Z \mathrm{H}-3$ & $\begin{array}{l}\text { SAM-11- } \\
30\end{array}$ & $\begin{array}{c}\text { BM-809- } \\
7-1\end{array}$ & $\begin{array}{c}140-20- \\
61091-63238\end{array}$ & $\begin{array}{l}\text { 3G60-CN-R1X6-ARCH-1, from } \\
\text { LANL, BM-809, Cut } 1 \text { to LANL, foil, } \\
\text { plate went to reactor }\end{array}$ & 3.81 & 3.301 & 0.65627181 & $19.881 \%$ & 1 \\
\hline R1X4 & $\begin{array}{l}\text { U-Mo Foil } \\
63240\end{array}$ & $\begin{array}{l}\text { 3G60-CK- } \\
\text { R1X4 }\end{array}$ & ARCHIVE & $\begin{array}{l}\text { SAM-11- } \\
28\end{array}$ & $\begin{array}{l}\text { BM-809- } \\
8-1\end{array}$ & $\begin{array}{l}14-20-61091- \\
63240\end{array}$ & $\begin{array}{c}\text { 3G60-CK-R1X4-ARCH-1, from } \\
\text { LANL, Cut } 1 \text { to LANL, LANL } \\
\text { ARCHIVE }\end{array}$ & 4.08 & 3.528 & 0.77158161 & $19.881 \%$ & 1 \\
\hline
\end{tabular}




\section{Characterization Techniques}

\section{Optical Microscopy}

An Olympus BX61 optical microscope was used for the optical metallography of the samples. This microscope is equipped with polarization filters, a Nomarski filter for differential interference contrast imaging and a motorized stage. Images are digitally captured using an Olympus UC50 camera, and acquired using the Olympus Stream software package. The microscope is equipped with an objective lens that can image the sample from $25 \mathrm{x}$ up to $500 \mathrm{x}$.

\section{Scanning Electron Microscope}

Characterization of the polished samples was performed on a JEOL 7600F field emission scanning electron microscope (FEG-SEM). The JEOL 7600F is equipped with a modern EDS detector, an Oxford Instruments X-Max $80 \mathrm{~mm} 2$, a Nordlys camera for electron backscatter diffraction analysis (EBSD), and three different types of electron detectors. The first is a low angle backscatter electron (LABE) detector exclusive to the JEOL 7600F, which provides a topdown perspective on the sample that is sensitive to compositional differences. The second type of detector is the LEI, a conventional Everhart-Thornley detector sensitive to both high energy secondary and backscatter electrons that is more sensitive to topographic variations on the sample surface. The third detector is an in-lens secondary detector (top down perspective) that is very sensitive to the very low energy secondary electrons $(<50 \mathrm{eV})$ produced by the primary electron beam interactions, providing high resolution information from the near surface regions. The low energy secondary electrons can only escape from within $2-5 \mathrm{~nm}$ of the surface, whereas backscatter electrons and higher energy secondary electrons are generated and can escape from hundreds of nanometers below the surface. The Oxford AZtec software system was used for all EDS analytical analysis. This instrument offers a range of accelerating voltage from $30 \mathrm{keV}$ to $0.5 \mathrm{keV}$. In combination with the fine probe, high beam currents from the field emission gun, the modern detectors, and the range of accelerating voltages, we were able to image the nanoscale features in the samples with little difficulty.

Note that any sample examined in the FEG-SEM was first coated with carbon to overcome the charging due to the presence of epoxy and the glass slides. The carbon layer was typically 5 $\mathrm{nm}$ or less, preferably no thicker than necessary to negate the specimen charging.

\section{Characterization Tasks}

INL requested that the following information be obtained from each set of material. In some cases this was not possible because a certain technique or feature was not available, for instance, no microprobe is available for work on radiological materials in our facilities, so this analysis was not included in this work.

\section{Optical Microscopy}

OM will be performed on fuel foil samples to obtain information on the following:

a) Microscopic defects (as needed)

i. Cracks and pores 
ii. Second phases

iii. Line up defects (more than $2 \mathrm{~mm}$ )

iv. Volume fraction and distribution of secondary phase

b) Grain size and grain structure (ASTM E112)

c) Grain aspect ratio

d) Banding (required magnifications: 100x, 200x, 00x)

e) General images (required magnifications: 100x, 200x, 500x)

f) Montage (taken at 200x)

A note about measuring grain sizes. As will be shown, polished cross-sections revealed that the grain structure of these particular foils consists of a heavily cold worked grain structure intermixed in some cases with abnormally coarse grains. This complex grain structure resists definition in regards to an ASTM grain size because ASTM standard E112 is written for well annealed structures, and specifically states that it should not be applied to heavily cold worked materials. Even with an etched surface (which was not attempted in this study) as called for in ASTM standard E112, a bimodal or complex grain structure may still be observed. Any material with a bimodal grain structure is directed to a different ASTM standard E1 181, and ASTM standard E930 should be used to estimate the size of the coarsest grain in the metallographic sample.

\section{Scanning Electron Microscopy (limited to areas of interest)}

SEM will be used to analyze areas of interest as identified by optical microscopy. Areas of interest could include the following:

a) Microscopic defects (as needed)

i. $\quad$ Cracks and pores

ii. Second phases

iii. $\quad$ Line up defects(more than $2 \mathrm{~mm}$ )

b) Second phases and homogeneity

i. Use EDS to determine chemical compositions of second phases and fuel foil (requested magnifications: 500x, 2000x).

ii. Banding (EDS is requested to determine chemical composition of banding).

iii. Distribution and volume fraction of second phases

c) $\mathrm{Zr} / \mathrm{U}-\mathrm{Mo}$ interaction layer

i. Phases

ii. Fraction of interface without interaction (average of a 4 to $5 \mathrm{~mm}$ length, both sides of foil).

iii. Element mapping for $\mathrm{O}, \mathrm{Fe}, \mathrm{U}, \mathrm{Zr}, \mathrm{Mo}, \& \mathrm{C}$.

iv. Microprobe for the composition of interaction layer (not available).

EBSD was not specifically called out in the request, however, it was indicated during discussions in the initial planning with INL that EBSD could answer several outstanding questions if we could obtain diffraction patterns from the sample. Assuming a reasonable indexing percentage of the patterns, that is, the patterns could be assigned unambiguously to a particular phase and indexed crystallographically, the grain size, phase identification, pole figures, texture of the phases, estimation of strain, plus a variety of other types of information could be extracted from the EBSD maps. To accomplish this, however, requires an 


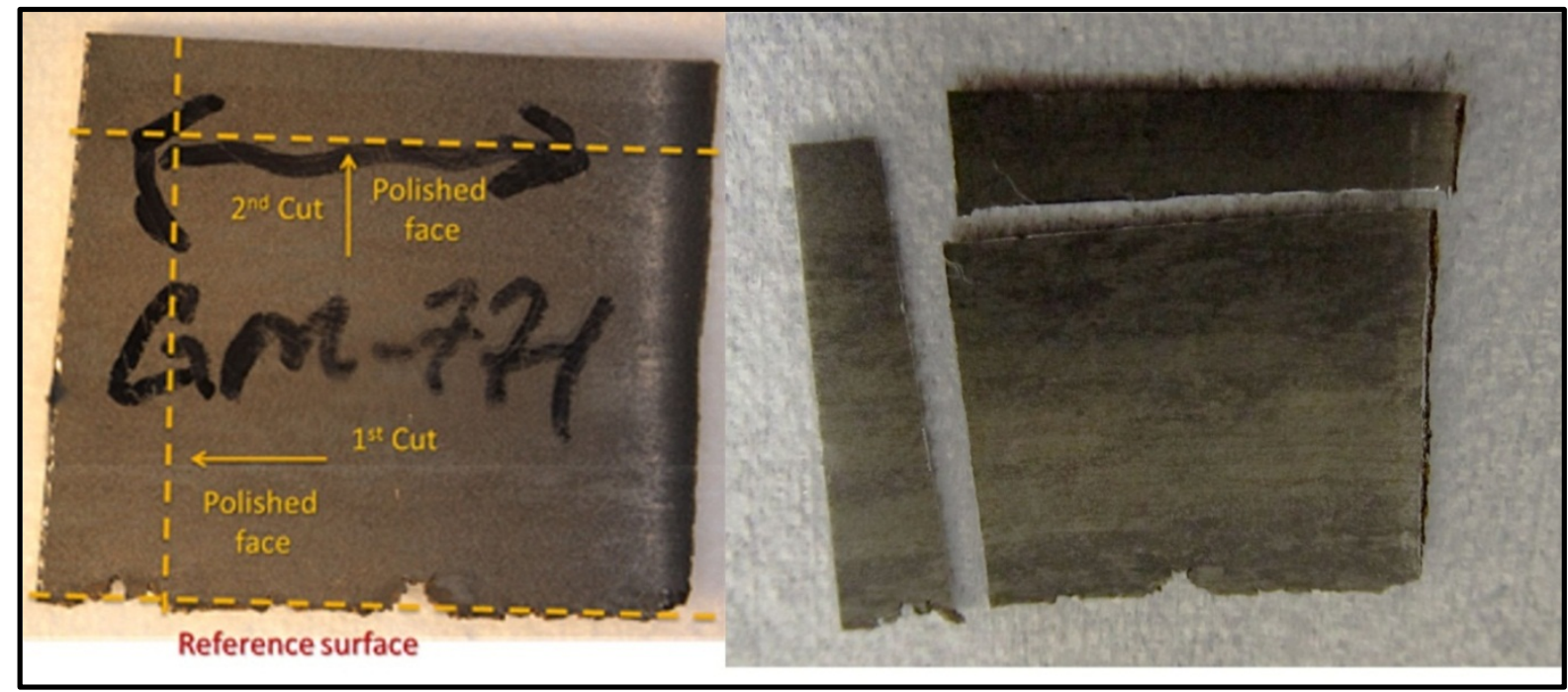

Figure 2-2. Two cuts were made from each sample, and mounted in epoxy such that the indicated cut faces were polished for characterization. The $1^{\text {st }}$ cut is the transverse orientation (perpendicular to the rolling direction indicated by the black arrows), and the $2^{\text {nd }}$ cut is the longitudinal orientation. The right image shows the final cuts used for characterization.

extraordinary surface finish for two reasons. Because the sample is tilted up for $70^{\circ}$, the interaction volume for the elastically scattered electrons is no more than $20 \mathrm{~nm}$ deep below the polished surface, hence, any scratches or residual deformation left from the prior mechanical polishing step will interfere with the scattering and prevent pattern formation. Oxidation of the surface and carbon coating will also degrade pattern quality, so the choice of specimen preparation techniques is very important. Another reason for attempting to achieve an EBSD quality surface finish is that high resolution electron images, particularly low keV backscatter imaging, will be greatly degraded if substantial subsurface deformation exists in the samples. Based on past experience, a $1 \mu \mathrm{m}$ surface finish is not sufficient to achieve the desired resolution to help clearly image nanoscale features, and will not allow EBSD patterns to be obtained under any foreseeable situation.

Preliminary measurements on the carbide sizes and area fraction were attempted though automated measurements using the Image $J$ program. The images were first threshholded to adjust the contrast to reveal only the carbides, then a routine was used to measure the particle area and obtain the statistics. One of the artefacts encountered was the presence of colloidal silica contamination, which cannot be visually separated from the carbides once it is thresholded. However, these clumps of particles are always smaller than most of the carbides present, so a threshold of $0.5 \mu \mathrm{m}$ was chosen to eliminate those clumps of colloidal silica from the size distributions. This may still introduce some error in the distribution for these two conditions, so it needs to be re-examined at some later time if more accuracy is desired.

\section{Sample Preparation}

Sectioning of each sample was conducted using a Buehler Isomet saw, following cutting diagrams laid out for each sample such as is shown in Figure 2.2. Each sample has a longitudinal and transverse cut as indicated in the figure, and the polished face chosen was the 


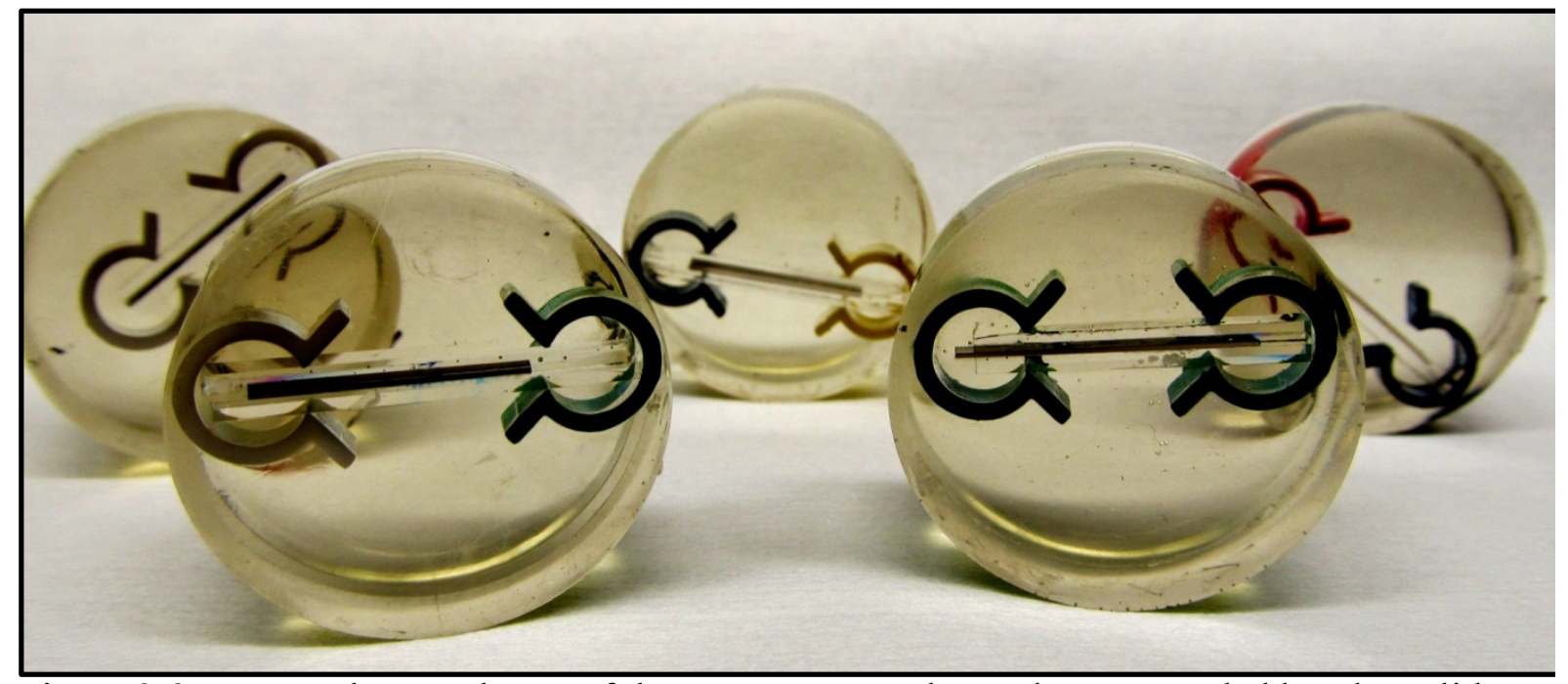

Figure 2-3. Examples are shown of the epoxy mounted samples surrounded by glass slides, and held in place with colored plastic clips.

internal interface opposite the sheared edge. These pieces were then mounted in epoxy using colored plastic clips, with glass slides mounted on both sides of the foil to preserve the edges during polish. Plastic clips were chosen over metal clips in case etching with corrosive solutions or electropolishing needed to be performed. The colors of the plastic clips were chosen to allow another method of assuring the identity of each sample. An example of several mounted and polished samples is shown in Figure 2.3.

Sample polishing was a multistep process involving hand grinding through successive grits on $\mathrm{SiC}$ paper to a final grit of 1200 , followed by polishing on diamond paste from $3 \mu \mathrm{m}$ to $1 \mu \mathrm{m}$. After the diamond mechanical polish, efforts were made to achieve a surface finish suitable for electron backscatter diffraction (EBSD) for the reasons described previously. A survey of the literature, discussion with other PNNL staff with prior experience, indicated that preparation of U-Mo is difficult due to oxidation of the surface. Many reports stop at a $1 \mu \mathrm{m}$ diamond finish, and either use that level of polish for their characterization, or attempt to electropolish the sample to achieve a better surface finish. A $1 \mu \mathrm{m}$ surface proved sufficient to reveal the zirconium layer on each side of the U-Mo foil in good detail, but scratches were clearly visible in both the U-Mo matrix and the $\mathrm{Zr}$ layers when imaged in the optical microscope at 200x and above, which is not deemed suitable for high resolution SEM.

Based on the report by Kelly et al.[3], we attempted to electropolish the samples using a 5\% $\mathrm{H}_{3} \mathrm{PO}_{4} /$ distilled water electrolyte over a range of voltages of 1-5 volts. A small needle-shaped probe was touched to the sample while the mounted sample was submerged in a beaker of the electrolyte using a Pt cathode. It proved difficult to achieve a proper electropolished surface, unfortunately the polishing conditions generally produced an etched appearance, not the mirrorlike surface finish typical of electropolished metals. The microstructure of both the $\mathrm{Zr}$ and U-Mo would not polarize in the optical microscope despite experimenting with a range of polishing voltages, so our goal was not met using this technique. Grain relief and etching of the diffusion layer occurred in each of the electropolished samples, in some cases proving beneficial because

${ }^{3}$ A. Kelly et al., "Metallographic Preparation Techniques for Uranium”, Journal of Nuclear Materials 353 (2006) pp. 158-166. 
the electropolishing revealed interesting features of the microstructure such as banding and stringers of carbides. Scratches still remained in the electropolished samples, so coupled with the lack of polarization, it was concluded that a different approach was necessary.

The next step was an attempt to utilize a vibratory polisher with $0.04 \mu \mathrm{m}$ Struers OPS colloidal silica, an oxide polishing suspension with an alkalinity of 9.8. The first attempt produced a very nicely polished surface finish after 3 hours on the vibratory polisher, all phases were revealed in great detail up to high magnifications in the SEM, and the sample surface was very uniform and flat. The $\mathrm{Zr}$ layer, U-Mo microstructure, $\mathrm{Zr} / \mathrm{U}-\mathrm{Mo}$ diffusion layer and carbides were easy to see, with no visible scratches for the most part when examined up to 500x in the optical microscope. It was clear, however, that contamination was present on areas of the polished sample by virtue of a stained appearance and micron-sized clumps of particles visible in the optical microscope. Despite this contamination, the grain structure was visible in the optical microscope, though not at great contrast, using a polarized filter. The sample was therefore coated with a light layer of carbon and placed in the FEG-SEM for imaging.

The SEM revealed a very nice sample finish, but when tilted up to $70^{\circ}$, only isolated EBSD patterns could be obtained from either the Zr layer or the U-Mo despite the polarized grain structure visible in the optical microscope. This is rather unusual, and the grain structure appeared relatively equiaxed on the first sample, so it wasn't clear if cold working was the culprit for the poor EBSD pattern formation.

Residue on the surface was next considered because of prior experience on other metals such as magnesium that polarized in the optical microscope after a final polish on colloidal silica, but didn't initially produce any diffraction patterns when EBSD was attempted. Imaging at $5 \mathrm{keV}$ and low beam currents revealed colloidal silica residue at a finer scale than could be seen in the optical microscope. Both Mg, U-Mo and the $\mathrm{Zr}$ appear to oxide quickly, and it is suspected that this makes the colloidal silica adhere to the surface if rinsing is delayed too long. Subsequent attempts used various rinses such as distilled water, ethanol and methanol individually in an ultrasonic cleaner with varying degrees of success, but never completely removed the fine colloidal silica particles (it did remove most of the large clumps). A Gatan MetEtch was used to try and clean the silica residue off of the samples. This instrument is essentially an ion mill, but unlike the tightly focused ion beam used to prepare TEM samples, the MetEtch ion beam covers up to a centimeter in area and can be used to ion etch or polish samples. Just as it did for the magnesium alloys, it worked very well at removing the colloidal silica, but unfortunately it oxidized both the U-Mo and the Zr layers, completely eliminating any polarization in the U-Mo and dulling the contrast in the Zr layers. It was also noted in the SEM that small scratches were still present in the sample, so the colloidal silica polishing as performed wasn't quite achieving the desired surface finish even if we could have solved the problem with the silica residue. If scratches are still visible in even in the SEM, this often results in poor pattern quality in EBSD.

Our next attempt to achieve a highly polished surface free of scratches and producing a polarized image of the grain structure was to borrow a trick used in polishing materials such as titanium. Hydrogen peroxide (30\% concentration) was added to the colloidal silica to form a 50/50 mixture of HP/CS. This provides a more aggressive mechanical and a chemical attack that is very useful on ductile materials to remove the final deformation layer. A felt cloth was then used to hand polish the mounted samples that had been polished on the colloidal silica. The samples were polished by hand on the felt cloth and moved in a figure 8 pattern for two minutes, then quickly rinsed with water, followed by ultrasonic cleaning in ethanol for 2 minutes, then rinsed one final time in ethanol. Optical microscopy revealed the best surface finish of the U-Mo 
thus far, showing very high contrast grain structures when imaged in polarized light. The surface was more uneven than a straight colloidal silica surface finish, which hindered the acquisition of optical images taken at 500x, and in cases even at magnifications of 200x. The Zr layer was not as polarized as achieved when just using straight colloidal silica, however, the grain structure was still visible. No scratches could be detected in either the optical microscope images using DIC imaging, nor in the SEM at low $\mathrm{keV}$, so this approach was used on all of the samples for optical microscopy. This included redoing the optical analysis of the first eight samples prepared to a final colloidal silica/MetEtch final that was presented to INL staff during a visit on August 21, 2012.

Because of the delays in overcoming the problem of the colloidal silica residue, there wasn't time to go back and redo a complete SEM characterization on all eight of the samples after redoing the final surface preparation using the hydrogen peroxide/CS attack polish. However, with respect to SEM imaging and EDS analysis, it is unlikely that a significant difference will arise when comparing samples prepared with just CS/MetEtch versus the hydrogen peroxide/CS surface finish. The interaction volume for backscattered electrons at $0^{\circ}$ tilt penetrates well below any surface oxide layer, for example at $5 \mathrm{keV}$ it is on the order of $20 \mathrm{~nm}$ and at $20 \mathrm{keV}$ it is close to $100 \mathrm{~nm}$. The samples prepared with the CS/MetEtch may have a thicker oxide layer compared to those prepared with the HP/CS attack polish, but at accelerating voltages of $20 \mathrm{keV}$, the impact should be minimal from both an imaging and chemical analysis standpoint. $20 \mathrm{keV}$ was used for most of the characterization, with limited characterization done in the beginning at $5 \mathrm{keV}$ as different imaging techniques were explored in the FEG-SEM. One final comment is that when the samples given the HP/CS attack polish were checked for EBSD patterns, the results were less than stellar. Given the lack of scratches, no abnormal oxidation of the surface that could be detected, and yet a high degree of polarization in the optical microscope, it was concluded that some of the sample conditions contained too high a level of cold work to allow EBSD patterns to be obtained. 


\section{3}

\section{CHARACTERIZATION RESULTS: LANL FOIL R1X4}

\section{ARCHIVE (63240) TRANSVERSE AND LONGITUDINAL}

\section{Optical Metallography \& Low Magnification FEG-SEM Imaging}

Transverse and longitudinal sections were cut from the as-received foil R1X4 as indicated in Figure 3-1. This particular sample was mechanically polished through $1 \mu \mathrm{m}$ diamond, then given the final surface finish using the HP/CS final polishing method. Metallographic examples of the polished cross-section of the foil are shown in Figures 3-2 and 3-3, revealing a complex grain structure of large, highly elongated regions interspersed with smaller, more equiaxed grains in the U-Mo foil. The elongated grains have a high aspect ratio, in some cases as high as 15 to 1 , with the elongation in the plane of the foil, forming what is likely a "pancake" grain structure. Some of the coarser grains can extend to widths as large as several hundred microns. The equiaxed grains tend to be much finer than the more elongated grains, ranging from 5 to $30 \mu \mathrm{m}$. The grains appear more elongated in the transverse section than the longitudinal section, which seems odd given that in a rolled structure the grains are more usually elongated in the longitudinal direction. Note that the sample orientation was carefully controlled through the

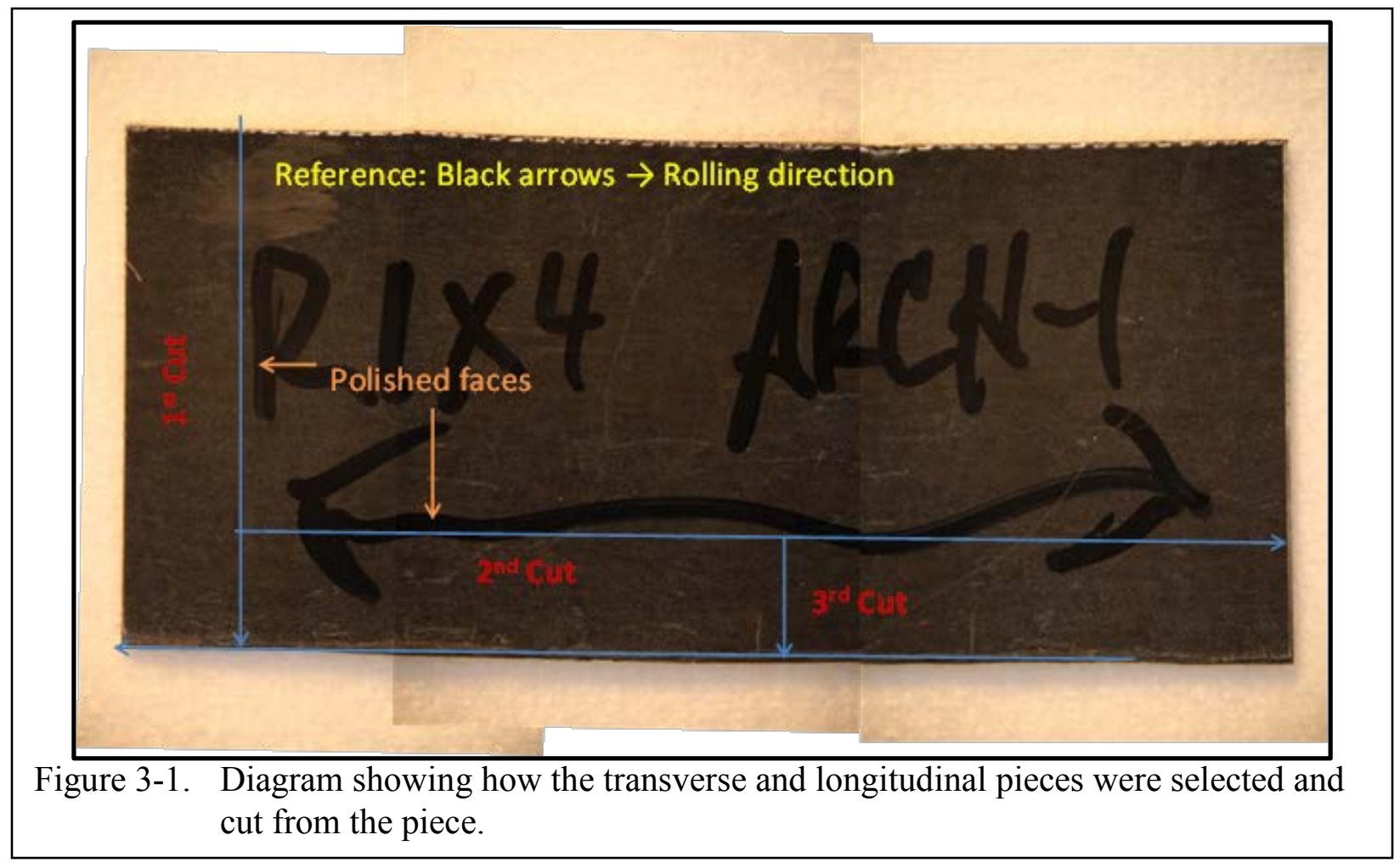




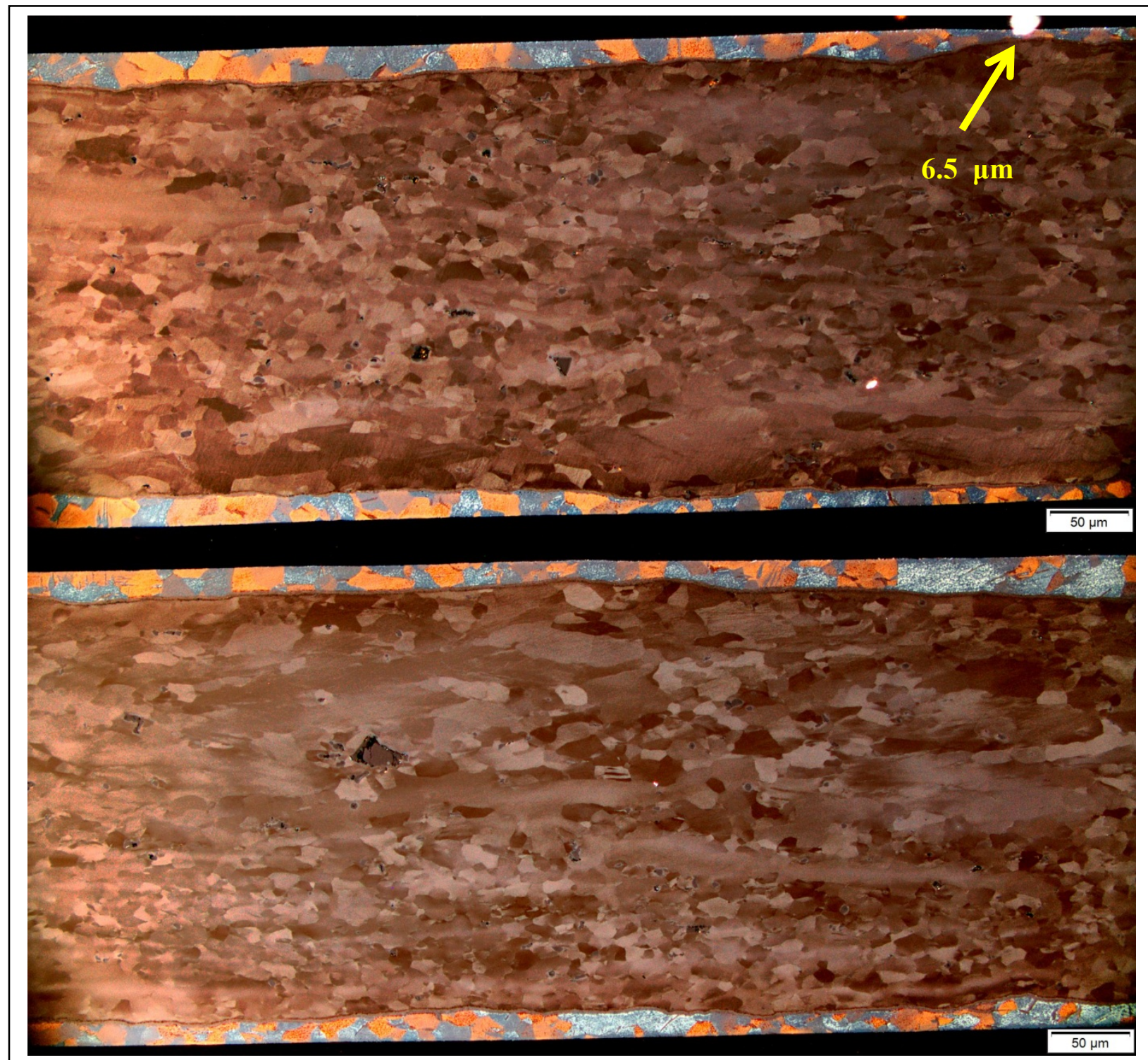

Figure 3-2. Optical micrographs taken at 200x reveal a highly variable grain structure in the transverse section of U-Mo foil R1X4, and considerable variation in the thickness of the zirc layer on both sides of the foil. The yellow arrow is shown to indicate the thinnest region found in this foil. Images were taken using a polarized filter, contrast enhanced in Corel PhotoPaint.

sample cutting and mounting, and was confirmed recently. Variation in the rolling schedules may result in the differences between elongation in the transverse section versus the longitudinal section. Alternatively, the rolling direction marked on the samples provided to PNNL could be erroneous. The only conceivable method to confirm the latter is prepare another sample from the foil to ensure similar observations. However, time and budget constraints did not permit this at the time. The grain structure of the zirconium layer is composed of equiaxed grains whose grain size varies from 15-100 $\mu \mathrm{m}$, larger than the nominal $30 \mu \mathrm{m}$ width of the layer.

Faceted uranium carbides are present in a somewhat random distribution extending through the entire visible foil area in the micrographs, ranging in size from 3-5 $\mu \mathrm{m}$ to as large as $30 \mu \mathrm{m}$. 


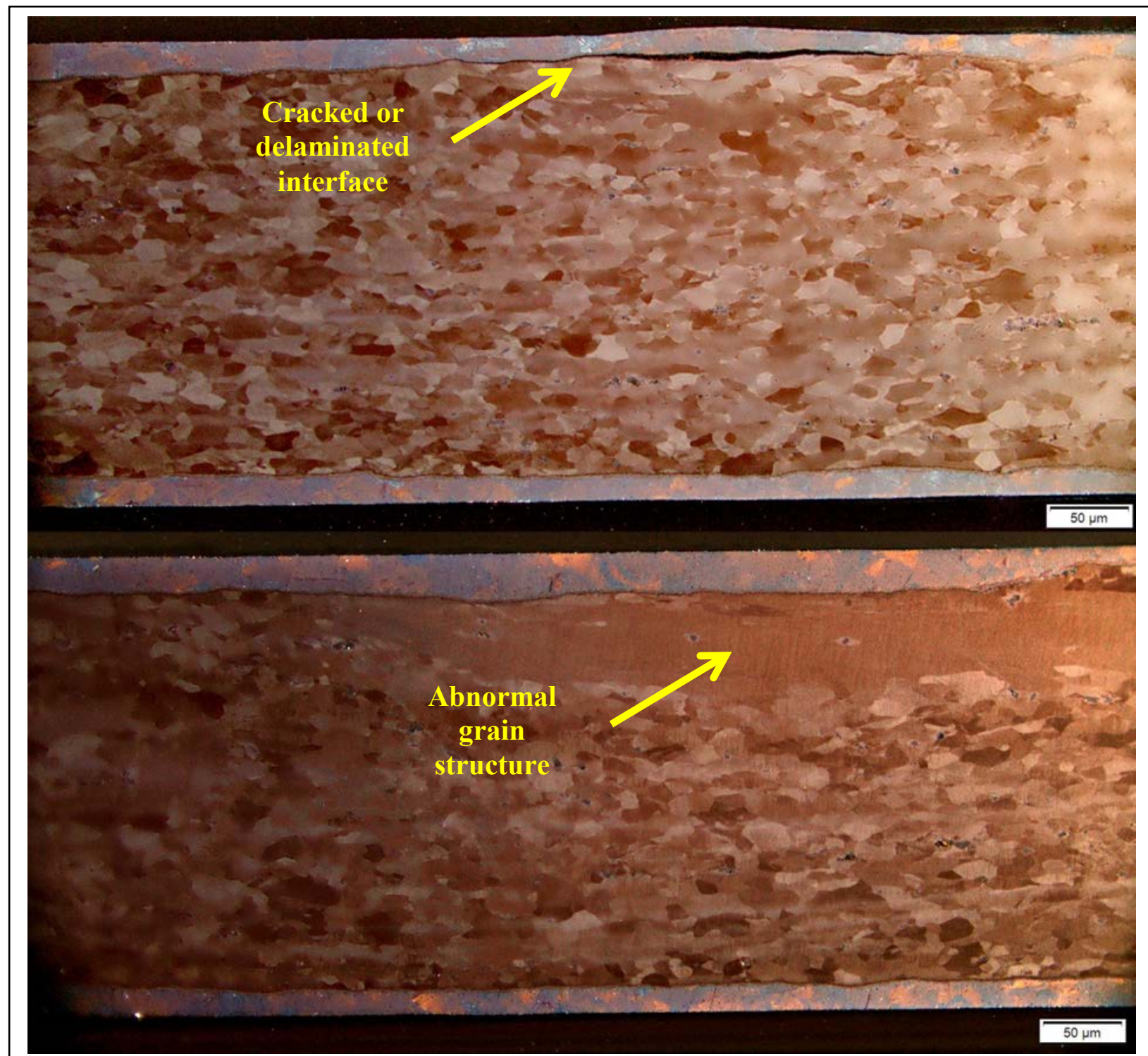

Figure 3-3. Optical micrographs taken at 200x reveal a highly variable grain structure in the longitudinal section of U-Mo foil R1X4. One area of this foil exhibited significant delamination as indicated by the arrow in the upper figure.

Many of the larger carbides are cracked, however it is not clear if this a consequence of the mechanical polishing or the foil processing. No visible cracking or delamination is present in the transverse foil, however, a $400 \mu \mathrm{m}$ wide region was found to have delaminated between the upper zirc layer and the underlying U-Mo foil in the longitudinal foil. The zirc layer varies considerably in thickness in both orientations, in some cases narrowing to as low as $6.5 \mu \mathrm{m}$ while in other regions it can be up to $30 \mu \mathrm{m}$ thick. Comparing the zirc layer on the top versus the bottom of the U-Mo foil reveals no real differences.

A closer look in the optical microscope at the interface between the zirconium layer and the U-Mo foil reveals a narrow diffusion zone, barely visible at 200x, but clear at 500x, that varies from 1-3 $\mu \mathrm{m}$ over the extent of the sample (see Figure 3-4). Little can be gleaned from the optical metallography other than there is minimal evidence of widespread cracking, pores, or delamination over the observed width of the samples in either the transverse or the longitudinal 


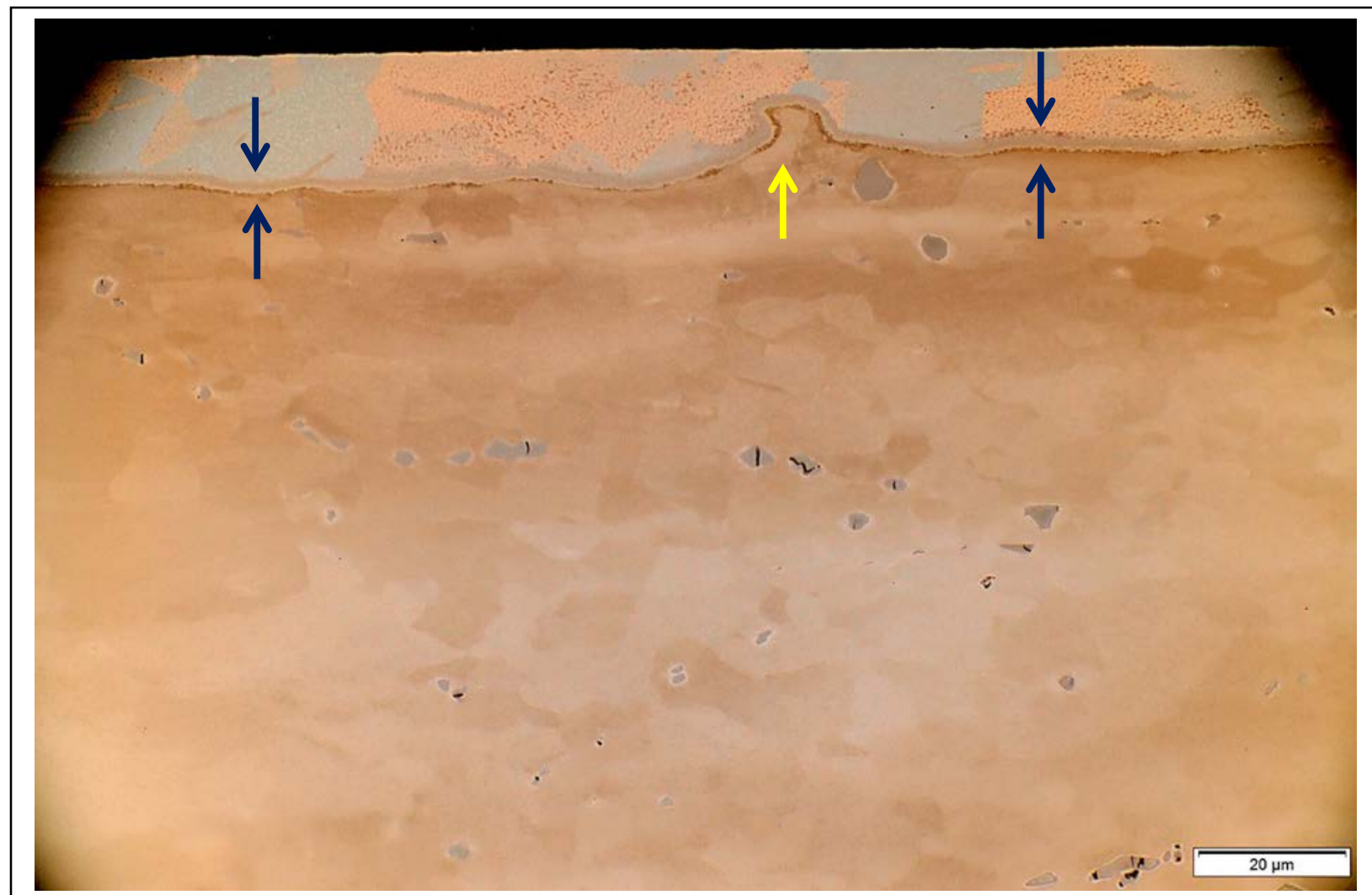

Figure 3-4. Optical micrographs taken at 500x provide a close-up view of the zirconium/UMo diffusion layer that forms during foil processing. The yellow arrow points to narrowed region in the protective zirconium. The diffusion zone does not preferentially etch during the HP/CS final polishing step. Fine carbides can be observed throughout the U-Mo foil.

samples of R1X4. To better explore this diffusion zone, the characterization effort was shifted to the FEG-SEM.

After carbon coating, the mounted sample was examined using various imaging detectors and EDS to interrogate the structure of the foil. EBSD was attempted on this sample, but no patterns were obtainable, suggesting a highly cold worked condition. Images taken in low mag mode at 250x (see Figure 3-5 through 3-7) reveal banding in the grain structure, suspected to be compositional related. This banding shows up as undulations in the foil surface topography in the LEI image, perhaps due to different hardness levels of the segregated regions, and as brighter versus darker regions in the LABE image shown at the bottom.

Elemental maps taken at $20 \mathrm{keV}$ with a high beam current to maximize the count rate are shown in Figure 3-8, confirming that a minor degree of Mo variation, $\sim 1 \%$ Mo, is present from the low Mo to the high Mo regions of the U-Mo foil. These maps were taken from the middle of the transverse foil. This variation appears to be enough to affect both the polishing and etching of the U-Mo foil, and there is evidence to suggest that the carbides form preferentially in the low Mo regions. Figures 3-9 and 3-10 present higher magnification images of the center of the foil, in particular focusing on the carbides that are present in this area. The coarse carbides are fractured in many cases, but appear for the most part to be single phase, with only occasional evidence of oxygen associated with the carbides. There are much finer particles, presumably fine carbides, that have formed along the grain boundaries and in the matrix, in some cases 


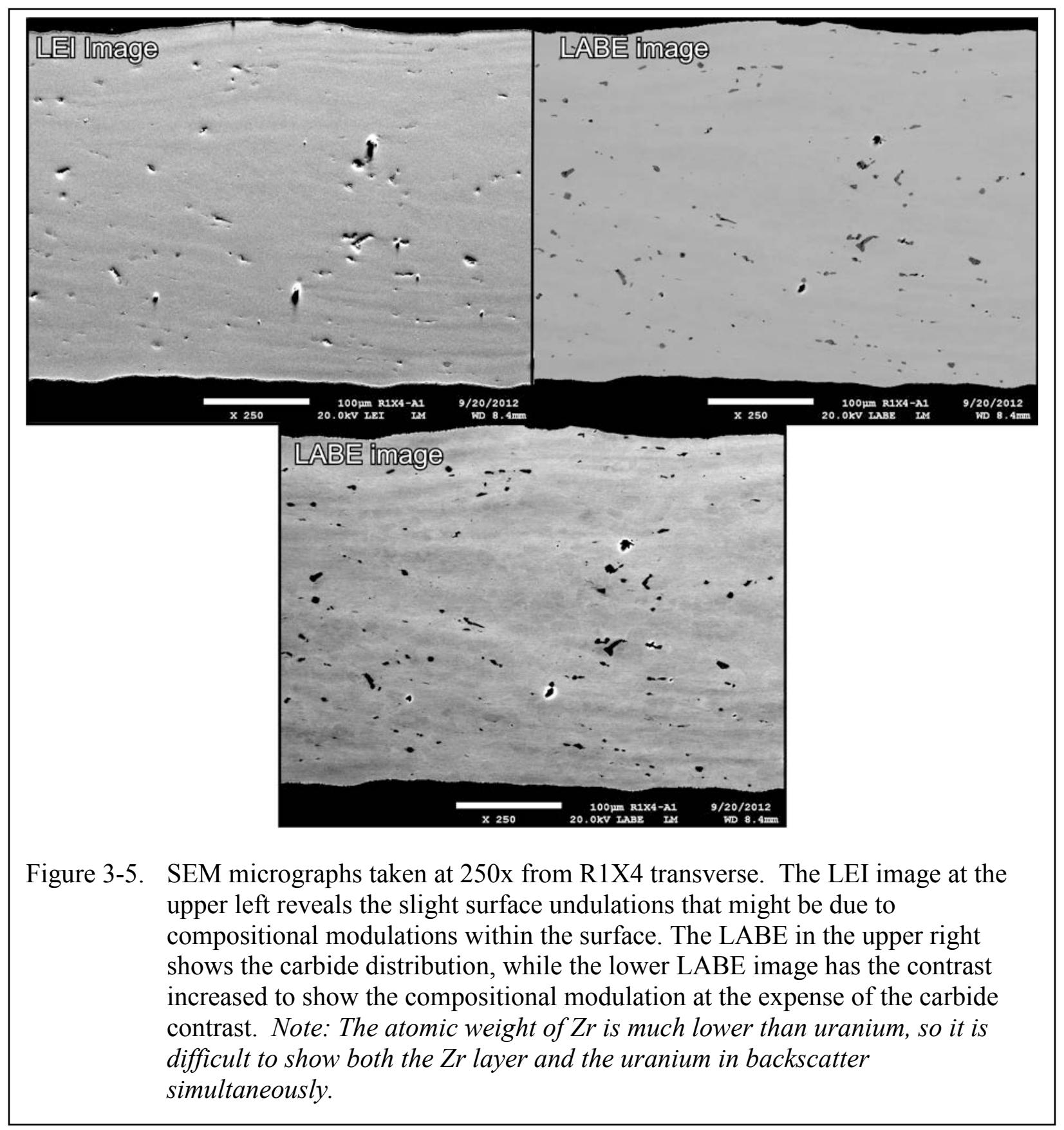

forming stringers. It seems likely that the fractured carbides resulted from the high degree of cold work in the foils given their polished appearance and the fractured appearance of the carbides. The LEI images in Figure 3-9 reveal nicely polished carbides with smooth transitions to the pores associated with the carbides, suggesting that some of the coarser inclusions have solidification porosity associated with them, not particle pull-out. Indeed, the polished carbides are sunk below the surrounding U-Mo matrix, indicating preferential etching from the final polish. Fractures are mostly confined to the coarsest elongated carbides that are more susceptible to bending stresses during cold rolling, whereas more equiaxed carbides are relatively free of fractures, but not necessarily porosity. The path of the fractures is also aligned. 


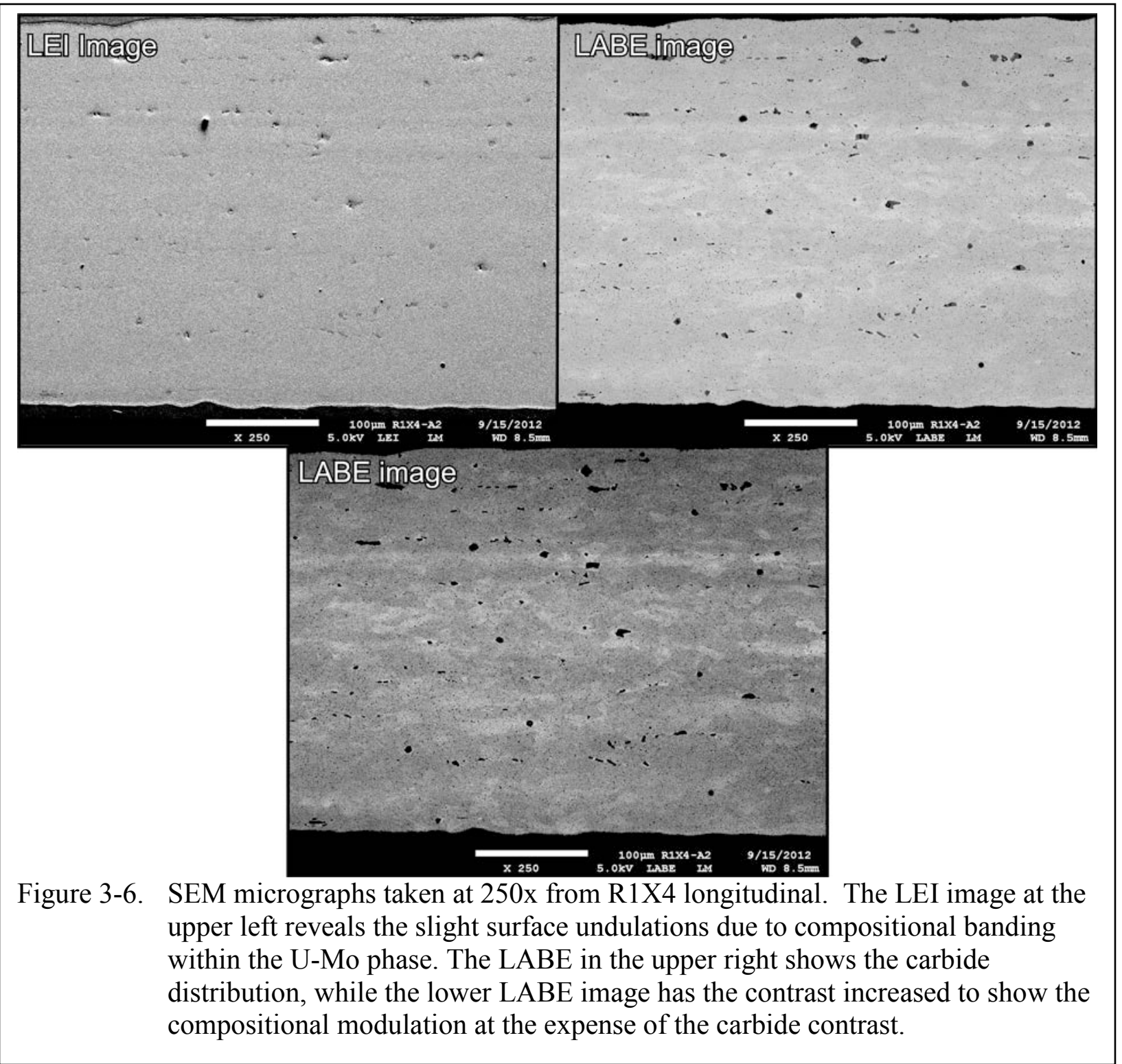

perpendicular to the rolling direction, and not random as might be expected if the particles were damaged during sample preparation. Note that the successive grinding through finer and finer grits usually prevents the fracture of brittle phases. Particle pull-out during final polish might be a greater concern if the CS or HP/CS preferentially attacked the supporting material around the carbides, however, the sunken appearance suggests it is the carbide phase that is preferentially polished, making it more difficult to pull the particles out 


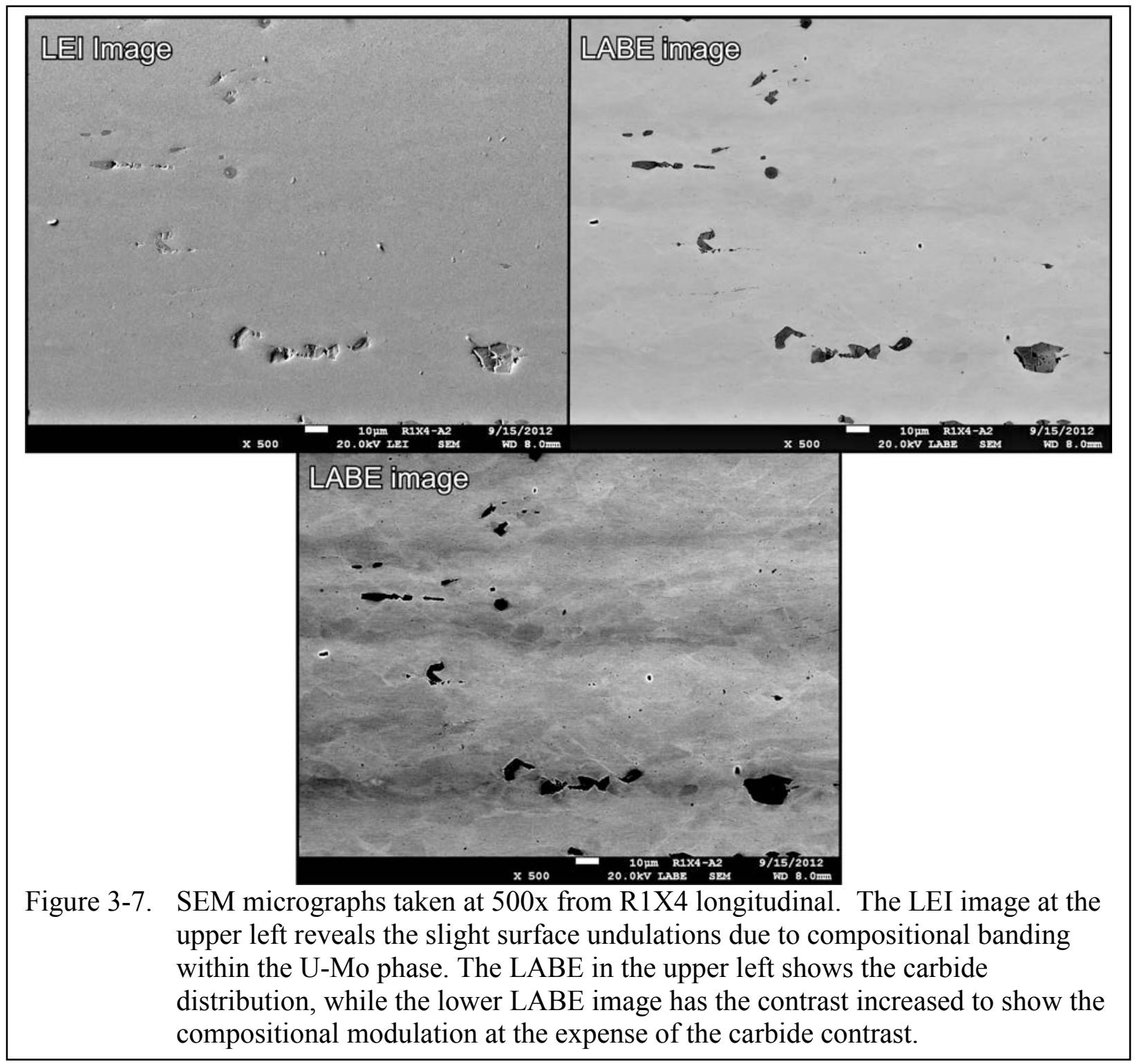




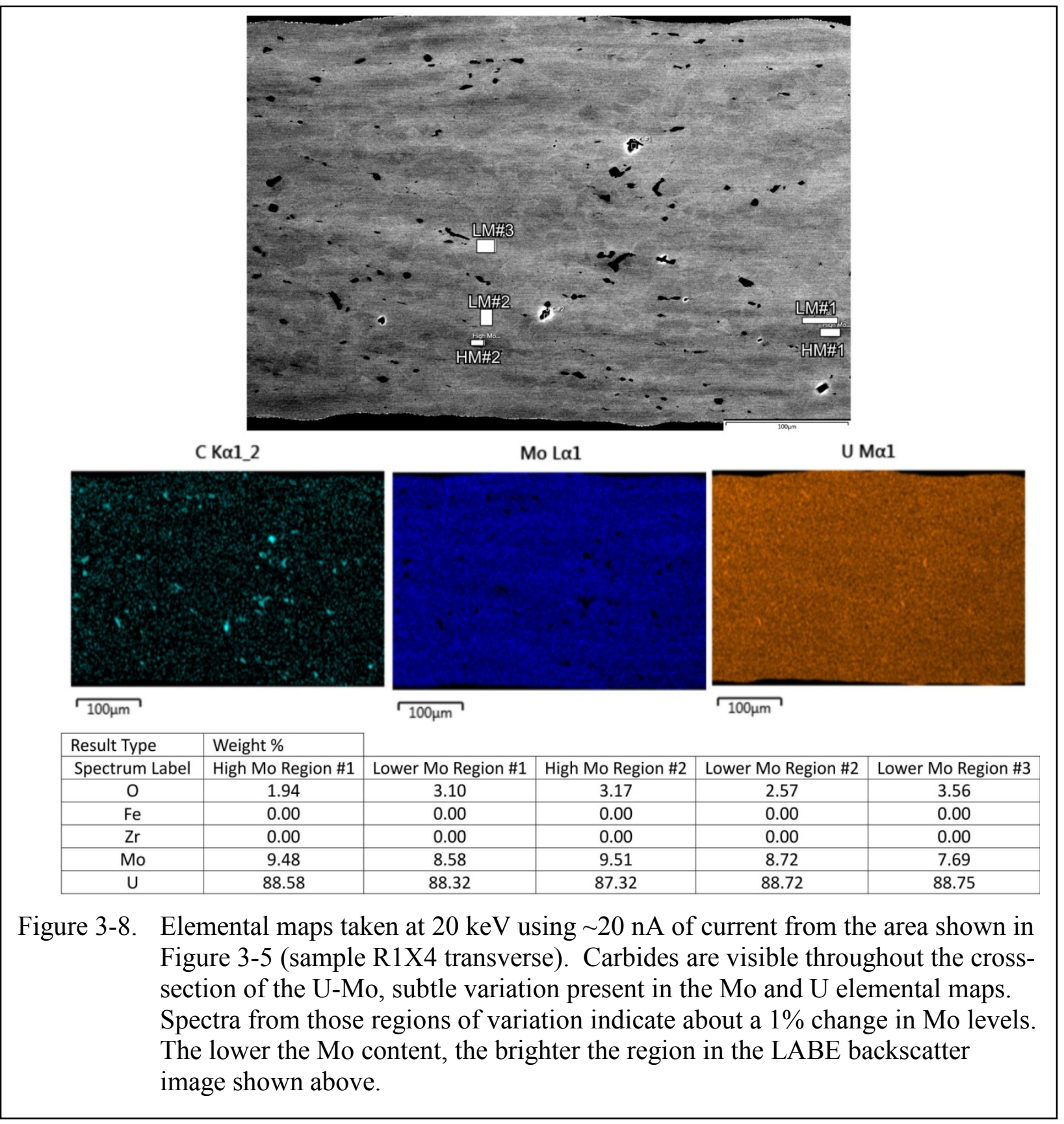




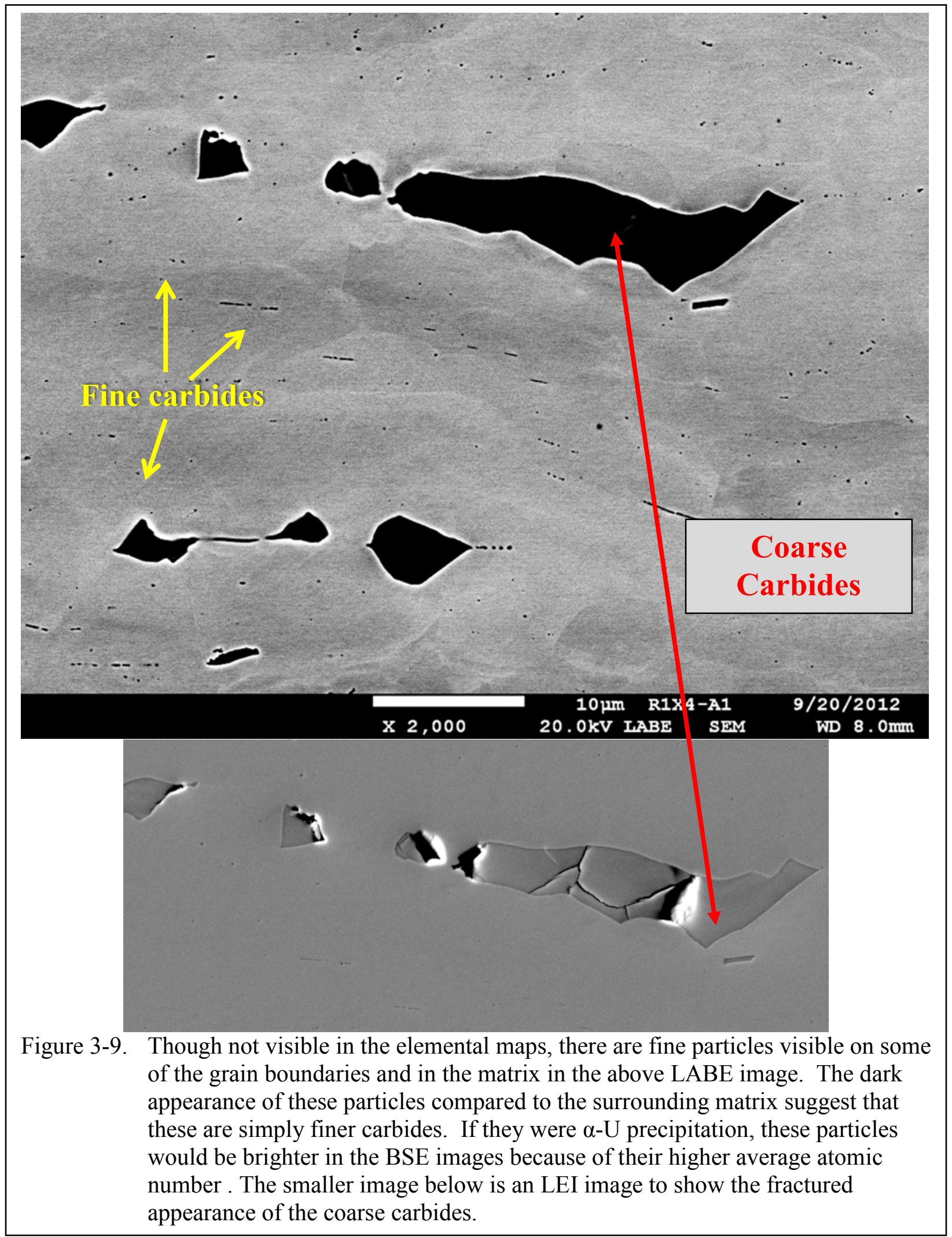




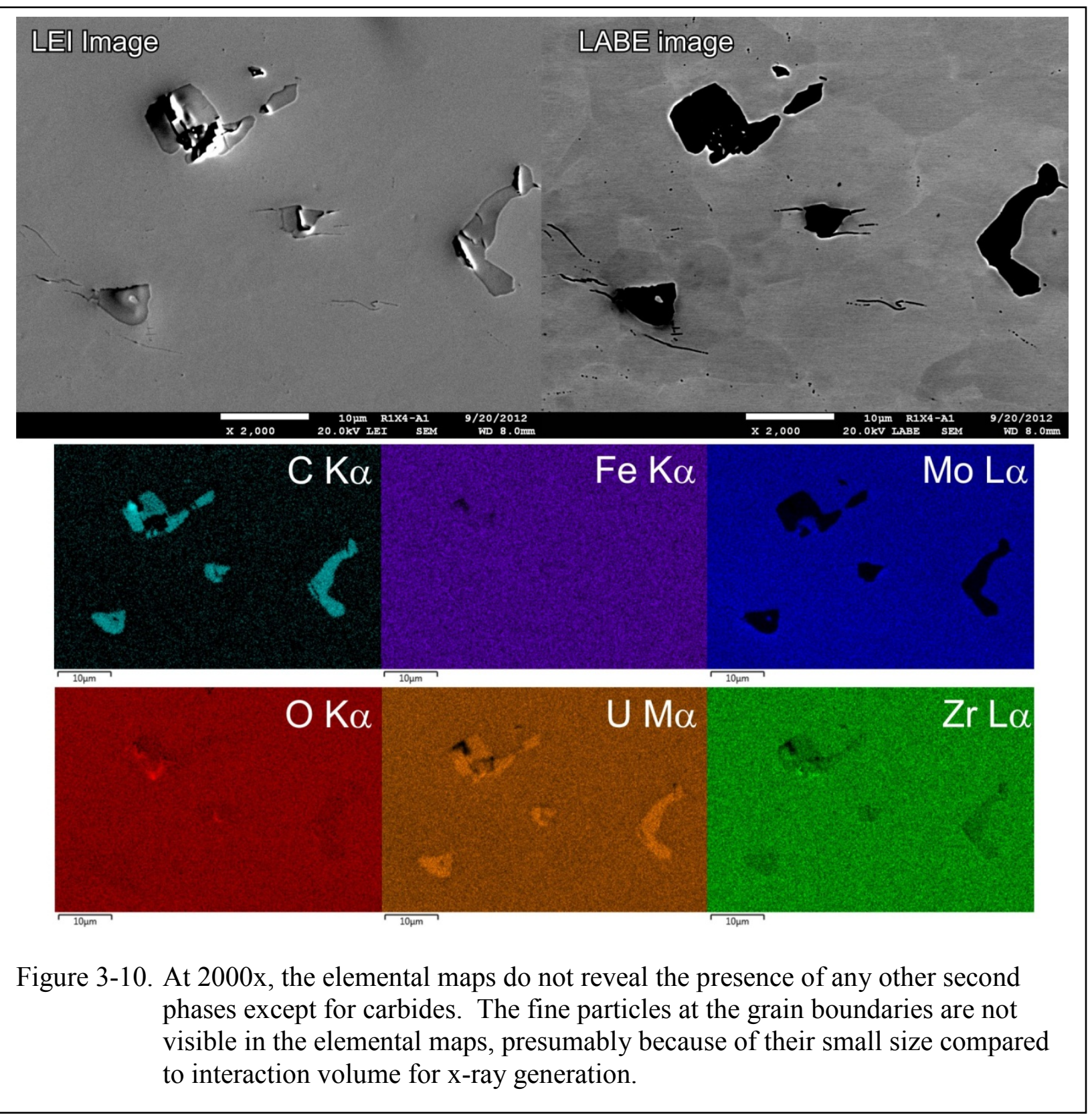




\section{Zirconium/U-10Mo Interaction Layer}

The interface between the U-Mo and the zirconium is a rather complex diffusion zone. The $\mathrm{HP} / \mathrm{CS}$ finish reveals very clearly that the diffusion zone has a mixture of second phases and different reaction layers. Examples of this interaction zone in both the transverse and the longitudinal orientation are shown in Figures 3-11 through 3-17, imaged with both LEI and LABE detectors over a range of magnifications and analyzed using EDS. The example shown in Figure 3-11 is typical of the interface, characterized by an upper layer of pure zirconium, which then transitions through a series of interaction layers into the U-Mo foil. The pure zirconium has a mottled appearance that suggests some type of structure, but without EBSD it is unclear what is causing this contrast because there was no chemical signature to suggest diffusion into the zirconium. Based strictly upon the change in contrast and relief polishing that is evident in the LEI image, 4 distinct layers could be identified that are different from the pure zirconium and the U-Mo. To aid in distinguishing the differences between these layers, EDS point compositions were obtained and are shown in Figure 3-12, an elemental map is provided in Figure 3-13, and a separate compositional profile is provided in Figure 3-14. Referring to the L1 layer labeled in Figure 3-11, L1 contains a small amount of uranium, up to a few weight percent that decreases to below EDS detection limits the further one moves toward the outer surface of the zirconium layer. This region is found to consistently polish differently the pure zirconium, giving a more uniform appearance than the mottled pure zirconium layer.

Below this is the L2 layer, which has significant levels of uranium and minor levels of Mo, and is probably the $\delta-\mathrm{UZr}_{2}$ phase suggested by the work of Perez et al [4]. The ratio of $\mathrm{Zr}$ to $\mathrm{U}$ is nearly 2 to 1 as would be expected if this region is $\delta-\mathrm{UZr}_{2}$. The $20 \mathrm{keV}$ LABE image shown in Figure 3-11 lacks any hint of grain boundary contrast, suggesting that it may be nanocrystalline. However, the LABE images taken at $5 \mathrm{keV}$ shown in Figures 3-15, 3-16 and -3-17 show small, nominally spherical precipitates in this particular layer, suggesting the presence of fine-scale precipitation in this region that isn't captured at the higher accelerating voltage used when acquiring the EDS maps presented in Figure 3-11. These fine precipitates were found to range in size from $15-50 \mathrm{~nm}$ in diameter. It is worth noting that these small particles often form on the side closest to the pure $\mathrm{Zr}$, which coupled with their darker appearance (corresponds to lower average atomic weight in backscatter imaging mode) may mean the small precipitates are small $\mathrm{Zr}$-rich particles, perhaps $\alpha-\mathrm{Zr}$ that precipitates out in the regions next to the pure $\mathrm{Zr}$. There was one example in this region of minor levels of Fe being detected.

Layer 3 mostly represents the discontinuous blocky particles of what are believed to be the $\mathrm{Mo}_{2} \mathrm{Zr}$ phase based on the Mo to $\mathrm{Zr}$ ratio of $\sim 1.5$ in point compositions \#1,2 and 5. The location and distribution of these blocky particles varies considerably, which can be seen by examining the four examples shown in Figures 3-11 through 3-17. Fe was also detected in minor levels when analyzing the composition of these particles. Layer 4 is a region that is slightly oxygenrich and noticeably depleted in Mo, and has been observed to etch or polish differently than the surrounding regions, often exhibiting a rough appearance that resembles popcorn. This region also exhibits different fine precipitates and possibly some form of a cellular or eutectic reaction occurring. The fine scale precipitation that occurs throughout the various interaction layers will

\footnotetext{
${ }^{4}$ E. Perez et al, "Microstructural analysis of as-processed U-10 wt.\%Mo monolithic fuel plate in AA6061 matrix with Zr diffusion barrier", Journal of Nuclear Materials 402 (2010) pp. 8-14. 
require TEM to sort out. Perez et al. [4] indicated that the cubic U-Mo phase adjacent to the beginning of the diffusion zone decomposes as Mo diffuses into the interaction layer \#4 to form the blocky $\mathrm{Mo}_{2} \mathrm{Zr}$ particles.

\section{Summary of Results for LANL Foil R1X4 Archive}

Optical metallography reveals a grain structure of mixed character, composed of coarse, high aspect ratio grains and a distribution of finer, more equiaxed grains. The grain structure appears to correspond to a highly cold worked structure. The transverse orientation appears to exhibit a more elongated grain structure than that observed in the longitudinal cross-section. One area of significant delamination was observed in the longitudinal sample, but otherwise the interface region between the zirconium and the U-Mo matrix appears to be continuous in the optical microscope. No observable cracks or porosity was found to exist over most regions. There were some regions of the zirconium layer that were very thin, on the order of 6-8 $\mu \mathrm{m}$, much thinner than a majority of the layer that is around 20-30 $\mu \mathrm{m}$ thick.

On the macroscale the chemical homogeneity of the U-Mo foil varies throughout the crosssection in both the transverse and longitudinal sections. This variability is due to fluctuations in the molybdenum levels on the order of 1 weight percent Mo or less. This fluctuation, though relatively minor, can be seen both in the LABE detector, and by virtue of an uneven polish as it etches differently during the hydrogen peroxide/colloidal silica final polish. It was also noted that the carbides appear to form preferentially in the low Mo regions, on the edges of the compositional bands.

The interface between the zirconium and the U-Mo was found to be quite complex when examined in the FEG-SEM, with up to 4 distinct interaction layers with various forms of precipitation, some of which was at the nanoscale. The FEG-SEM images confirmed that no fine scale cracks, pores or delamination existed in any of the regions examined in the SEM.

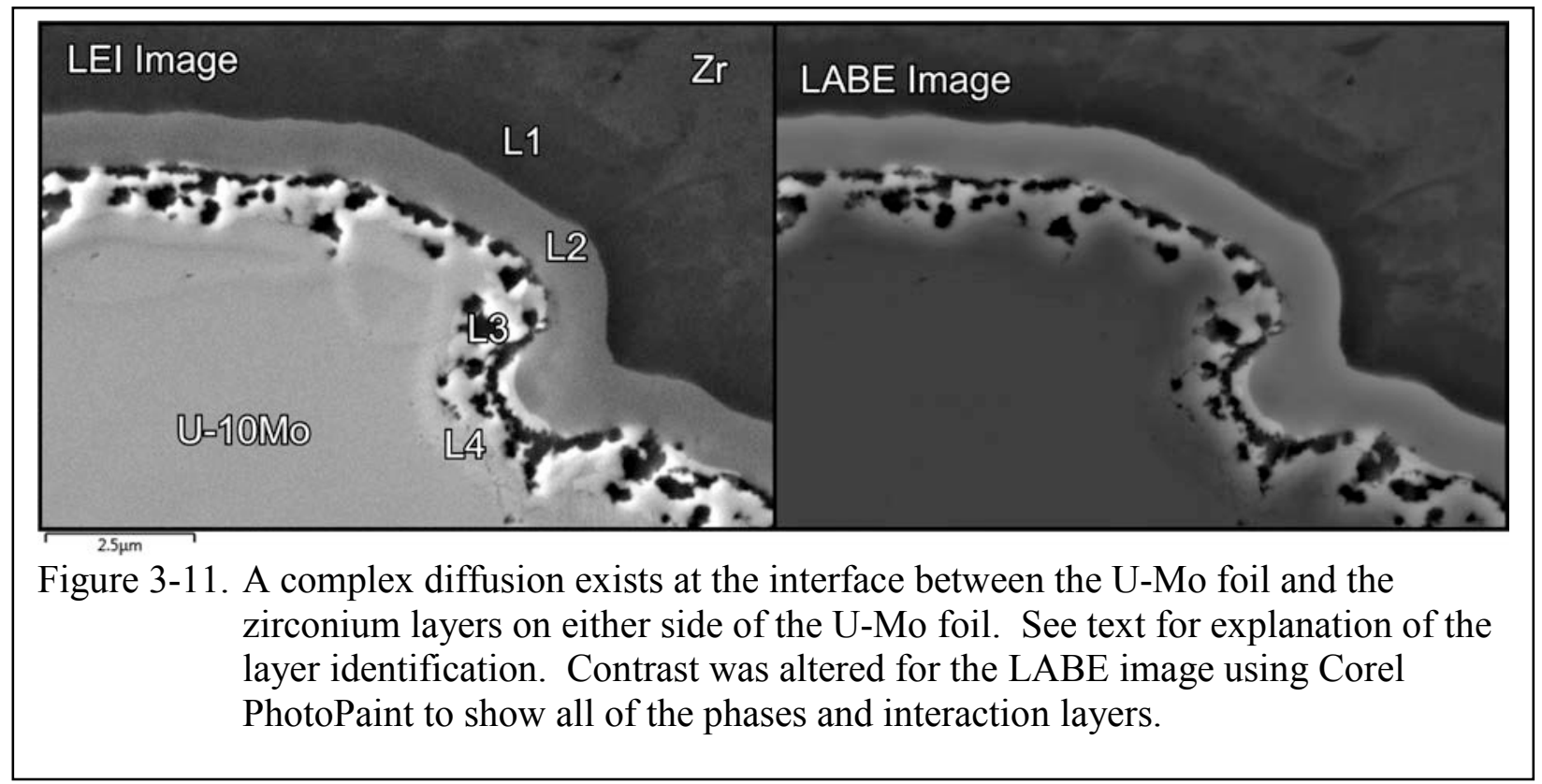




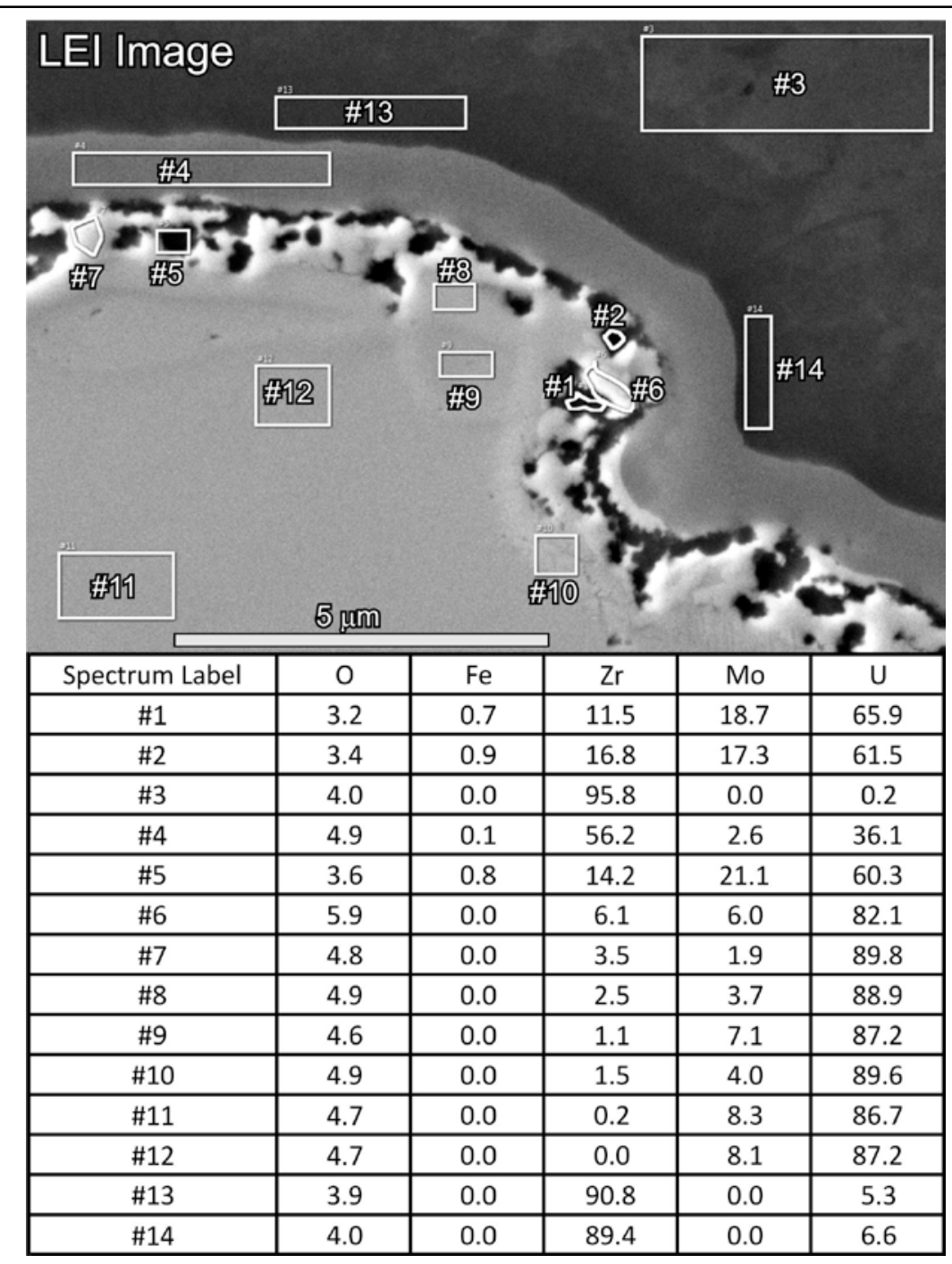

Figure 3-12. A series of point analyses were taken from the individual areas. These were derived from post-processing the elemental maps. The spectra taken from regions \#1, 2, 4 and 5 indicated minor levels of Fe may be present. Compositions are given in weight percent. 


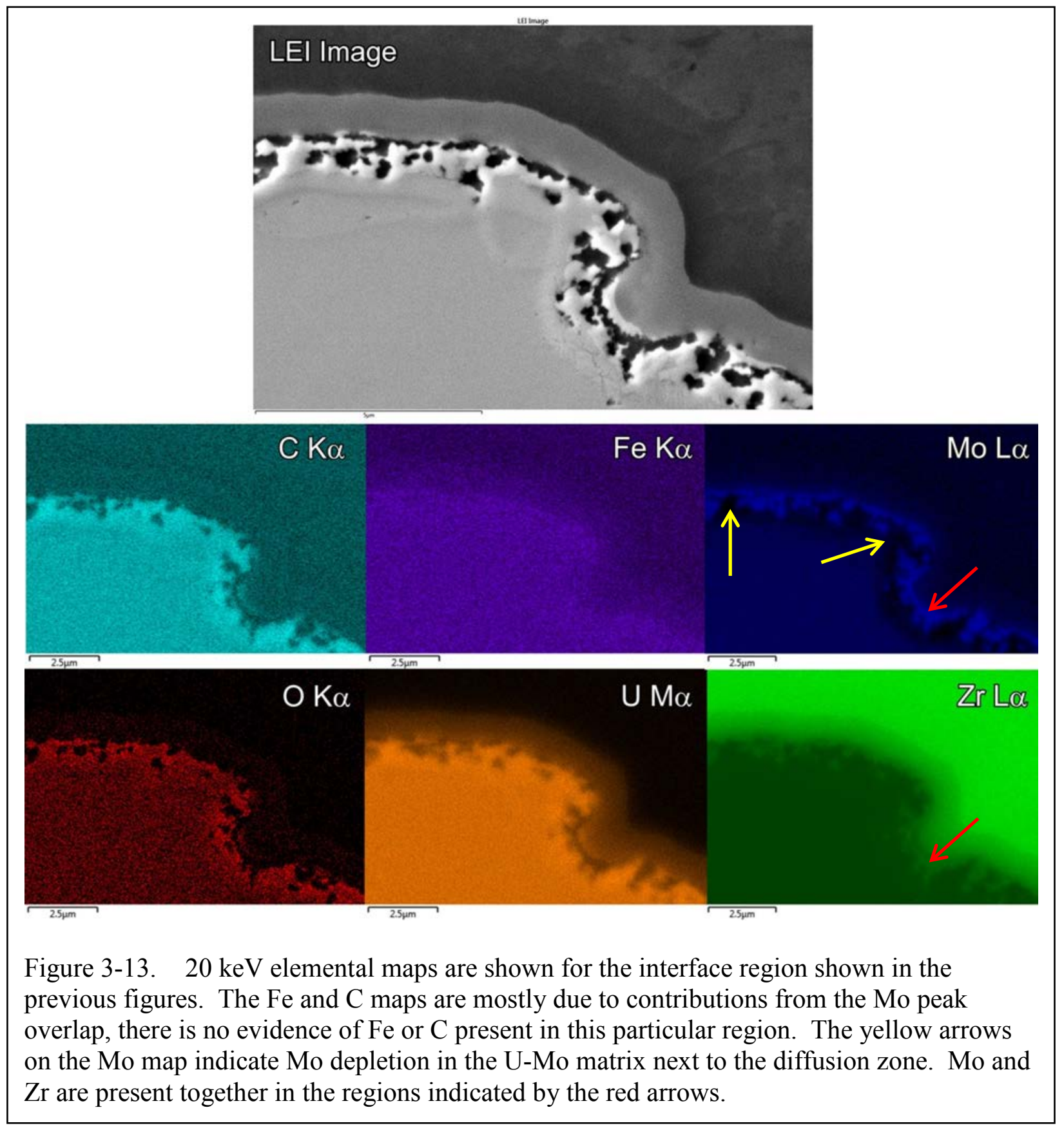



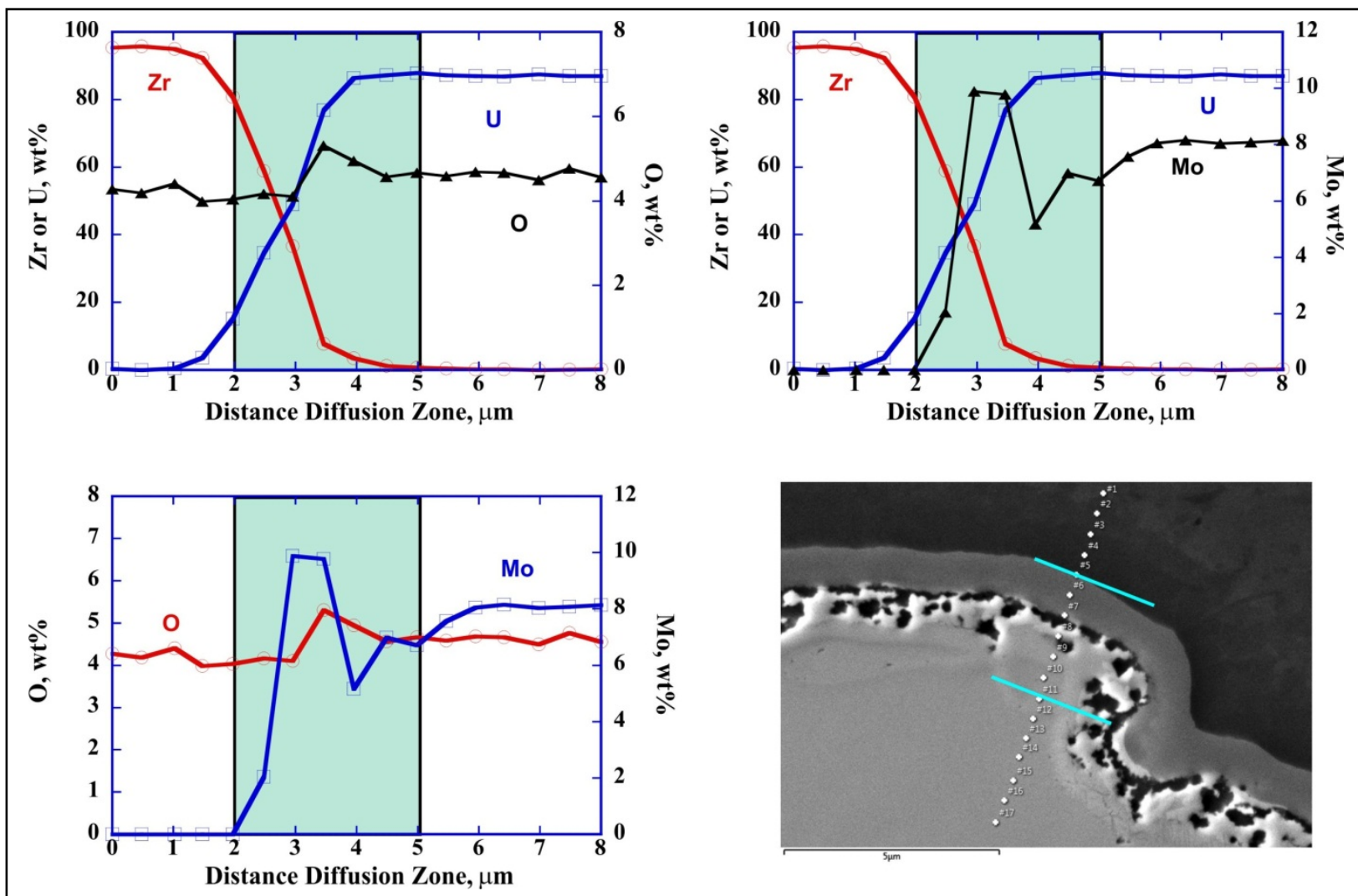

Figure 3-14. A series of point compositions were taken from the same mapped region to highlight the change in composition over this region. The $\mathrm{Zr}$ and $\mathrm{U}$ vary monotonically across the diffusion zone, but the Mo and $\mathrm{O}$ profiles exhibit a different behavior that corresponds to regions either enriched or depleted in Mo, and enriched in the L4 layer. 


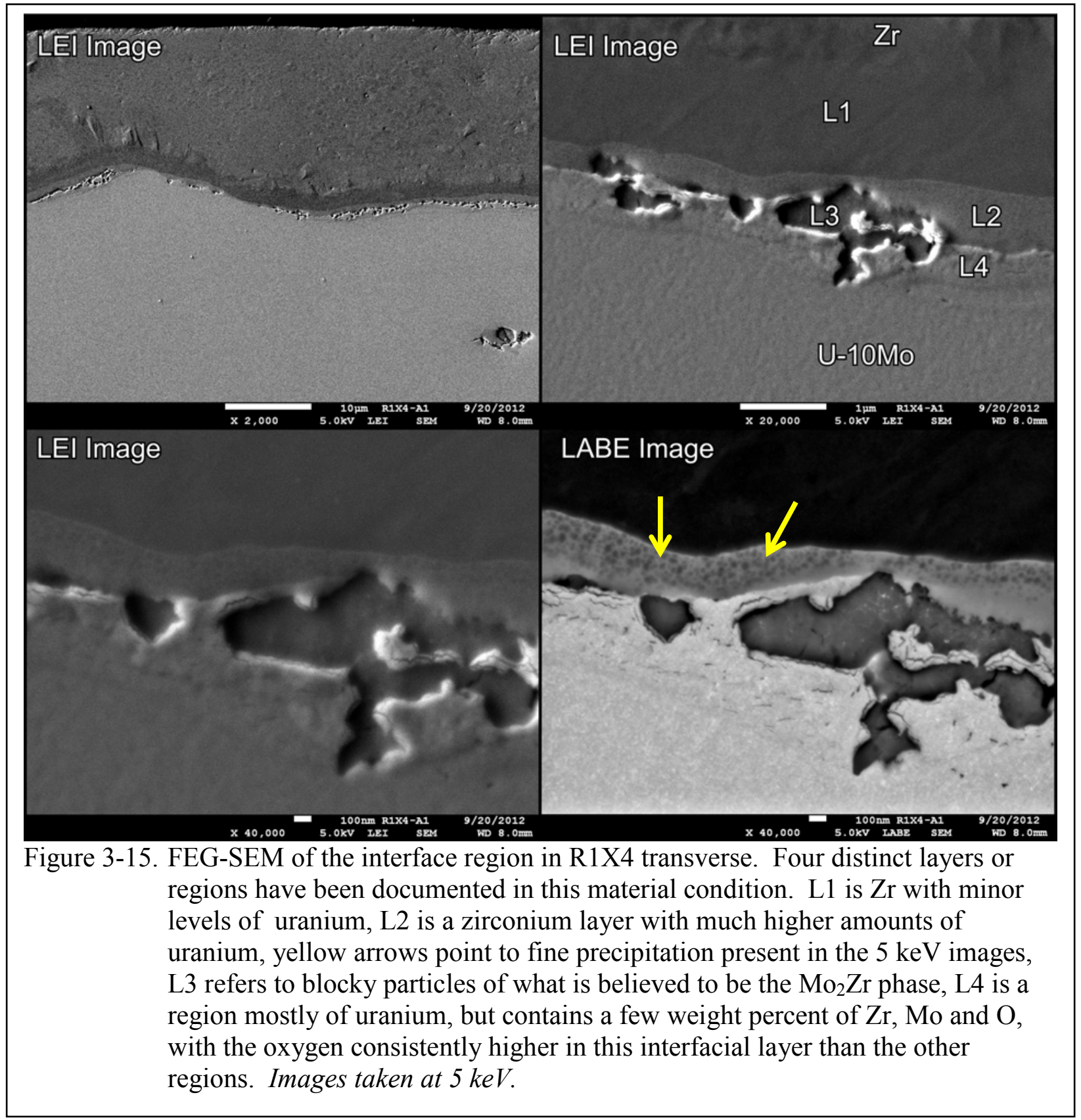




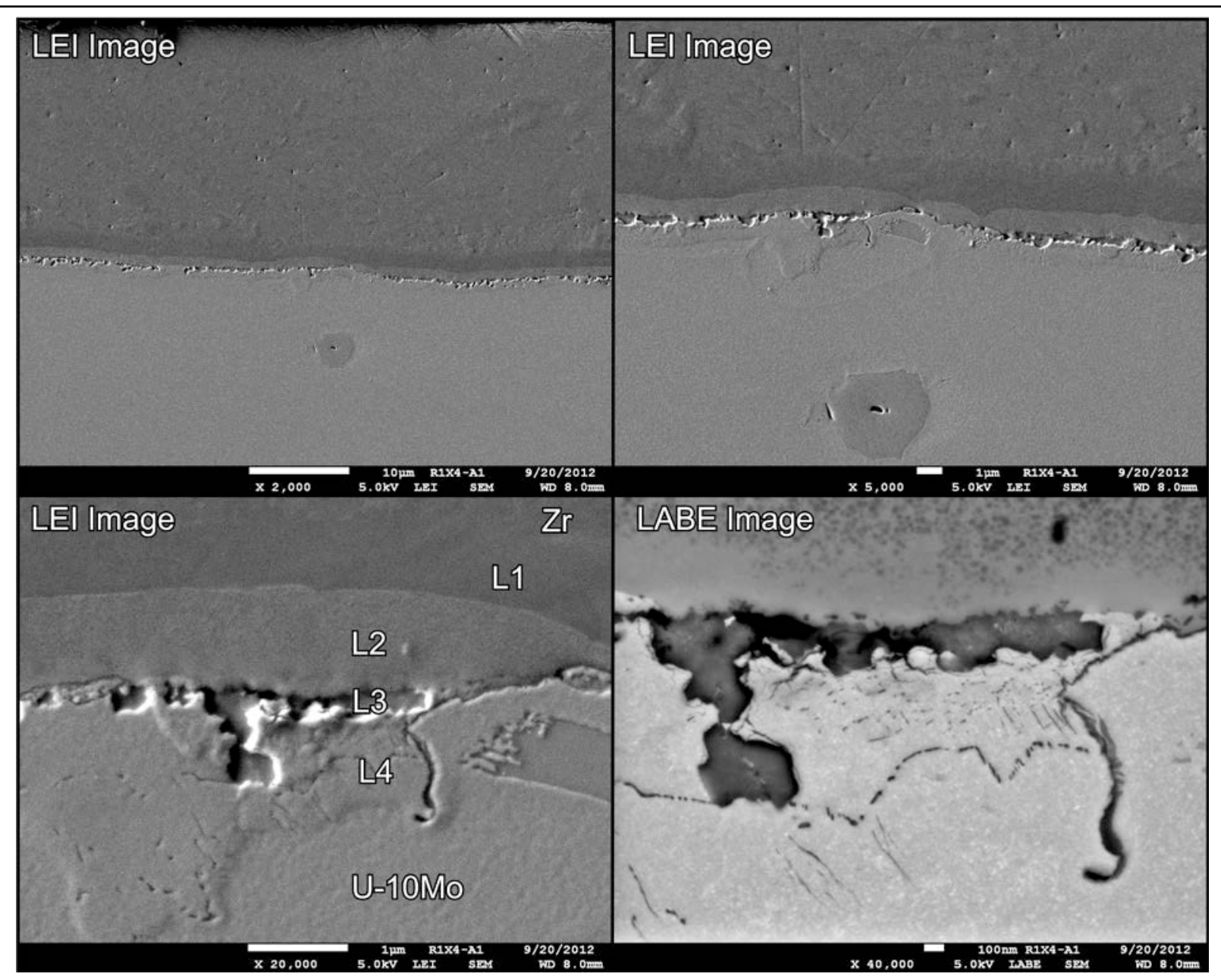

Figure 3-16. FEG-SEM of the interface region at a second region in R1X4 transverse. This region of the sample has similar characteristics as the area shown in Figure 3-11. Images taken at $5 \mathrm{keV}$. 


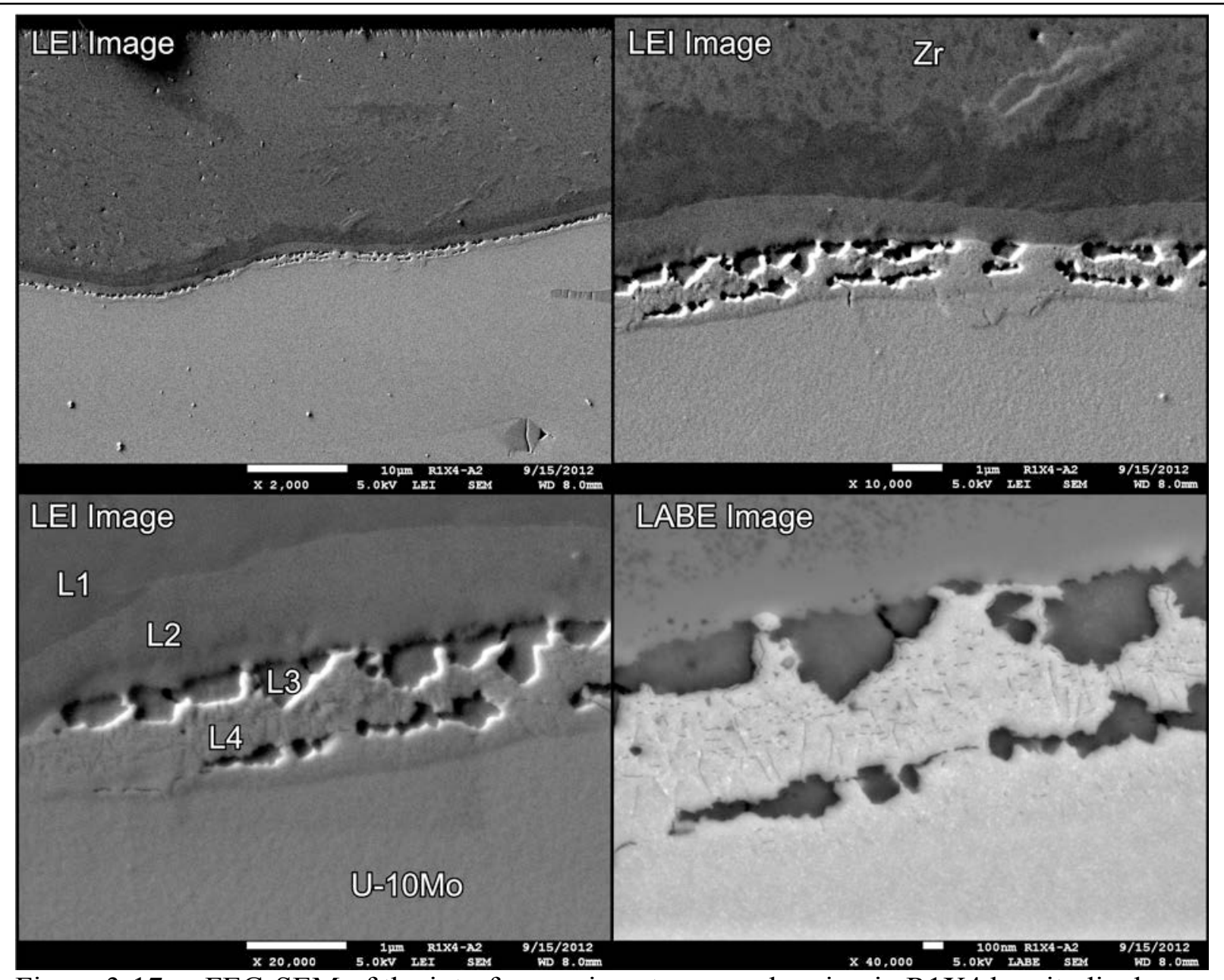

Figure 3-17. FEG-SEM of the interface region at a second region in R1X4 longitudinal. This region of the sample has similar characteristics to the interfacial regions of the transverse section shown in Figures 3-11 and 3-14, 3-15 and 3-16. Images taken at $5 \mathrm{keV}$. 


\section{4}

\section{CHARACTERIZATION RESULTS: Y-12 FOIL R9HW}

\section{ARCHIVE (63233) TRANSVERSE AND LONGITUDINAL}

\section{Optical Metallography \& Low Magnification FEG-SEM Imaging}

This foil is archive material processed at Y-12. Three pieces were sent to PNNL, all of comparable quality. One of the three pieces was sectioned into transverse $\left(1^{\text {st }} \mathrm{cut}\right)$ and longitudinal ( $2^{\text {nd }}$ cut $)$ pieces as shown below in Figure 4-1, and mounted in epoxy and polished to colloidal silica. These two samples were initially polished to just the CS final polish, and SEM was only completed on the longitudinal sample in this condition. The samples were repolished using the HP/CS final polish, but given time constraints only optical metallography was performed on both the transverse and longitudinal samples. There wasn't time to place the newly prepared samples in the SEM and do a complete analysis, however, the imaging and EDS analysis in the SEM isn't as sensitive to the CS versus the HP/CS final surface preparation as long as the silica residue is removed using the Gatan MetEtch or at least rinsed more effectively.

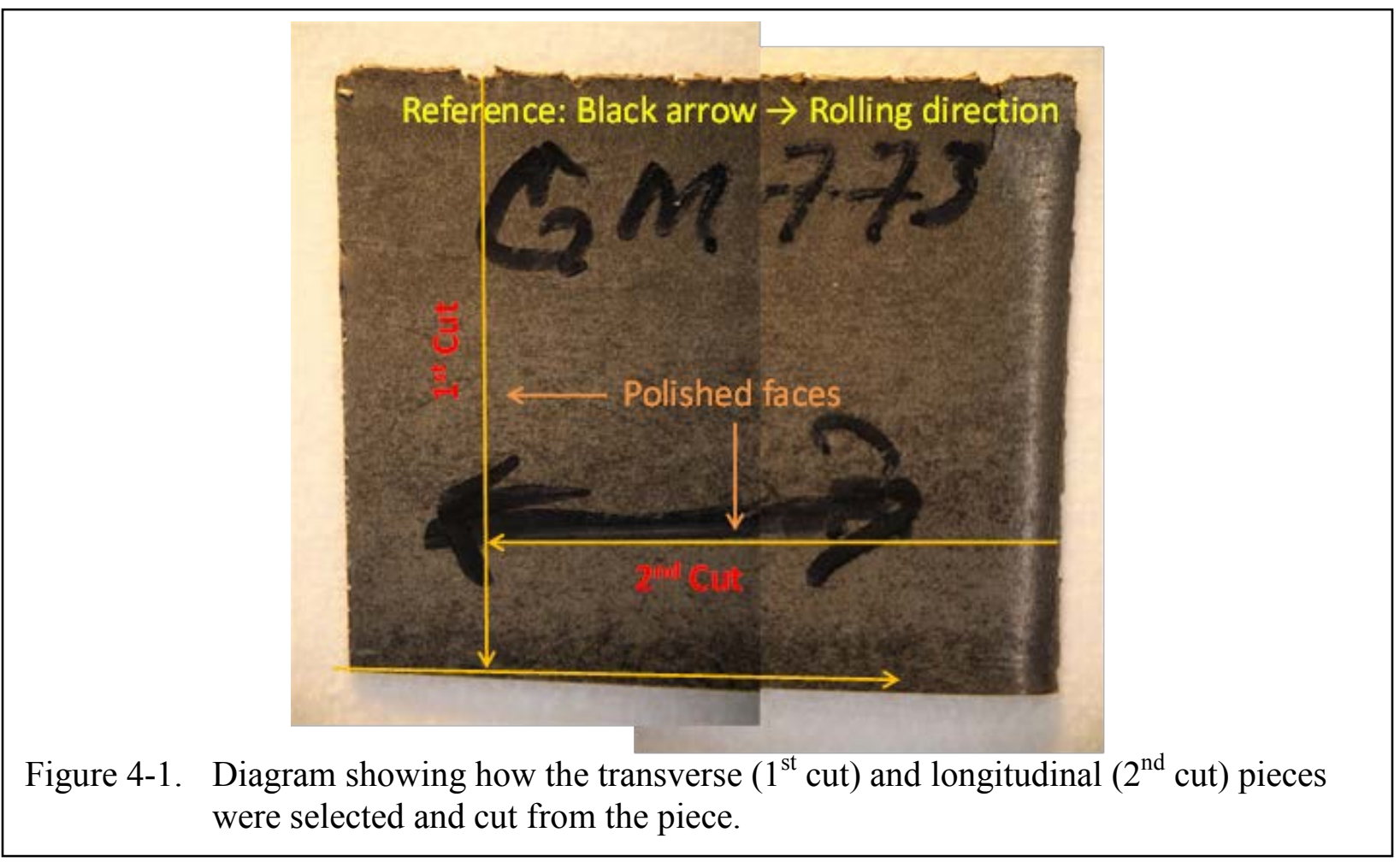




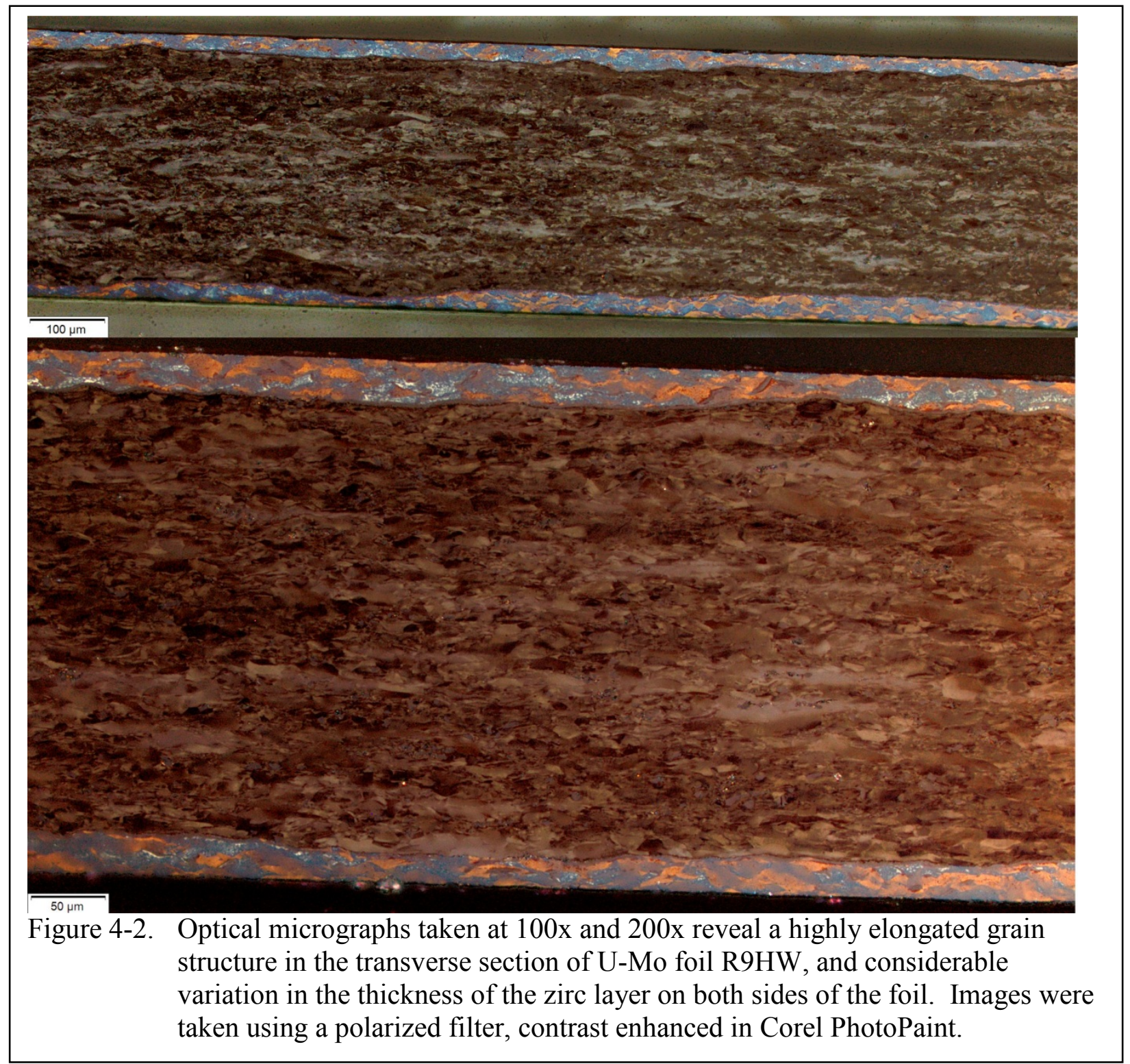

Metallographic images taken at 100x and 200x are shown for the transverse and longitudinal orientations in Figures 4-2 and 4-3, respectively. The total measured thickness of the foil is $\sim 335$ to $350 \mu \mathrm{m}$. The grain structure in the transverse sample is mostly composed of fine, highly elongated grains with a lower fraction of very coarse, elongated grains when compared to the LANL archive material, R1X4. The longitudinal sample is much different, however, with a much larger fraction of the grains being very coarse and highly elongated. The observation of the grain structure variation from transverse to longitudinal is opposite of what is found in the case of the LANL R1X4 condition, for reasons that aren't clear.

As in the R1X4 samples, it is difficult to accurately assess the average grain dimensions from these optical images. A rough estimate shows that the finer grains in the transverse condition range in size from 5 to $30 \mu \mathrm{m}$ (aspect ratio of $\sim 4$ to 1 ), whereas much coarser grains can be found with lengths of up to a few hundred microns, and an aspect ratio of 6-8 in the transverse direction. In the longitudinal case, the structure is so highly deformed that it is difficult to really measure finer grains in a meaningful manner. Close examination of the coarse grains reveals 


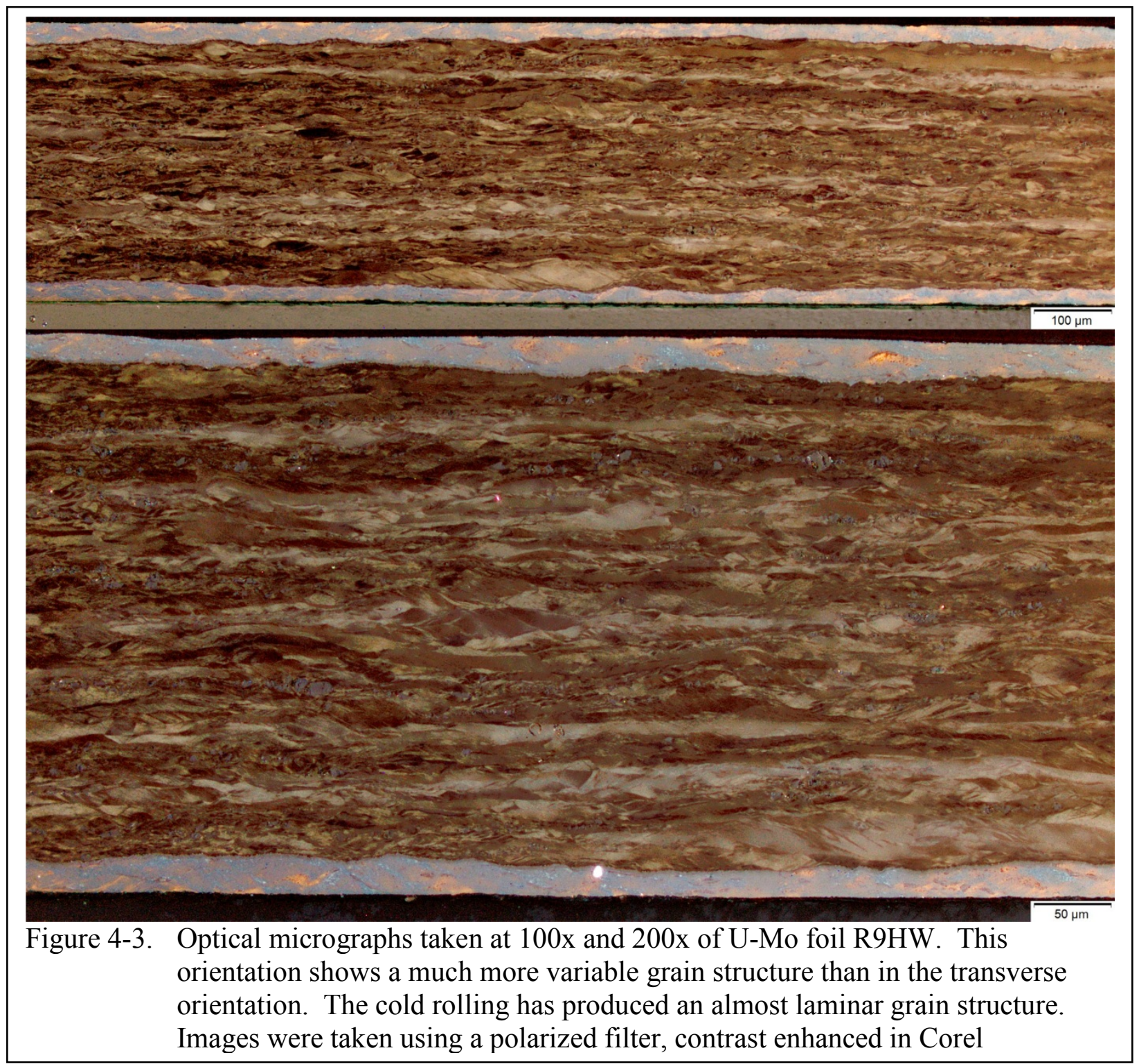

considerable shear banding and subgrains inside the long, flat grains, indicative of a high degree of cold rolling. Some of the coarse grains in the longitudinal sample have an aspect ratio of up to 30 to 1 , but it is highly variable.

The zirconium layers on both sides of the foil vary greatly in thickness along the width of the prepared samples, forming an undulating structure on the internal interface that is bonded to the U-Mo, but exhibiting a fairly flat and uniform outside surface on each side of the foil. Regions in the zirconium layer can be found that are as thin as $13 \mu \mathrm{m}$, with the adjacent region up to nearly $40 \mu \mathrm{m}$. The zirconium grain structure is characteristic of a highly deformed grain structure, with the grains extending up to $20-50 \mu \mathrm{m}$ in the rolling plane of the foil, but only 5-15 $\mu \mathrm{m}$ in the vertical direction as shown in Figure 4-3. 


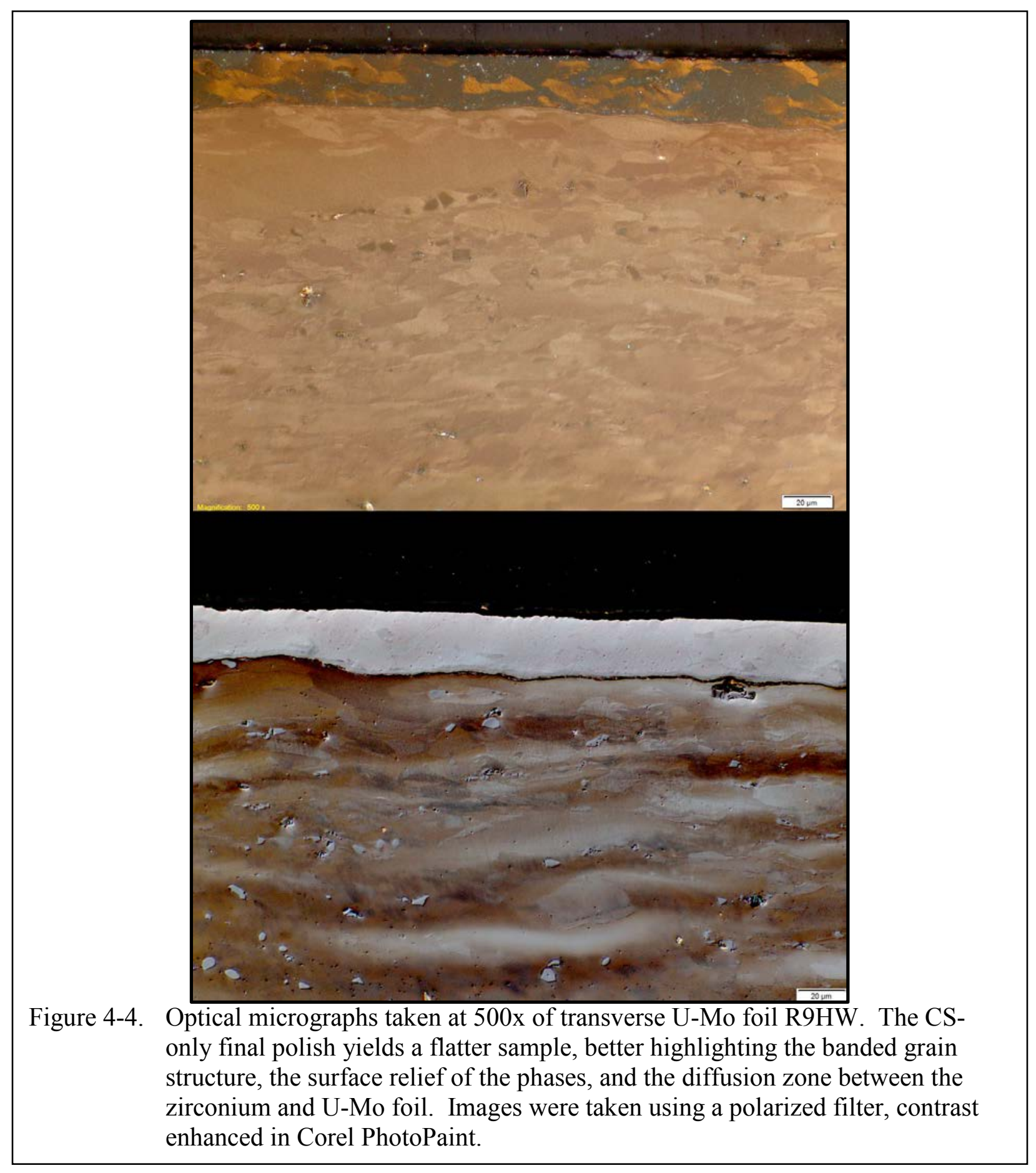




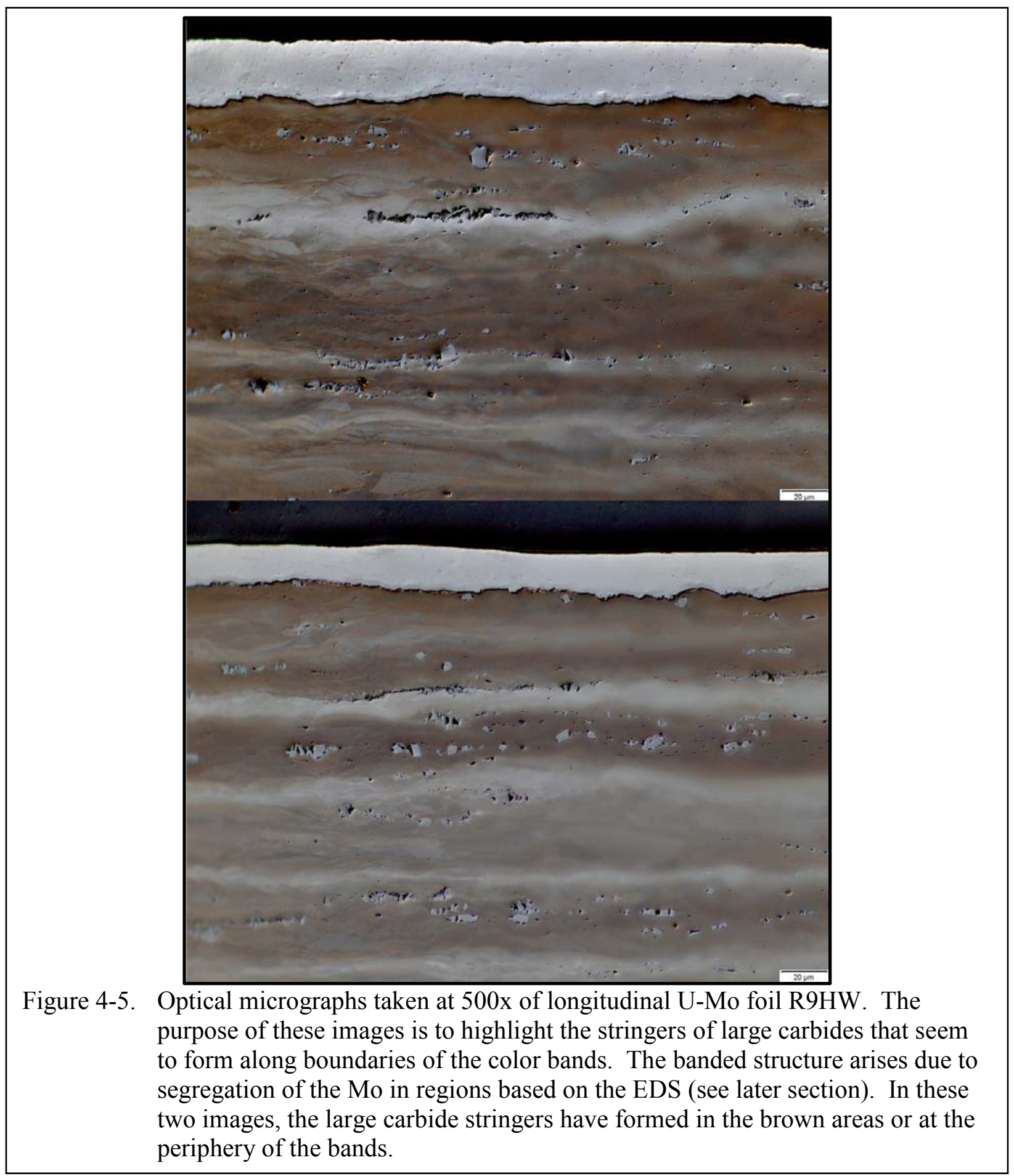


The optical images in Figure 4-4 and 4-5 demonstrate that carbides over a wide size range are present throughout the foil, and are often focused in stringers that appear to correspond to the banded structure present in this foil, visible by virtue of the laminar grain structure shown in the earlier figures and in the 500x images. The coarsest of the carbides can reach $15 \mu \mathrm{m}$, but many exist to less than a micron. The contrast in the images in Figure 4-4 and 4-5 was altered to remove the grain to grain contrast and highlight more of the surface relief believed to be due to the carbides and the zirconium interface being harder than the U-Mo matrix. The carbides are often present in the dark colored bands for both sets of images, however, this color scheme arises because of the setting on the DIC prism, which is difficult to reproduce consistently because no settings are labeled on the position of the dial. The EDS results that will be presented next to confirm the presence of chemical banding, so the optical and SEM are complementary in this regard.

SEM was only conducted on the R9HW longitudinal sample after a colloidal silica final polish. The sample was MetEtched to remove as much of the colloidal silica residue as possible, providing a decent sample that didn't polarize for optical imaging, but proved suitable for SEM imaging and chemical analysis of the microstructure. The SEM images (Figures 4-6 and 4-7) taken in low magnification mode show the distribution of carbides throughout the structure, as well as confirms the suspected chemical banding due to Mo variations. In both figures, the carbides are usually concentrated in the lighter colored regions (in the LABE images), which correspond to the lower Mo regions. This light colored appearance is confirmed with the EDS mapping and selected area compositions derived from the elemental maps provided in Figure 48. The banding due to Mo variation is evident in the EDS map, as is the location of the carbides in those regions of lowest Mo levels. The color mix image at the top is an overlay of the indicated elements on the LABE image, showing that the bright colored regions are richer in $\mathrm{U}$, lower in Mo. The Mo levels were measured from the indicated "Lo Moly" versus "Hi-Moly" regions, yielding 7.8 to $8.2 \mathrm{wt} \%$ Mo at the lowest levels up to $9.5 \mathrm{wt} \%$ for the higher Mo regions. This range is slightly greater than observed in the LANL R1X4 archive, but shouldn't be taken as an absolute given the $\mathrm{x}$-ray generation volume at $20 \mathrm{keV}$, width of the regions, and possibility of carbides hidden beneath the surface that might alter the results. Figure 4-9 provides a series of images showing the carbides at two different locations and magnifications. The images mostly demonstrate that some of the coarse carbides have fractured, likely during the rolling of the foil, not during sample preparation. 


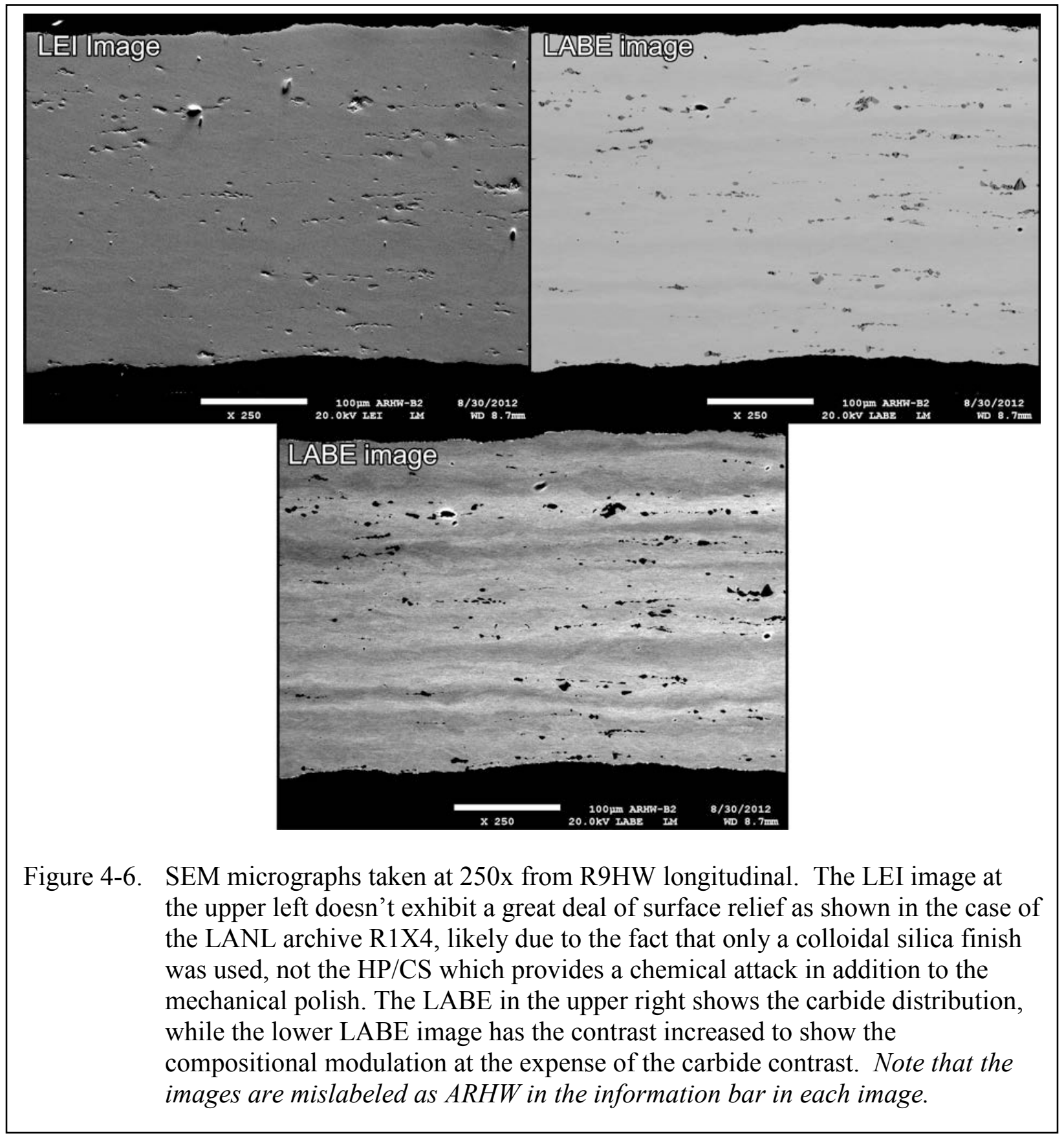




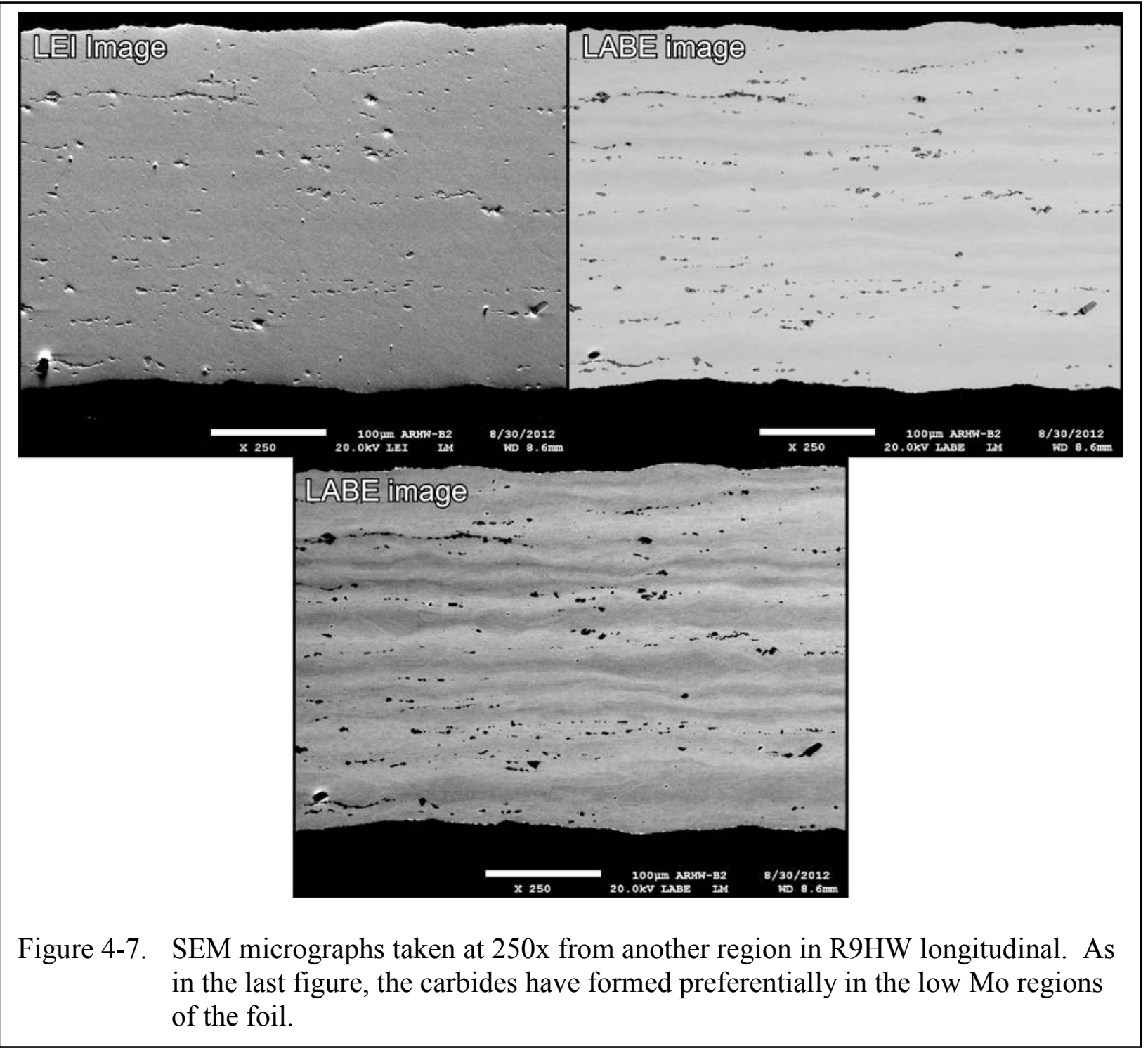




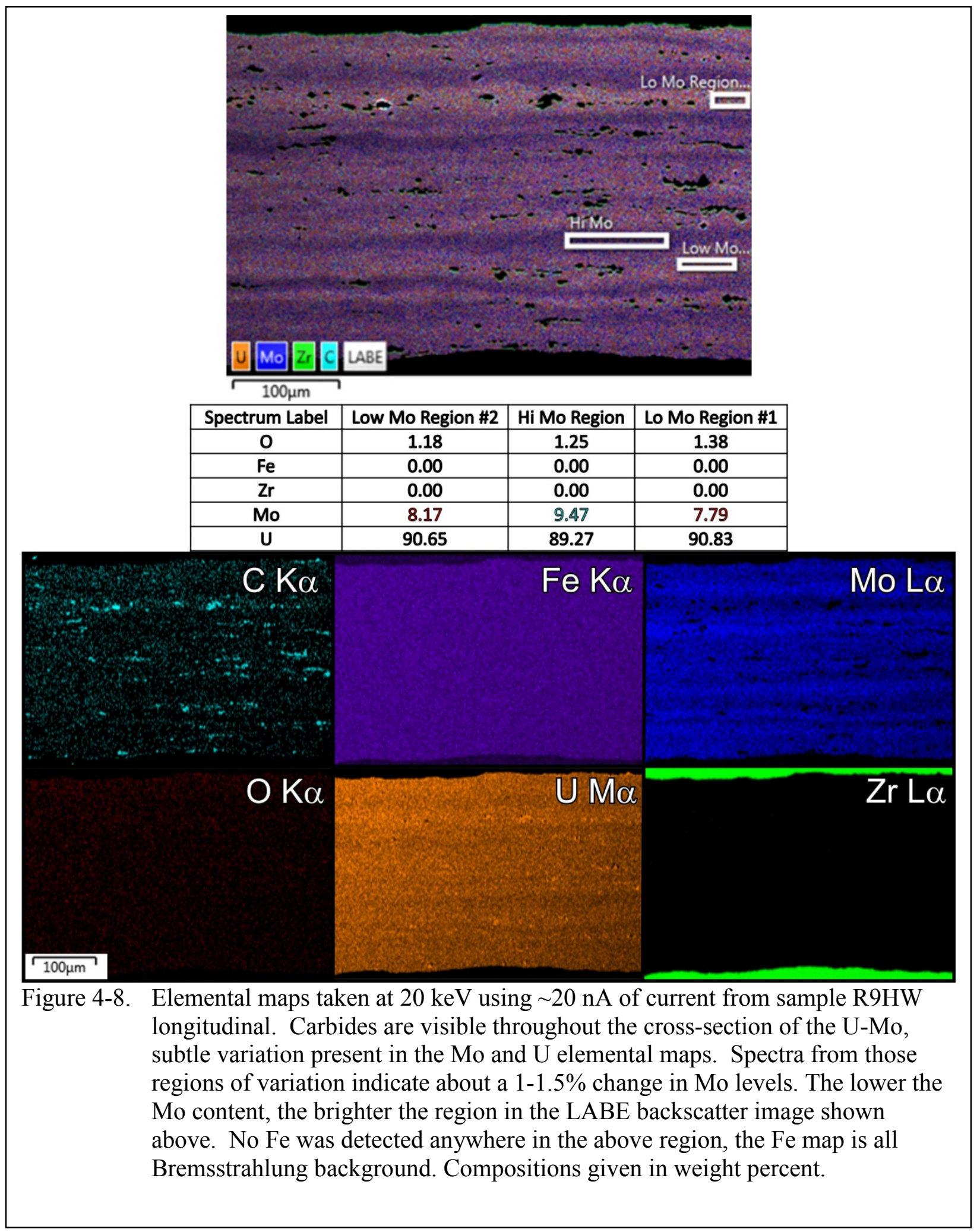




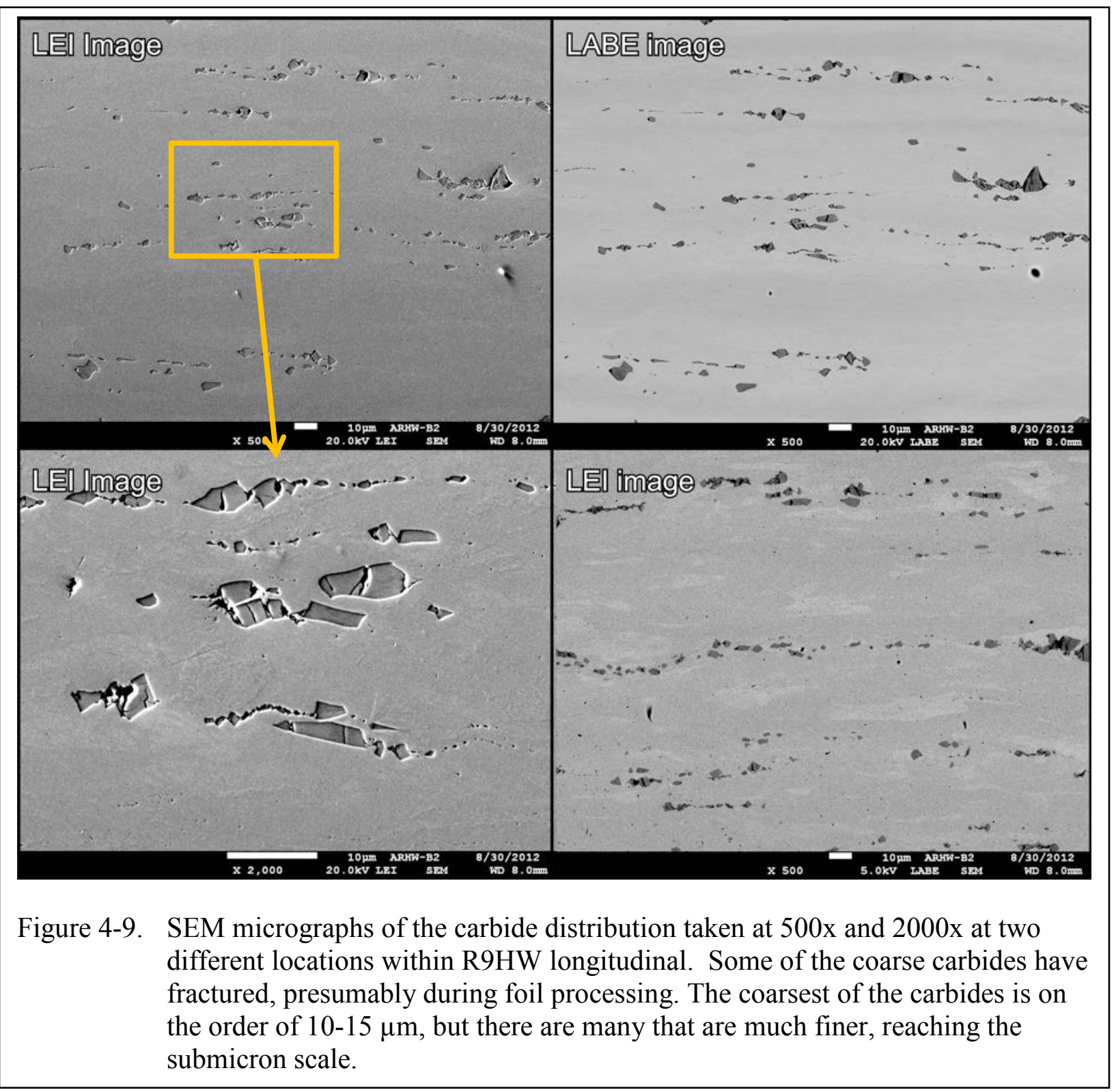




\section{Zirconium/U-10Mo Interaction Layer}

As in the case of the LANL R1X4 archive, this archive foil also exhibits a complex diffusion zone, with similar interaction layers as described for the other foil. Examples of the diffusion layer between the $\mathrm{Zr} / \mathrm{U}-\mathrm{Mo}$ are provided in Figures 4-10 and 4-11. A full description of the main characteristics have already been presented for R1X4, so only the differences observed in this condition will discussed. One of the most notable differences is that in this archive material, the decomposition zone and interactions are not as uniform and continuous as was observed in the LANL R1X4 archive material. More interesting is that in both of the examples given, there is a common orientation that is related to the one side of the interface undulation. Referring to Figures 4-10 and 4-11, white arrows are shown that indicate this orientation. This was not observed in the regions selected for analysis in the R1X4 condition. The decomposition region L4 is a bit different in that the platelets of the dark phase, probably some Mo-rich phase, formed in an oriented manner whose long axis is parallel to the arrows. One possible source of this oriented decomposition reaction is that the surface of the Y-12 U-Mo foils surface was left in a mechanically strained state prior to bonding with the zirconium, which promoted a discontinuous reaction zone during subsequent processing.

Another difference observed is the L2 layer, which is thought to be the $\delta-\mathrm{UZr}_{2}$ based on its composition and the results of Perez et. al [4], does not have the speckled appearance observed in the LANL archive. However, the sample examined in the SEM was not given the HP/CS finish, it was only polished to the colloidal silica final polish. While colloidal silica ( $40 \mathrm{~nm}$ sized oxide suspension) produces very fine surface finishes, there remains a possibility that at the scale of precipitation observed in the R1X4 $(15-50 \mathrm{~nm})$, there may be enough residual surface deformation that backscatter images of the small particles cannot be observed. Use of the hydrogen peroxide/CS may improve this detection of the fine-scale precipitates through the additional etching, effectively removing any residual deformation that might interfere with imaging these small precipitates. Careful examination of the in-lens secondary images (SEI detector) for the R1X4 did not reveal any etching of the surface in the region of the particles in the $\delta-\mathrm{UZr}_{2}$ that might have corresponded to the particles themselves, so the image contrast in the R1X4 interaction zone appears to be predominately a backscatter effect due to a phase precipitating with an average lower atomic weight than the surrounding $\delta-\mathrm{UZr}_{2}$. This cannot be confirmed at present unless we can examine a another Y-12 foil using the same HP/CS final finish as the R1X4.

In Figures 4-10 and 4-11, there are indications that the blocky precipitates thought to be $\mathrm{Mo}_{2} \mathrm{Zr}$ in the L3 layer may either vary in composition (the phase diagram for this phase shows $\mathrm{Mo}_{2} \mathrm{Zr}$ can vary from 32 to $39 \mathrm{wt} \% \mathrm{Zr}$ ), or perhaps a different phase is present. At $20 \mathrm{keV}$ this difference in contrast doesn't show up, possibly due to scattering from the surrounding regions. At $5 \mathrm{keV}$, there is clearly a difference in the contrast of some of the particles, suggesting that some of the particles closer to the $\delta-\mathrm{UZr}_{2}$ that are lighter in appearance may have a higher average atomic weight.

The profiles across the diffusion zone and various interaction layers are fairly similar to what was observed in the LANL archive R1X4. The oxygen variation slightly peaks in the middle of the diffusion profile, which corresponds to the beginning of the L4 region. The L4 region was proposed by Perez et al. [4] as a decomposition of the cubic U-Mo to an orthorhombic phase as the Mo is pulled away into the large, discrete $\mathrm{Mo}_{2} \mathrm{Zr}$ particles. We note this region also tends to have a slight enrichment of oxygen, but it is not clear if that plays a role. 


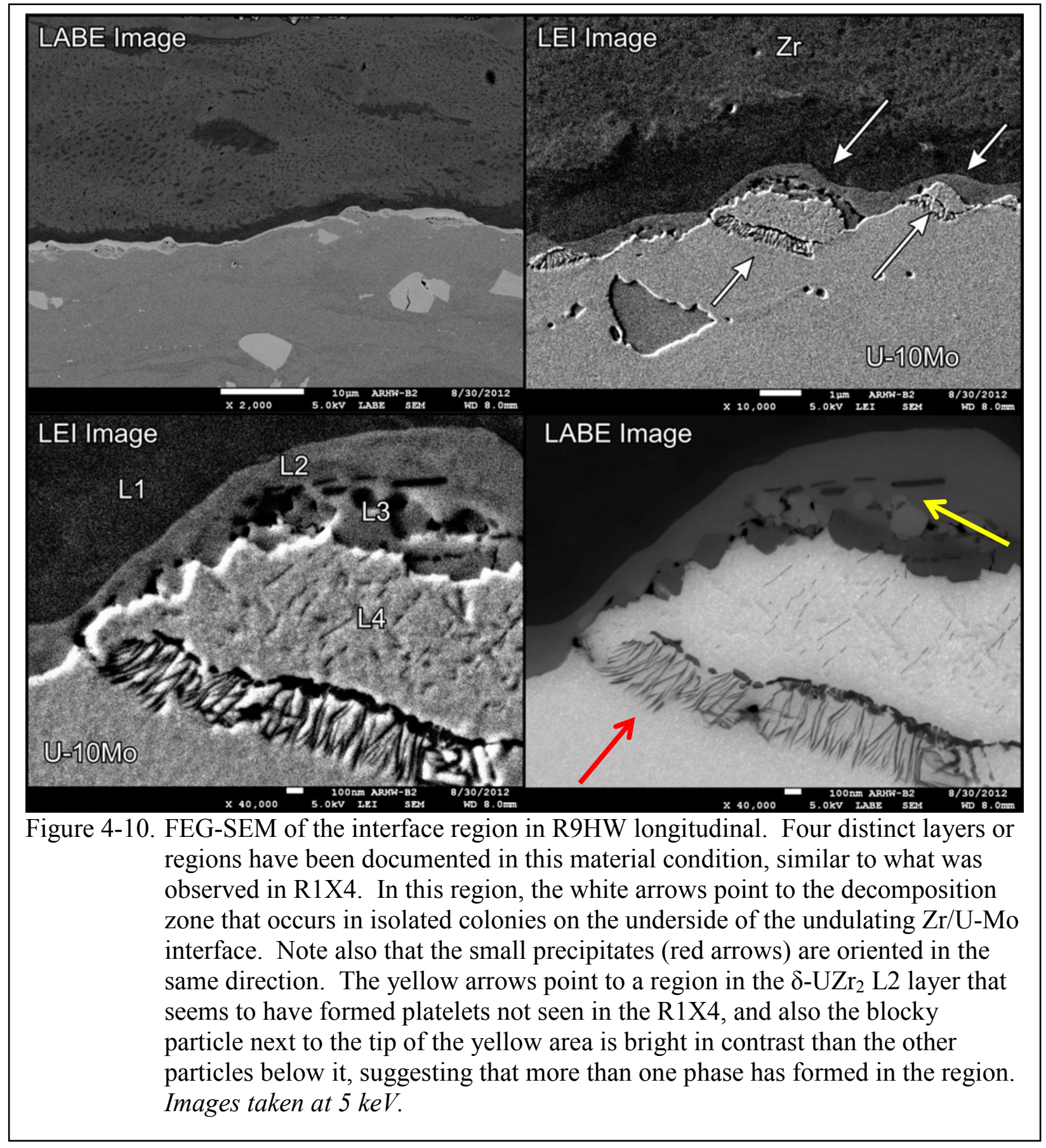




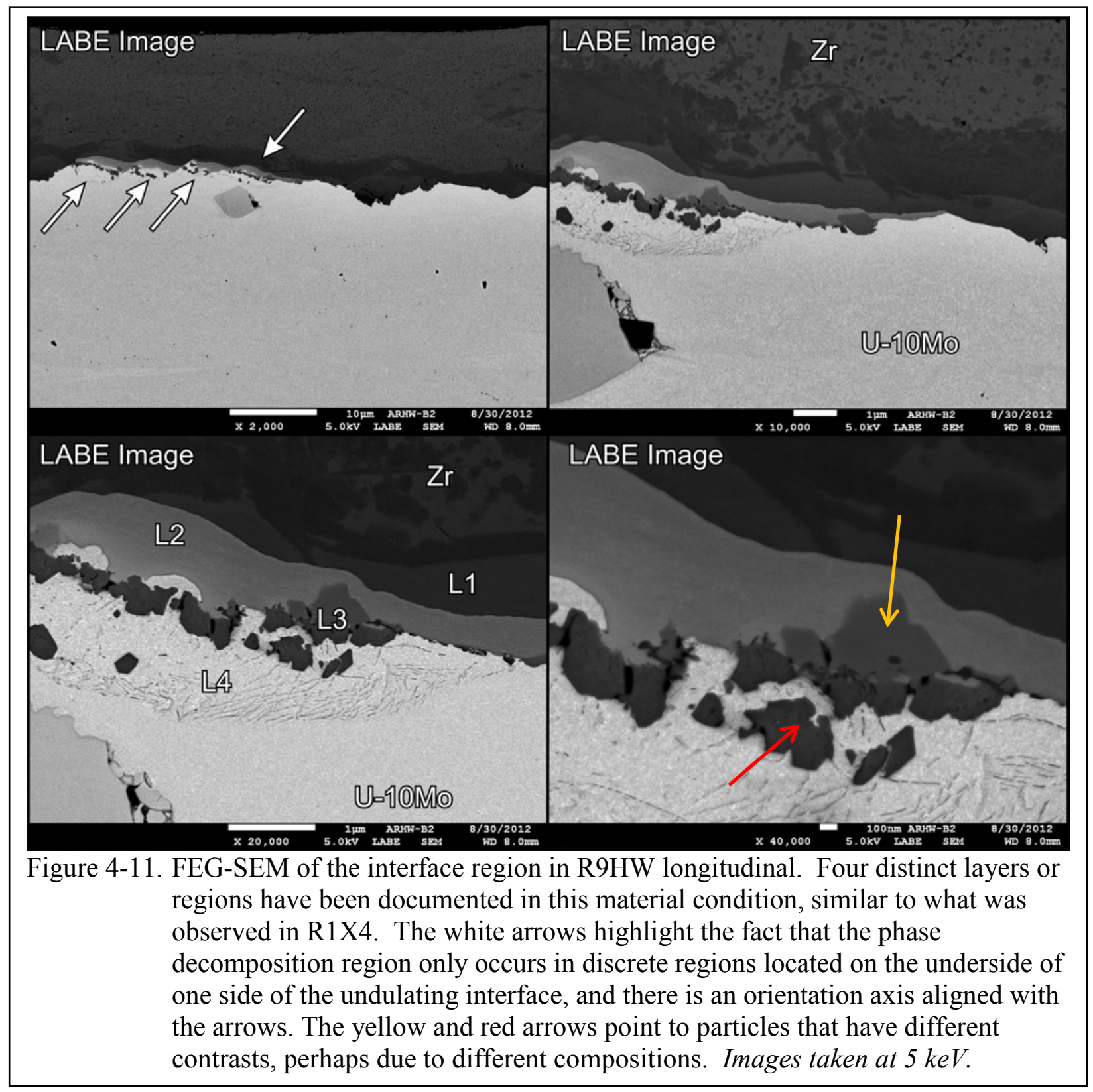




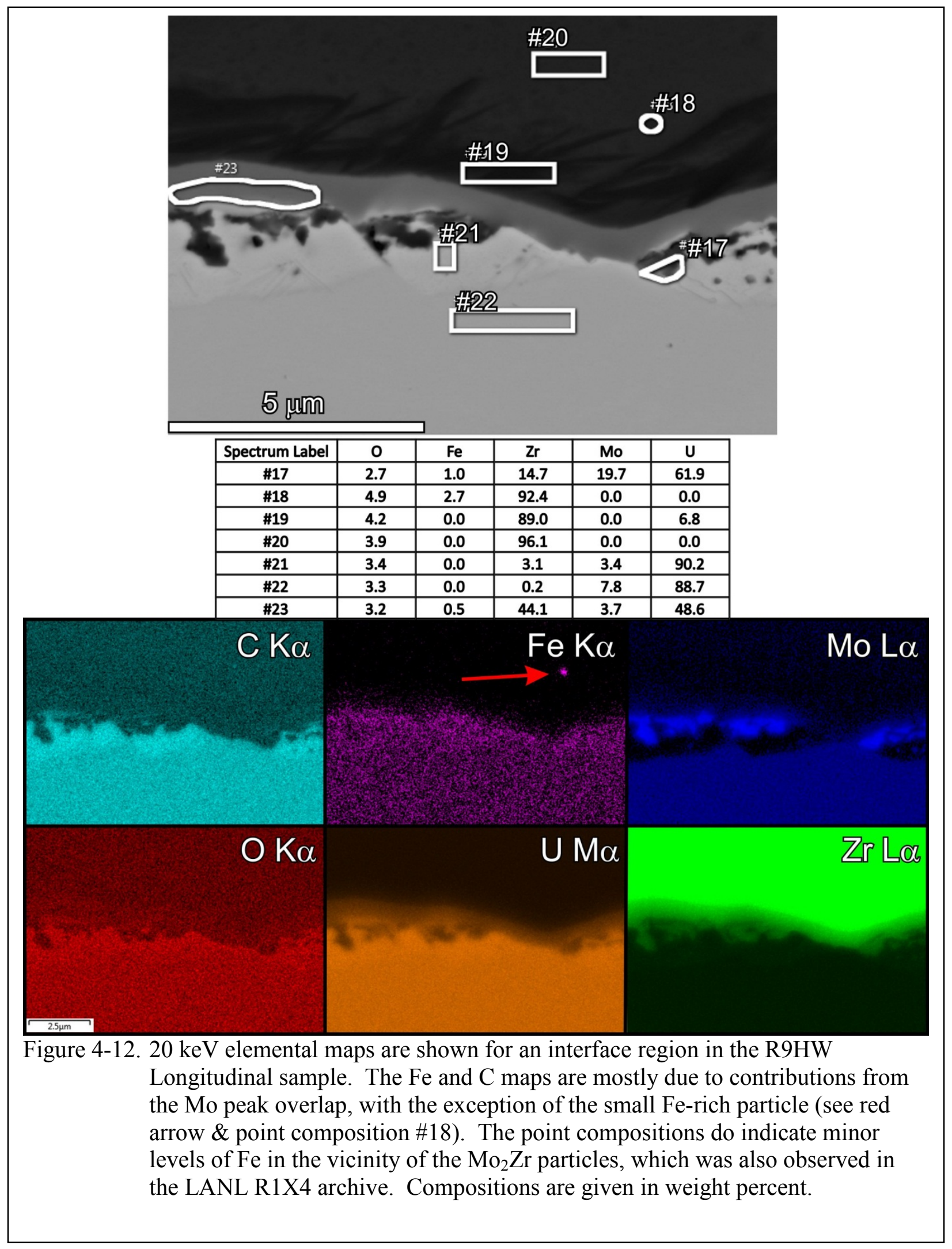



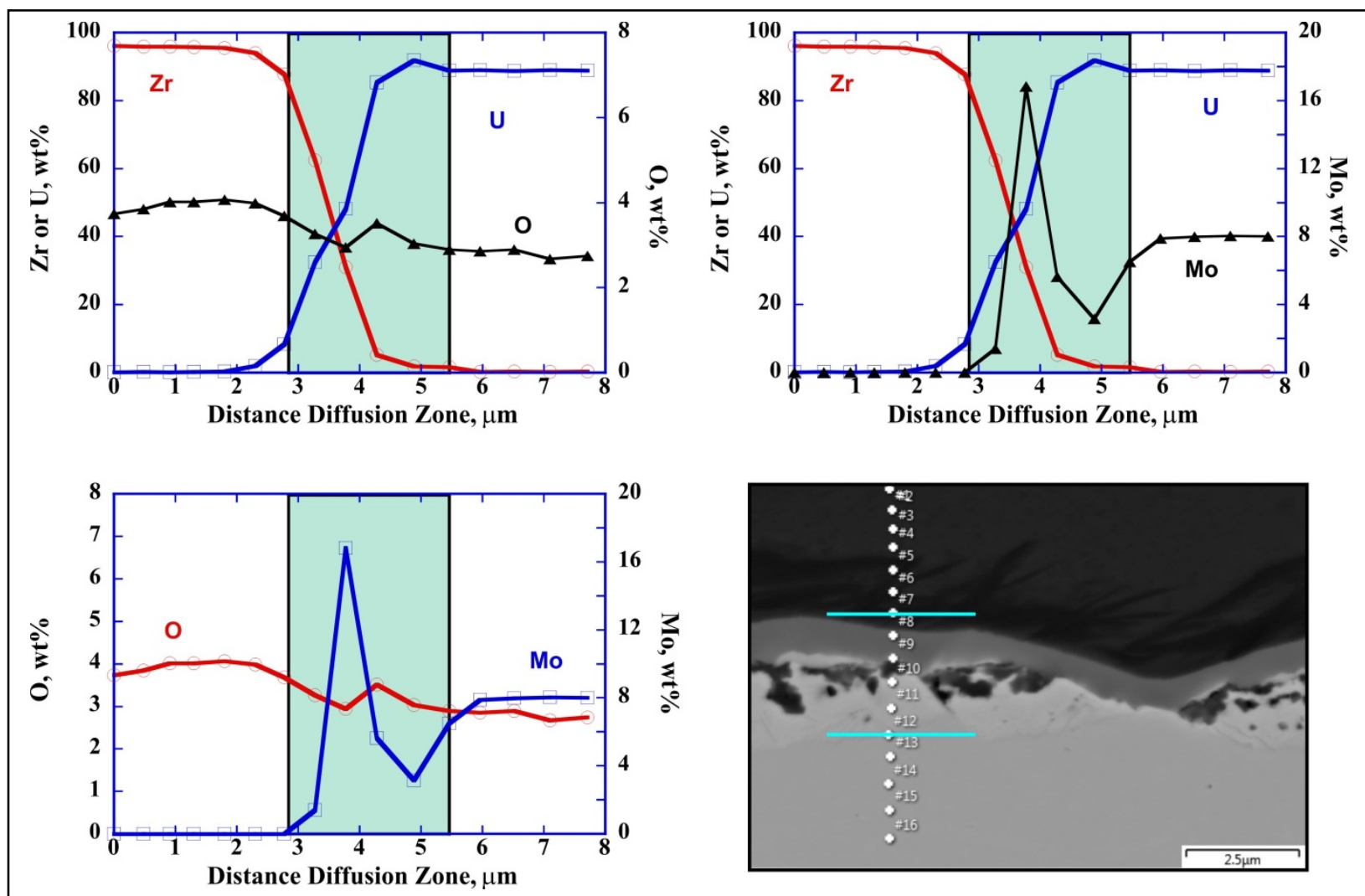

Figure 4-13. A series of point compositions were taken from the same mapped region to highlight the change in composition over this region. The results are similar to what was observed in the LANL R1X4 archive. The $\mathrm{Zr}$ and $\mathrm{U}$ vary monotonically across the diffusion zone, but the Mo and $\mathrm{O}$ profiles exhibit a different behavior that corresponds to regions either enriched or depleted in Mo.

\section{Summary of Results for Y-12 Foil R9HW Archive}

Very similar grain structure to that observed in the R1X4 in that both orientations show a difference in the fraction of highly elongated grains. R9HW appears to be more heavily cold worked, but it is challenging to quantify this given the heavily distorted grain structure present in each material. Curiously, the orientation that exhibits the greatest degree of very coarse, elongated grains is the transverse section in R1X4, but in R9HW it is the longitudinal orientation. A check of the orientation as mounted confirmed the sample orientation was preserved between the two conditions. The zirconium interface of the two is similar with respect to undulation along the width of the samples, however, the grain structure in the Y-12 R9HW condition is considerably finer than that of the LANL R1X4 archive.

The diffusion zone in the R9HW condition has a distinctly different appearance at moderate magnifications. It is not as continuous nor as uniform in width as that observed in both orientations for the $\mathrm{R} 1 \mathrm{X} 4$, and the decomposition reaction that occurs has some noteworthy differences. Unlike the R1X4, the decomposition occurs only in isolated regions with an axial 
orientation to the internal interface between the U-Mo and the zirconium layer. This axial relationship also extends to the precipitates that form inside the diffusion zone, producing an oriented structure that was different than the more random precipitation observed in R1X4. Some regions along the diffusion zone do not show any significant formation of the $\mathrm{Mo}_{2} \mathrm{Zr}$ particles, nor the apparent decomposition of the adjacent U-Mo matrix. There is usually a layer of zirconium with a lower levels of uranium that transitions in the pure zirconium. 


\section{5}

\section{CHARACTERIZATION RESULTS: Y-12 U-10MO FOIL}

\section{R9HT (63231) TRANSVERSE AND LONGITUDINAL}

\section{Optical Metallography \& Low Magnification FEG-SEM Imaging}

Foil R9HT is a foil processed at Y-12 and eventually sent to the reactor for irradiation. Three separate pieces of this condition were included in the shipment. One piece was selected for sectioning according to the diagram below in Figure 5-1, the first cut is the transverse and second cut is the longitudinal section. These two conditions were two of the first prepared for examination in the early part of the program, so after mounting in epoxy, the two samples were mechanically polished to $1 \mu \mathrm{m}$, and then attempts were made to electropolish the samples to produce an EBSD-quality surface finish. The results were mixed, yielding reasonable images for optical metallography and SEM of the U-Mo foil itself, but the zirconium layer did not polish well. Both samples were later polished using the CS final polish. The SEM results were therefore taken on colloidal silica (CS) finished samples. Both samples were eventually repolished using the HP/CS preparation method, but only optical metallography was completed before the end of the program after this final repolish.

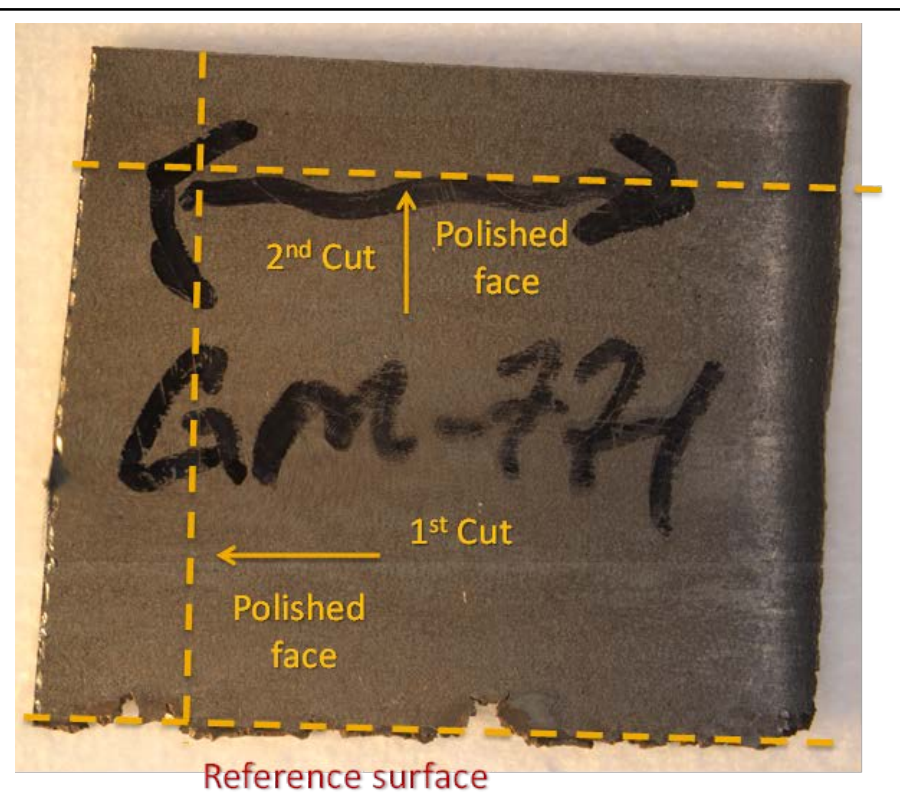

Figure 5-1. Diagram showing how the transverse and longitudinal pieces were selected and cut from the piece. 


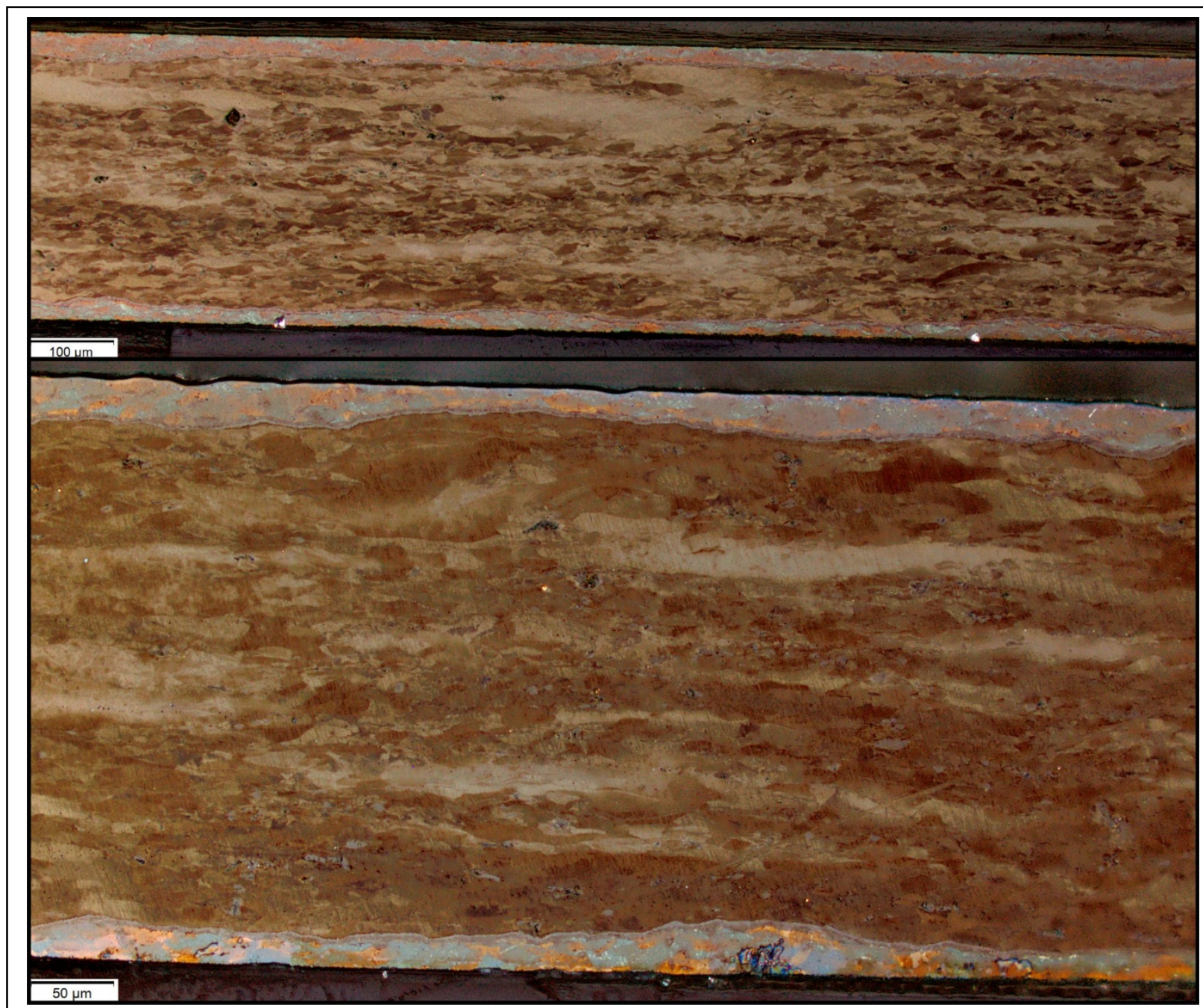

Figure 5-2. Optical micrographs taken at 100x and 200x (HP/CS final polish) reveal a highly elongated grain structure in the transverse section of Y-12 U-Mo foil R9HT. A mixed microstructure of coarse grains is interspersed with a much finer grain structure. The zirconium layer is highly variable on both sides of the foil. Images were taken using a polarized filter, contrast enhanced in Corel PhotoPaint.

The grain structure of this particular foil appears to be highly cold worked, qualitatively similar to that observed in the R9HW archive condition. Optical images of the grain structure are provided in Figures 5-2 and 5-3. Very coarse, elongated grains that can extend for 100's of microns are visible throughout the observed length of the foil in both orientations, interspersed with a much finer grain structure. The overall grain structure could be referred to as a laminartype structure, and the longitudinal orientation is arguably more laminar than the transverse orientation. Aspect ratios for the coarsest grains can be as high as 15 to 1, but for the finer grains it is more typically around 3 or 4 to 1 . The zirconium layer is both heavily deformed with respect to the grain structure, but is also high variable in its thickness. A number of regions can be found as thin as $10 \mu \mathrm{m}$, where other areas are as thick as $35 \mu \mathrm{m}$. Grain size in the zirconium layers ranges from $5-30 \mu \mathrm{m}$. 


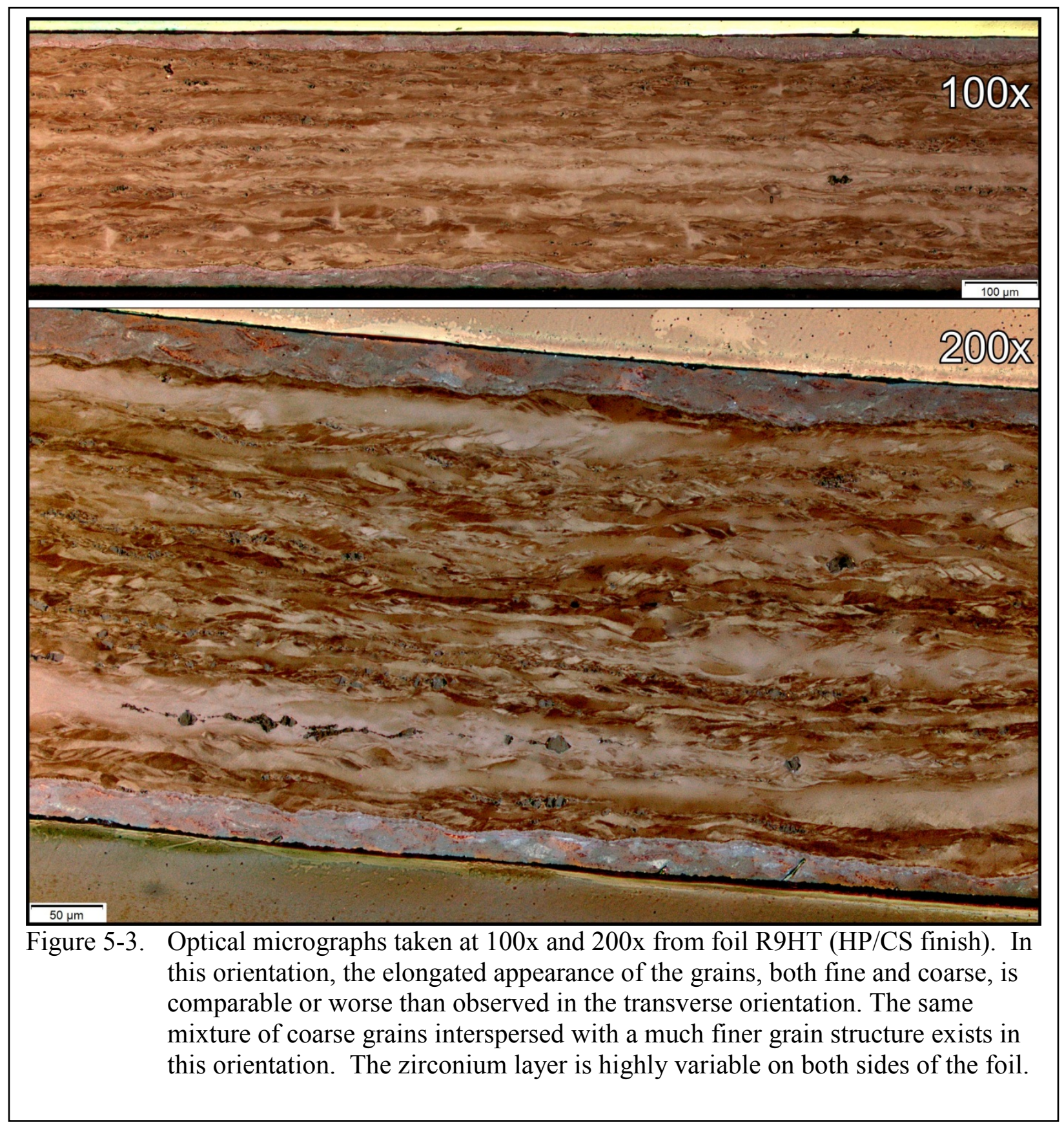

Carbides are present as stringers of both coarse and fine particles, as shown in Figure 5-4 and the previous sets of optical images. SEM images are provided in Figure 5-5 and 5-6, highlighting the compositional banding and stringers of carbides present in the foil. The SEM images show that in this foil condition, as in the archive material R9HW, the carbides are often associated with the lighter bands, which are known to be lower in Mo. This is confirmed with the elemental map taken in the SEM at 250x, showing the elemental distribution over the entire cross-section in the center of the foil. The carbides visible in the elemental maps are almost always associated with the regions lower in Mo than the surrounding matrix. The compositional banding corresponds to $\sim 1$ to $1.5 \mathrm{wt} \%$ variation in the Mo levels, fairly consistent with what was observed in the R9HW. 


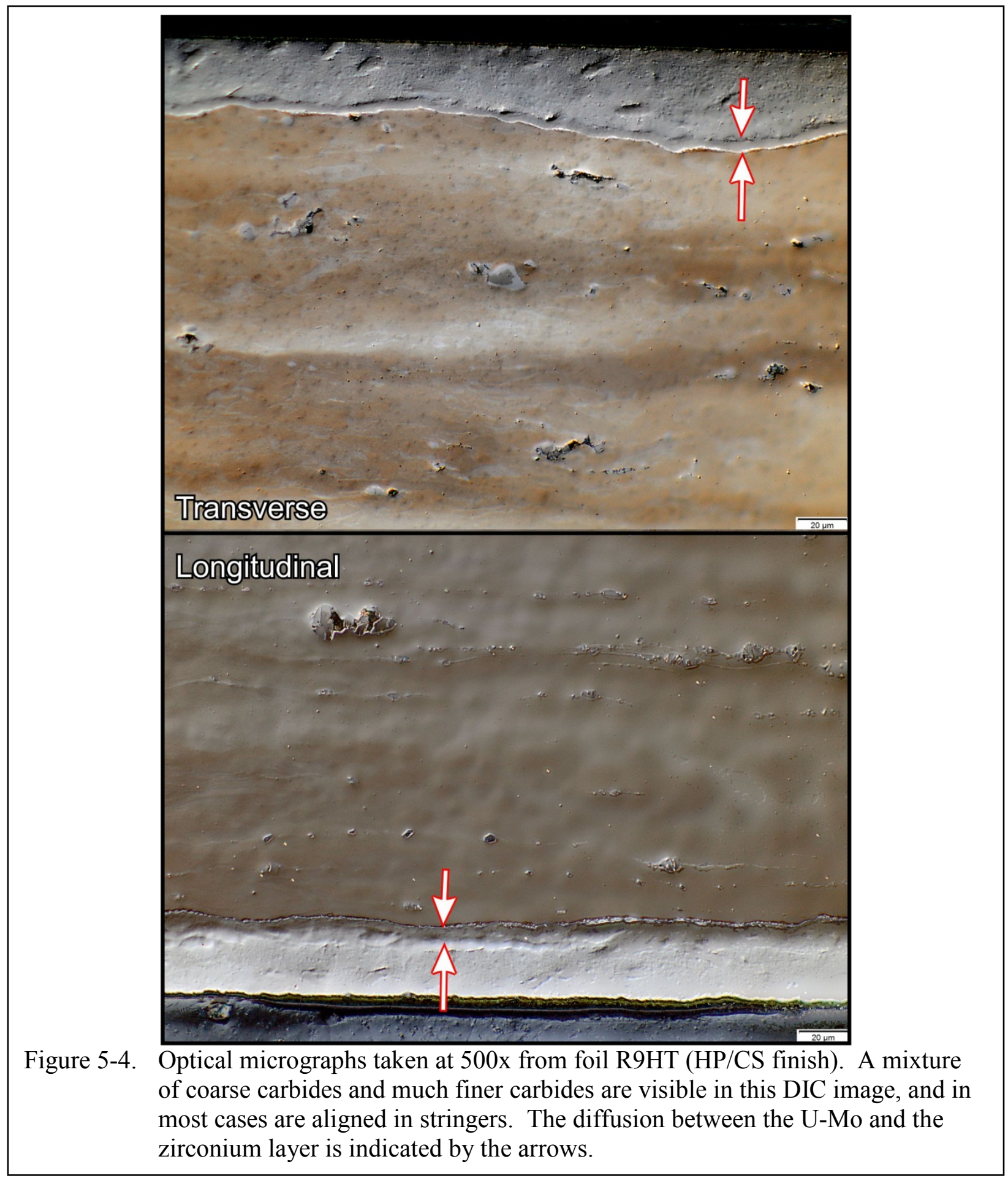




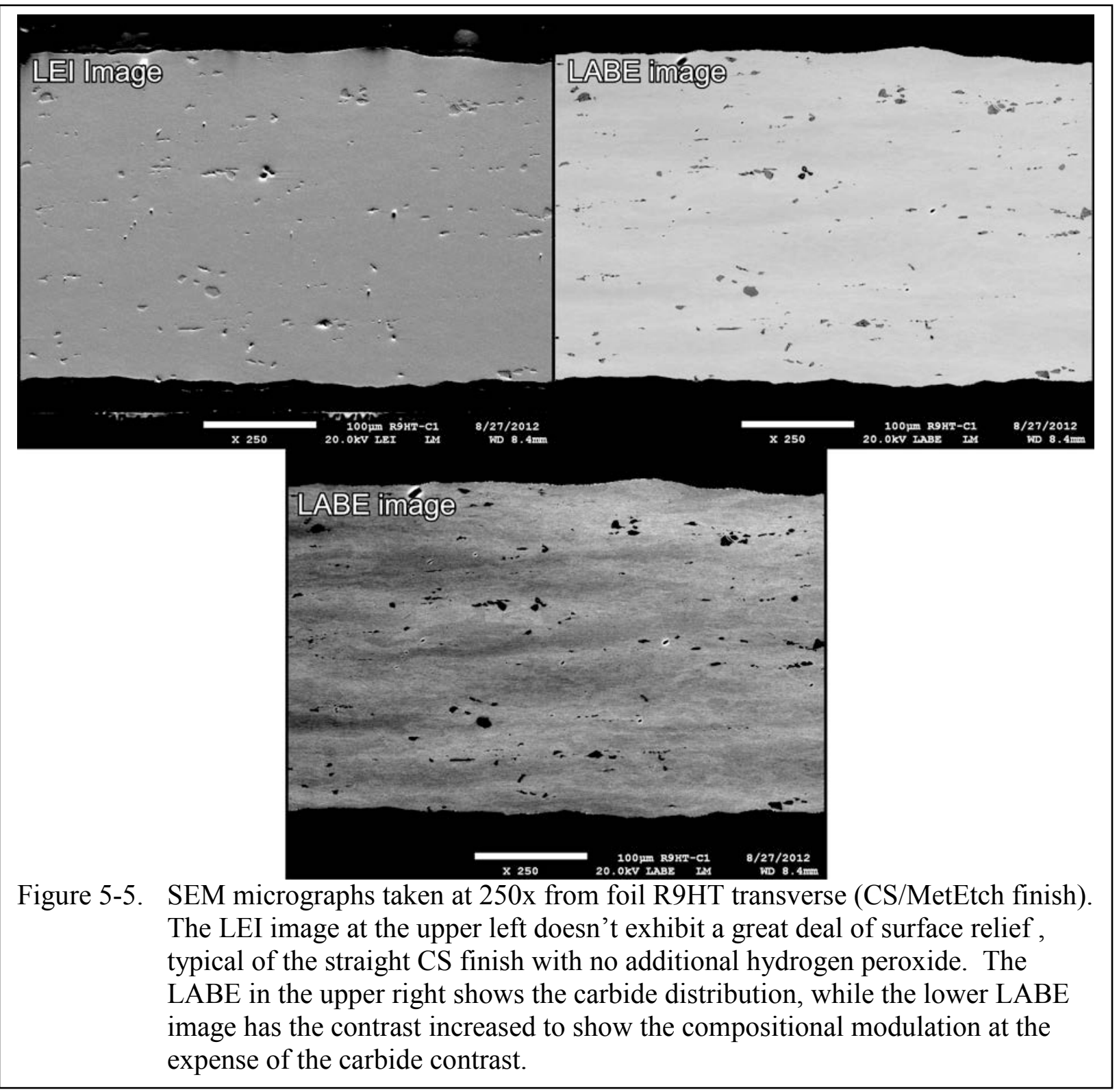




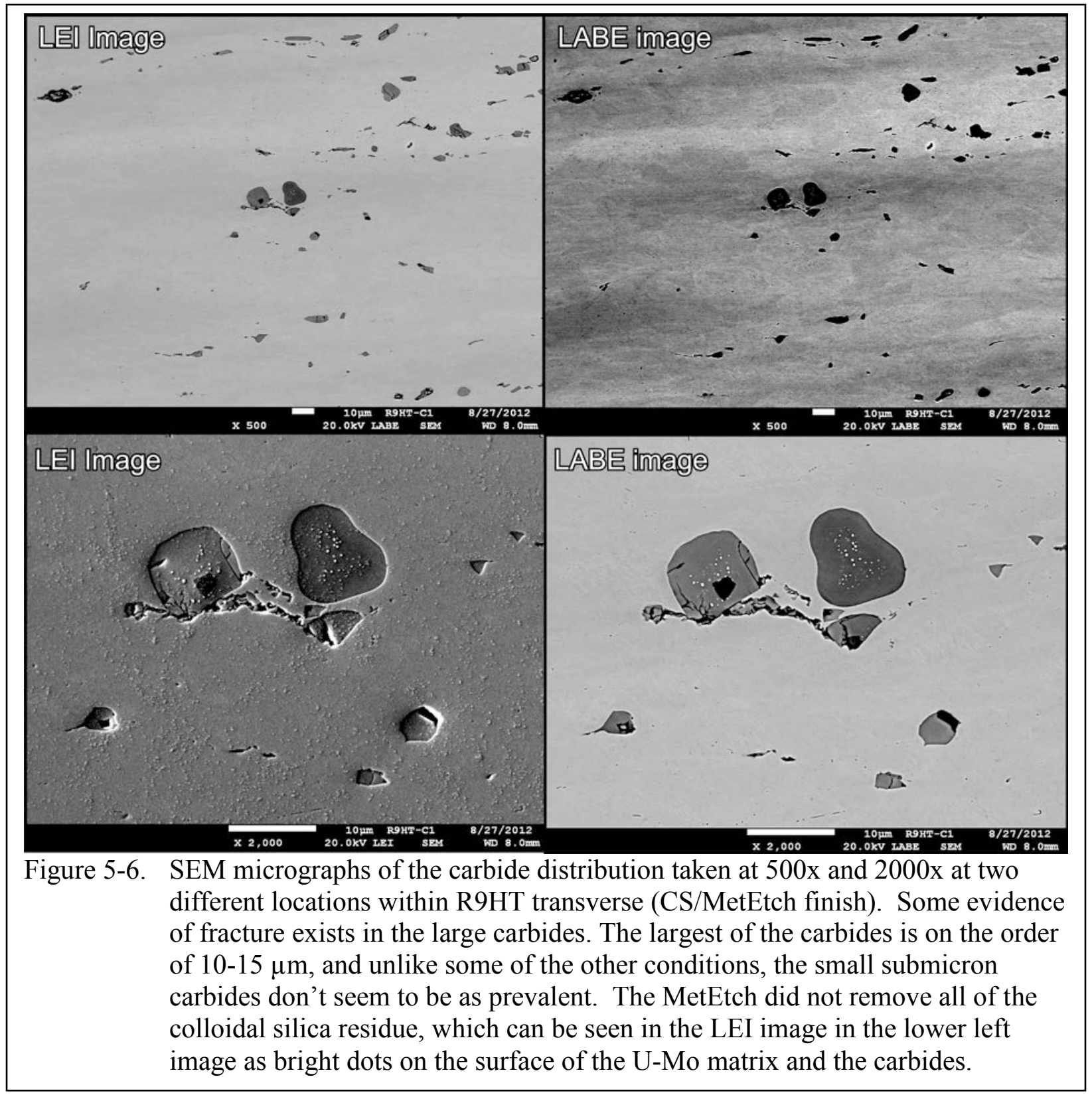




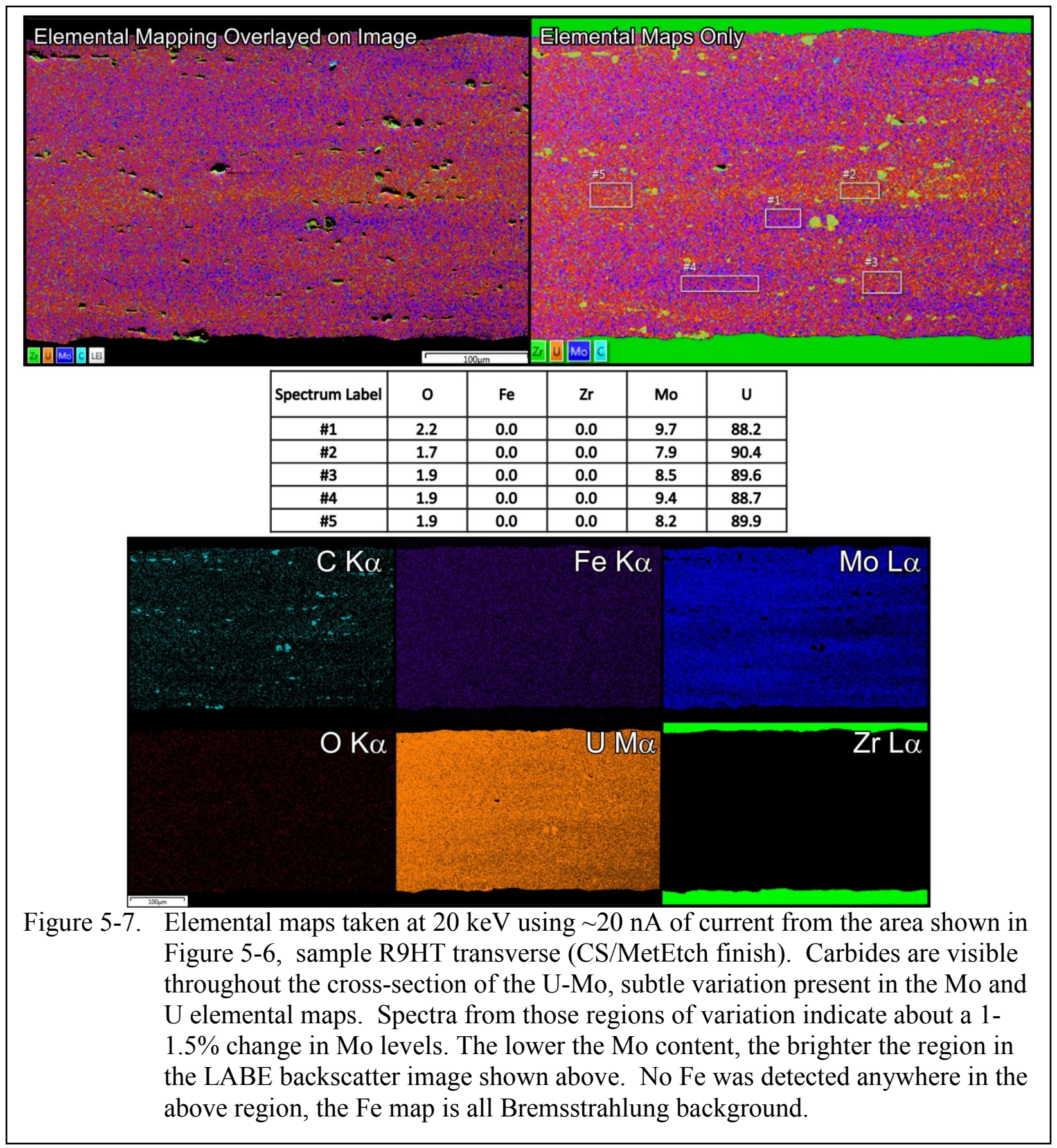




\section{Zirconium/U-10Mo Interaction Layer}

This foil condition exhibits a very similar diffusion zone as compared to the R9HW archive. The diffusion zone is not a continuous layer as observed in the LANL specimens, but fluctuates in an almost periodic manner in some locations, where in others it is either almost absent, or is missing some of the interaction layers observed in both of LANL archive R1X4 and R9HW. Various examples of the diffusion zone are provided in Figures 5-8 through 5-11, illustrating the variation that is present on both sides of the foil, in both the transverse and longitudinal orientations. There are two main features that stand out in this sample. The first is represented by the dashed lines that are visible in each of Figures 5-8 through 5-11, which represents a transition between the zirconium with low levels of uranium and the pure zirconium. This transition is simply represented by the change in contrast, which appears to be due to a response to colloidal silica polishing suspension. This L1 layer doesn't have the same appearance in the SEM as the pure zirconium. It was noted in this sample that the L1 layer is wider than seen in the two archive foils, LANL R1X4 and Y-12 R9HW. The significance is not yet known, but may be related to further ingress of the uranium at levels that aren't detectable with EDS, and may require further examination using a WDS-equipped system.

The second feature involves Fe. Whereas the previous two conditions LANL R1X4 and Y12 R9HW only yielded hints of Fe segregation in the diffusion zone, in this condition it was identified with certainty as a discrete phase that precipitated between the L2 layer, which is most likely $\delta-\mathrm{UZr}_{2}$, and the $\mathrm{L} 3$ layer, where the $\mathrm{Mo}_{2} \mathrm{Zr}$ forms as the U-Mo decomposes. The elemental maps shown in Figure 5-12, which were taken from the same region as Figure 5-11, show clear indications of $\mathrm{Fe}$ as a discrete phase. The elemental maps were taken at $5 \mathrm{keV}$, so the compositions are suspect, but the quantitative analysis indicated that approximately 22 at $\% \mathrm{Fe}, 8$ at $\% \mathrm{Mo}$, and the remainder $\mathrm{Zr}$. The ratio of $\mathrm{Fe}$ to $\mathrm{Zr}$ is close to that of $\mathrm{Zr}_{3} \mathrm{Fe}$, but further work is needed to confirm this.

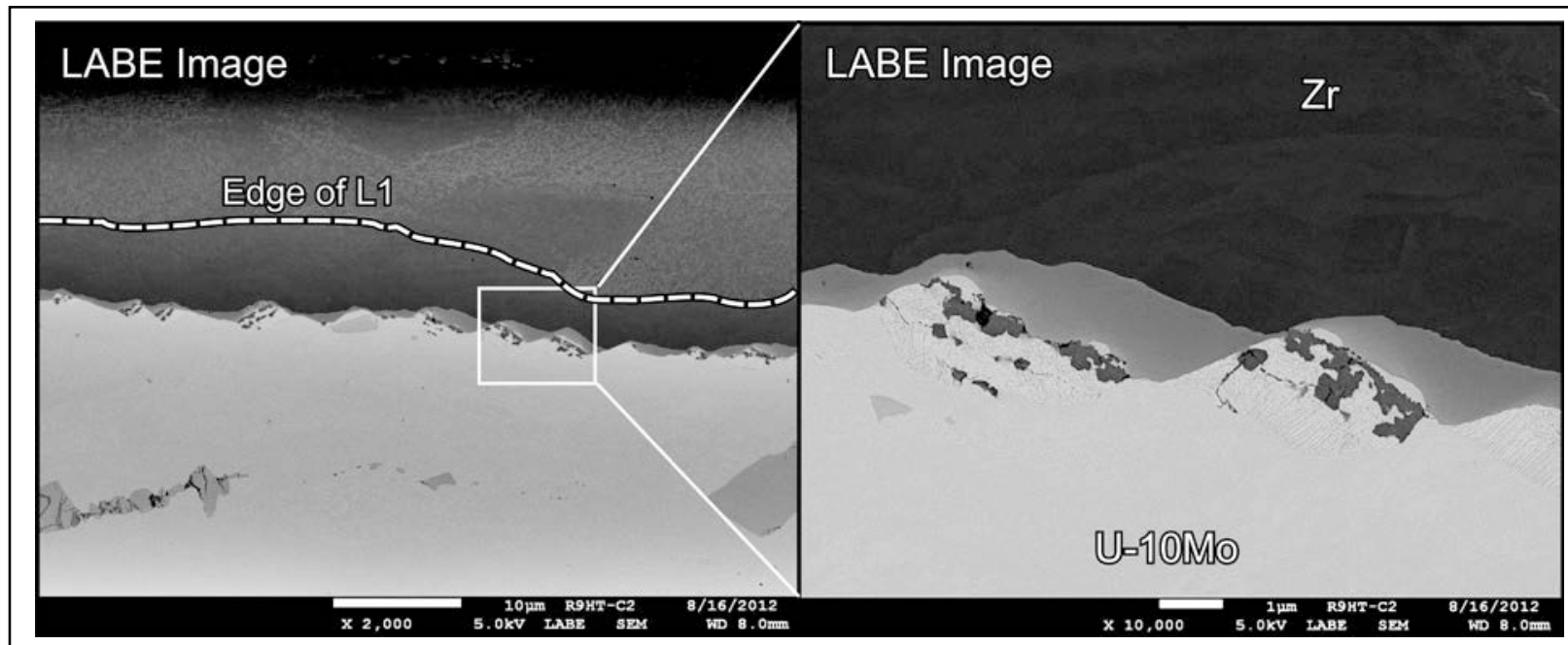

Figure 5-8. FEG-SEM of the interface in the longitudinal sample of R9HT (CS/MetEtch). The diffusion zone forms a series of interaction layers, but not all regions contain the same degree of interaction between the zirconium and the U-Mo foil. Discrete colonies exist on one side of the undulating zirconium/U-Mo interface, first described in the case of the R9HW archive material. The dashed line indicates the upper edge of the L1 layer as seen in the LEI and LABE images. 


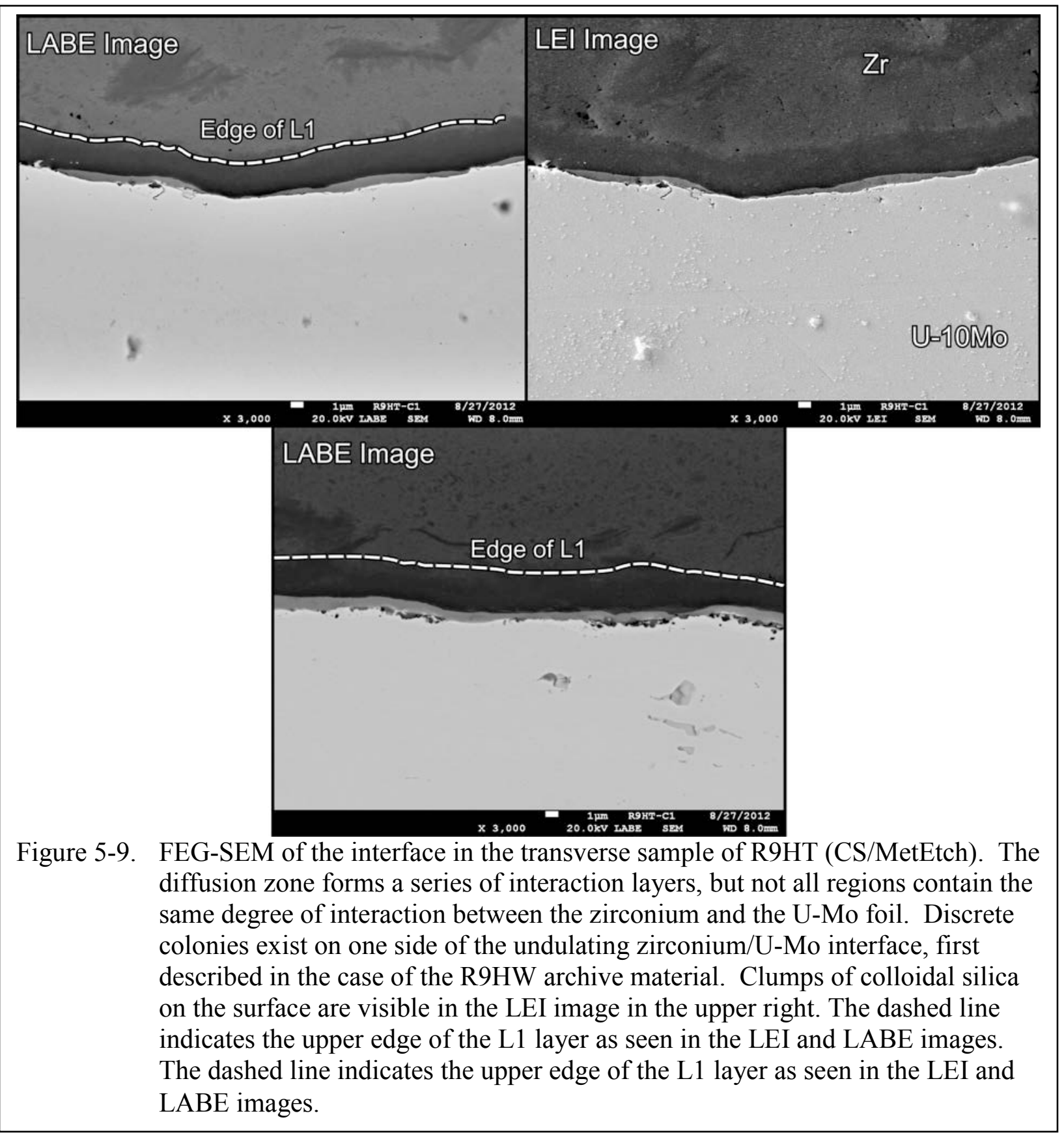




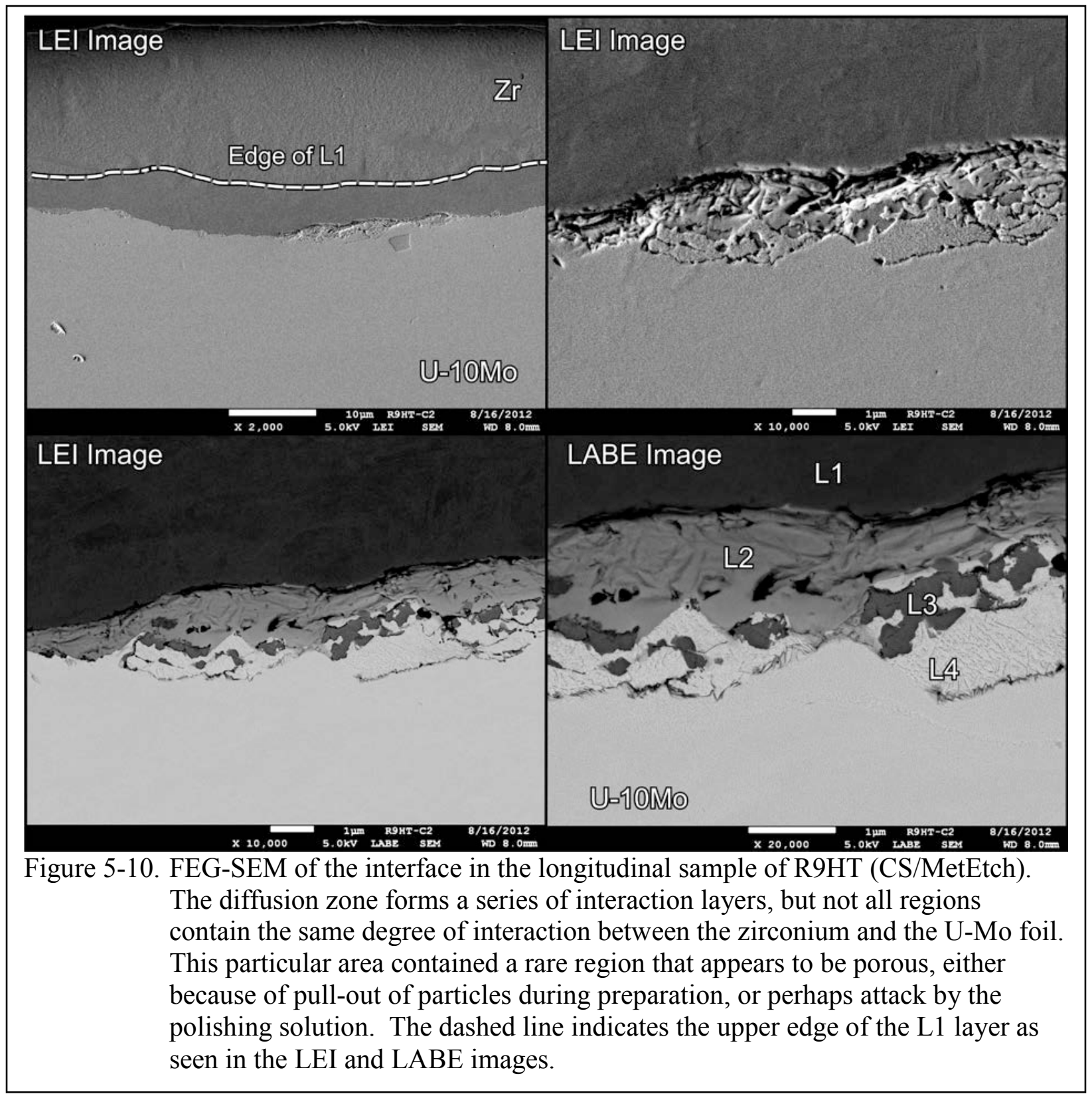




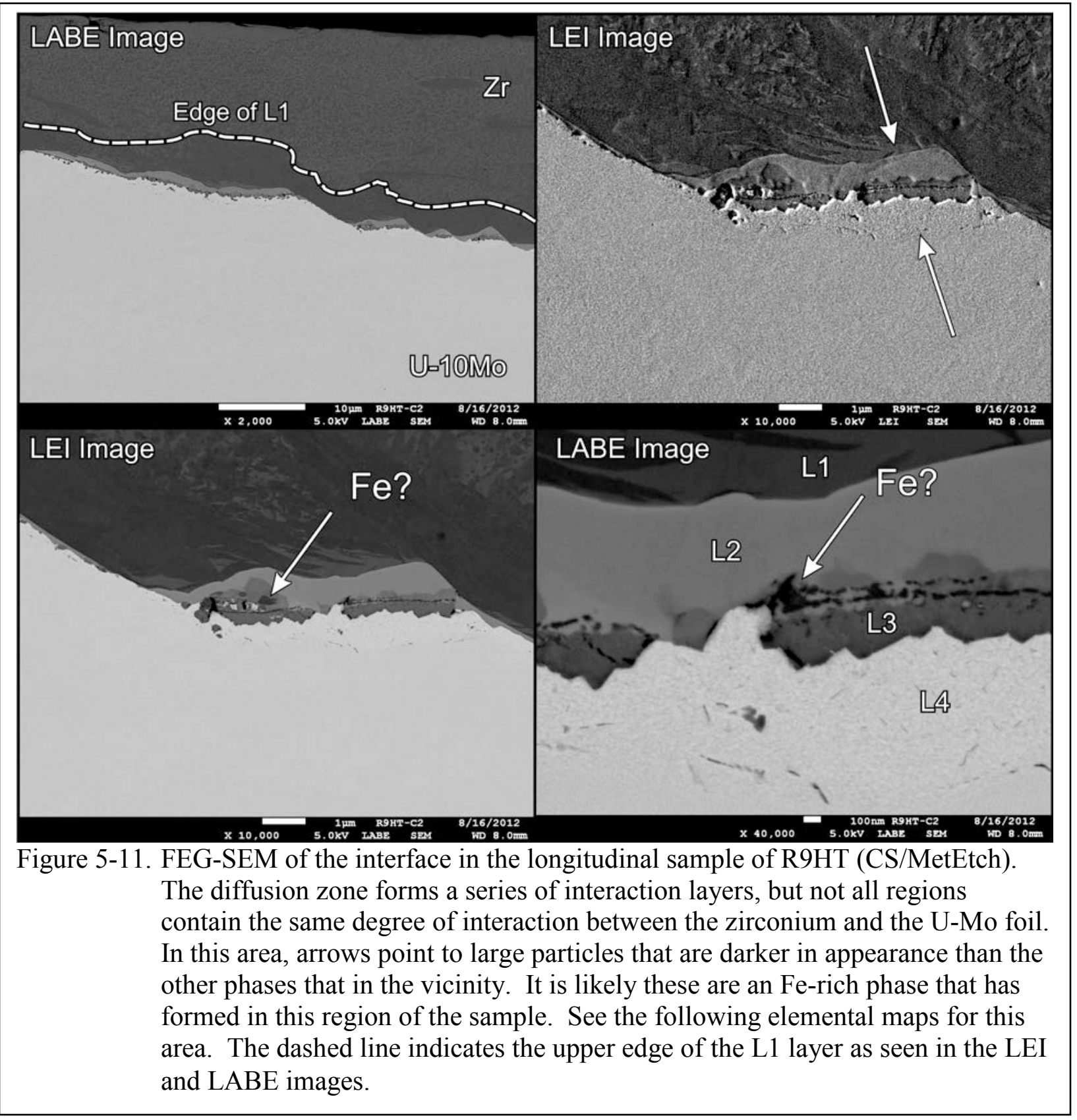




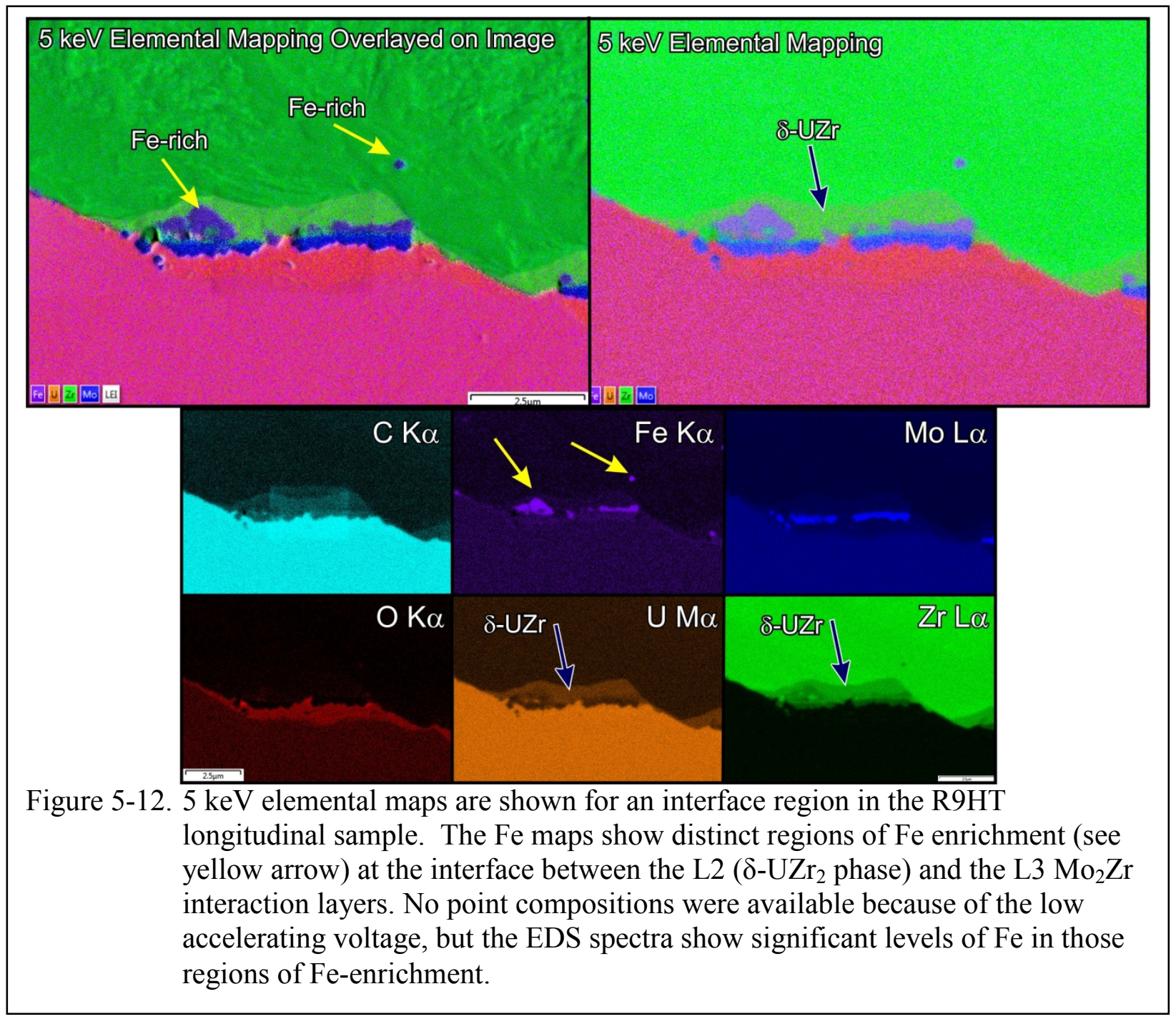




\section{Summary of Results for Y-12 Foil R9HT}

From a macrostructure perspective, this foil is very similar to the Y-12 R9HW archive material. Both conditions show a highly cold worked grain structure with very coarse, elongated grains that are interspersed with a finer, elongated grain structure. The longitudinal orientation, at least from a qualitative standpoint, appears to be more heavily deformed than the grain structure in the transverse orientation. Carbide distributions are similar between the foil sets of foils, and in each case the same fluctuations in Mo levels are detected in the U-Mo, giving rise to banding that shows up in the backscatter images and in the elemental mapping.

At smaller scales, the two sets of materials are also similar, showing a discontinuous diffusion zone with various interaction layers. In the simplest form, the diffusion zone appears in the SEM to be just a transition from the U-Mo to the a narrow zone with minor levels of uranium that taper off into the pure zirconium. Both R9HW archive and R9HT have regions where a much more complicated diffusion zone has developed, which is actually identical in most respects to the nearly continuous, complex diffusion zone that develops in the LANL archive R1X4. In this case there are 4 distinct interaction layers, each of which are marked by certain phases and compositions (though there is a range of compositions present in each layer, phase). In this condition, Fe was found in isolated regions to have formed what could be argued is an additional interaction layer, forming what may be an $\mathrm{Zr}_{3} \mathrm{Fe}$ phase between the $\mathrm{L} 2 \delta$ - $\mathrm{UZr}_{2}$ layer and the $\mathrm{L} 3 \mathrm{Mo}_{2} \mathrm{Zr}$ layer. There are also indications that the $\mathrm{L} 1$ layer is broader in this R9HT foil compared to what was observed in the LANL R1X4 and the Y-12 R9HW foils. If this turns out to be the case, then it may signal that uranium has diffused further into the zirconium when the diffusion zone is discontinuous. This bears further investigation and should be checked with an SEM equipped with a WDS to extend the detection limits. 


\section{6}

\section{CHARACTERIZATION RESULTS: LANL U-10MO}

\section{FOIL: R1X6 (63238) TRANSVERSE AND}

\section{LONGITUDINAL}

\section{Optical Metallography \& Low Magnification FEG-SEM Imaging}

The sample was cut as shown in the diagram provided in Figure 6.1. This sample had a couple of visible cracks on the edge chosen for reference, and during cutting it broke on one of the cracks. The sample selected for mounting and polishing is the middle piece between the $2^{\text {nd }}$ and $3^{\text {rd }}$ cuts. The edges of this foil exhibited sharply cut edges, with no visible burrs or major deformation from handling. Examples of the cross-sectional microstructure are provided in Figures 6-2 and 6-3, showing optical images of the foils after polishing with the HP/CS final polish. The measured width of the cross-section specimen is $\sim 350 \mu \mathrm{m}$. Both the U-Mo and zirconium grain structure are visible after the final polish. The grain structure of the transverse orientation is composed mostly a mix of equiaxed and slightly elongated grains, with a low fraction of much coarser elongated grains. The majority of the U-Mo grains are in the range of 10 to $20 \mu \mathrm{m}$, with some of the coarse grains extending to 150 to $200 \mu \mathrm{m}$. The zirconium grains are in the same size range, in some cases extending through the entire zirconium layer. The

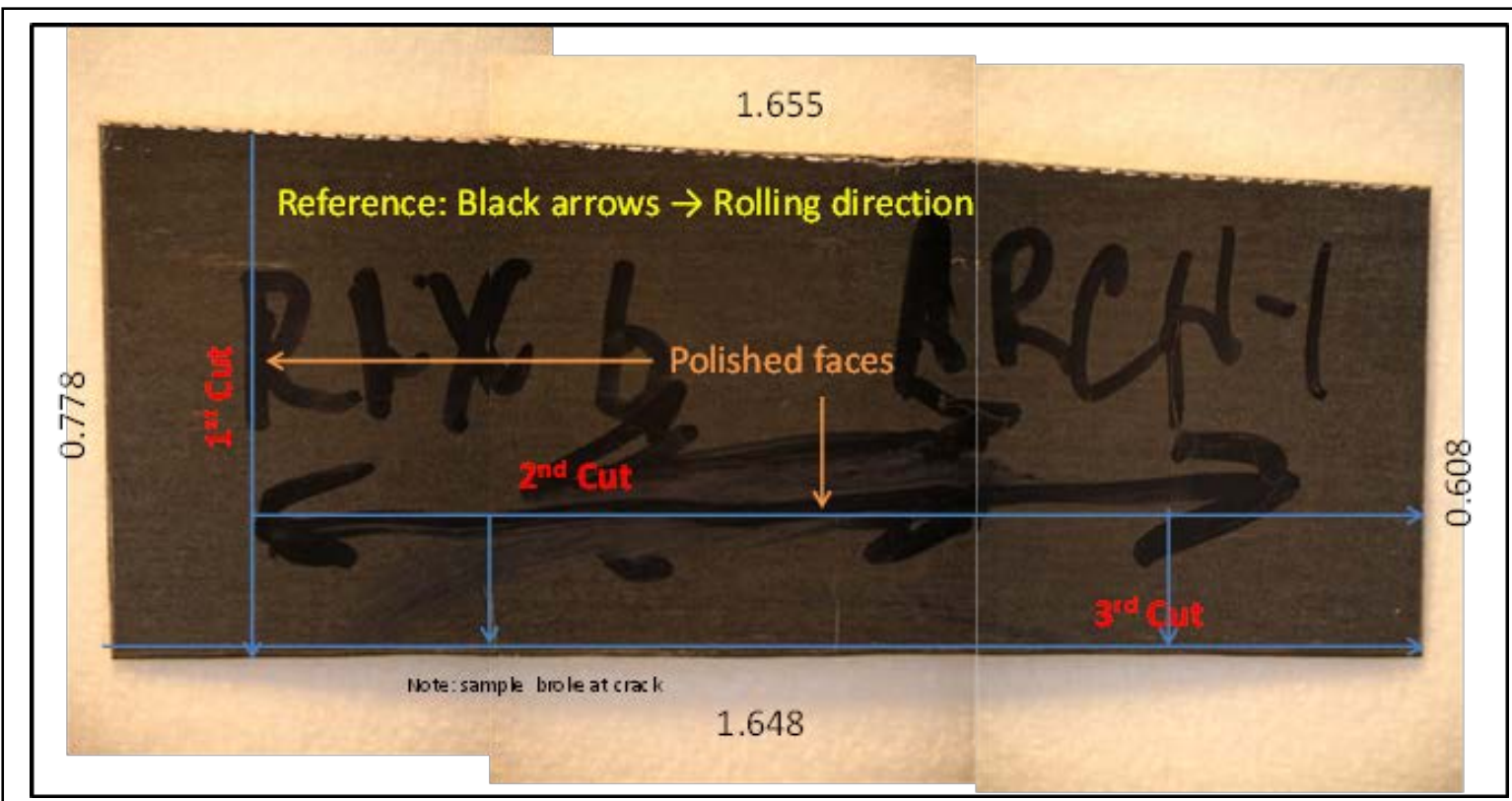

Figure 6-1. Diagram showing how the transverse and longitudinal pieces were selected and cut from the piece. 


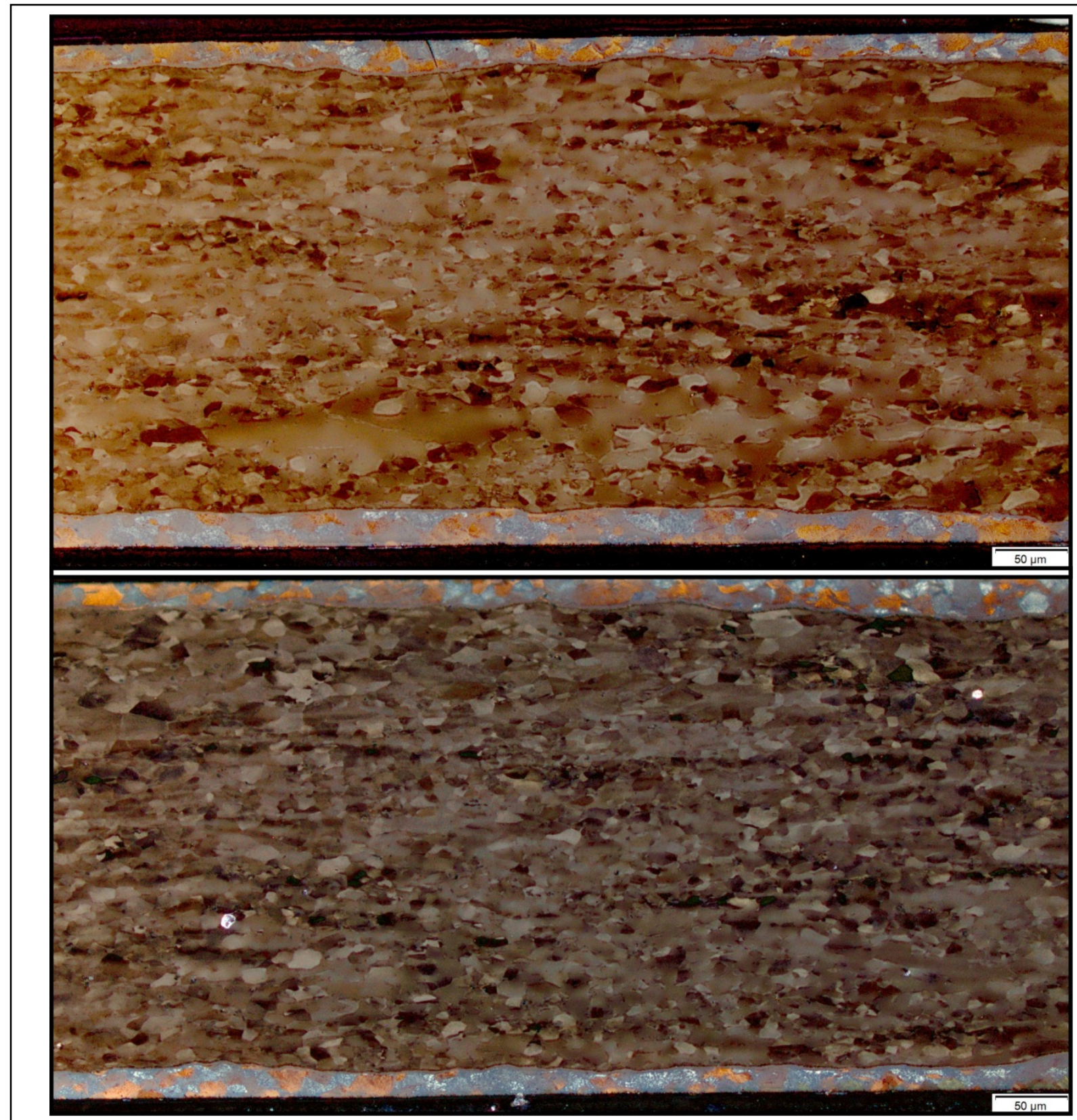

Figure 6-2. Optical micrographs taken at 200x (HP/CS final polish) of the transverse section of LANL U-Mo foil R1X6 reveal a mixture of relatively small elongated grain interspersed with a small fraction of coarse elongated grains. A mixed microstructure of coarse grains is interspersed with a much finer grain structure. The zirconium layer is highly variable on both sides of the foil. Images were taken using a polarized filter, contrast enhanced in Corel PhotoPaint.

zirconium layer is relatively flat and uniform on the surface, but the internal interfaces undulate across the width of the foils, just as in the R1X4 conditions. In isolated regions the zirconium layer reaches a minimum of $\sim 10 \mu \mathrm{m}$ of thickness, and can reach a peak of nearly $25 \mu \mathrm{m}$.

The longitudinal section shows a more laminar structure, however the grain structure is a mixture of very fine equiaxed grains in the size range of 3-10 $\mu \mathrm{m}$, with grains larger than that 


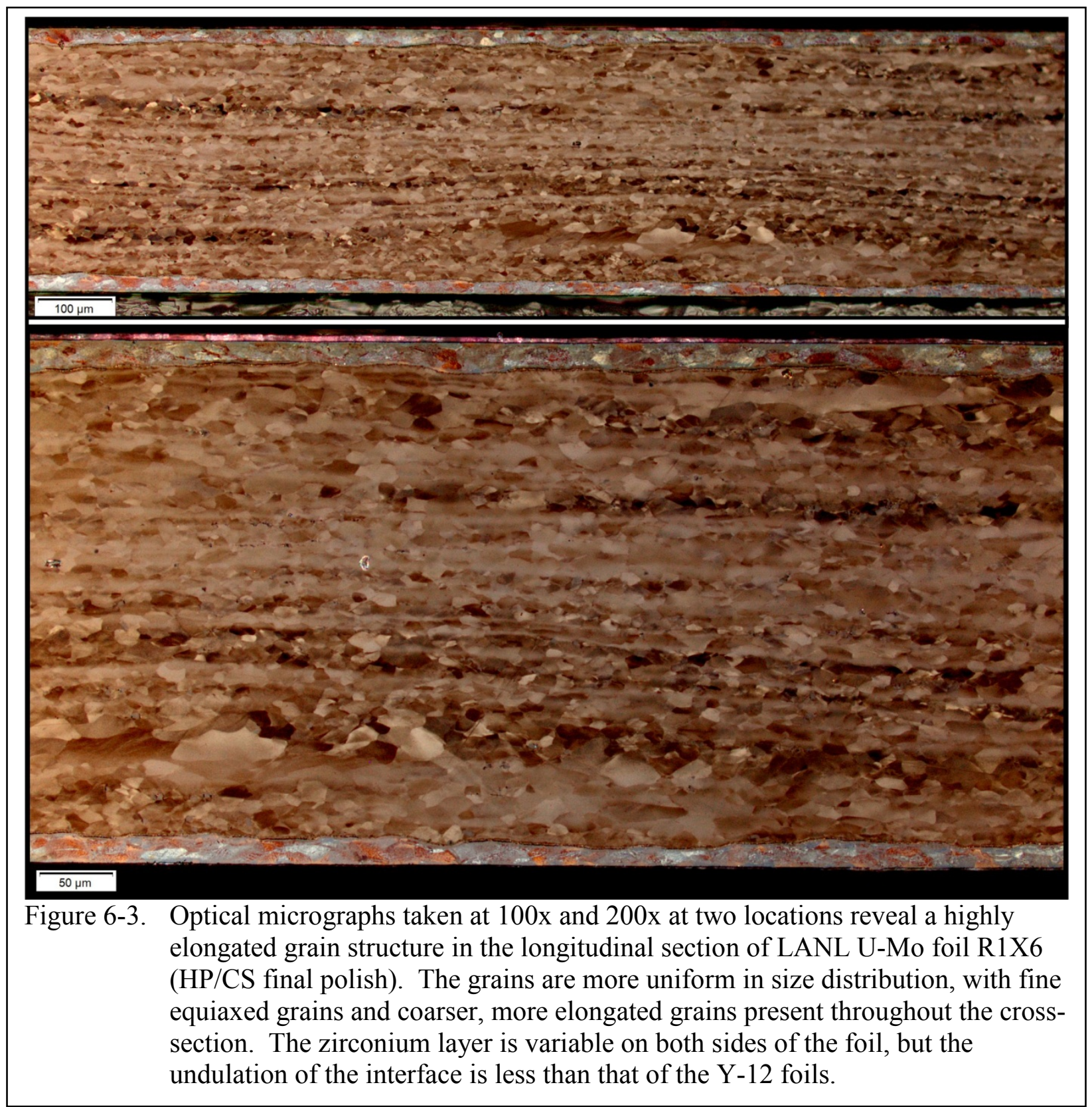

showing increasingly larger aspect ratios. A rough estimate would place the medium size grains in the range of $15-40 \mu \mathrm{m}$ and the low fraction of very coarse grains that are elongated in the rolling plane with an upper size of 100 to $150 \mu \mathrm{m}$. Flow lines are clearly visible in Figure 6-3 in both regions. The zirconium grains in the longitudinal orientation are comparable to the those observed in the transverse orientation.

The banding in the U-Mo foil is evident in the SEM images taken from the polished crosssections of the longitudinal sample (see Figures 6-4 through 6-6). The samples used for SEM were only polished on the CS final finish, time did not permit re-examination of the samples after polishing on the HP/CS final polish. As in the other foils, the bright/dark bands in the LABE images are due to fluctuations in the Mo content, with low Mo regions producing bright contrast because of the higher average atomic weight. The interesting feature in these 


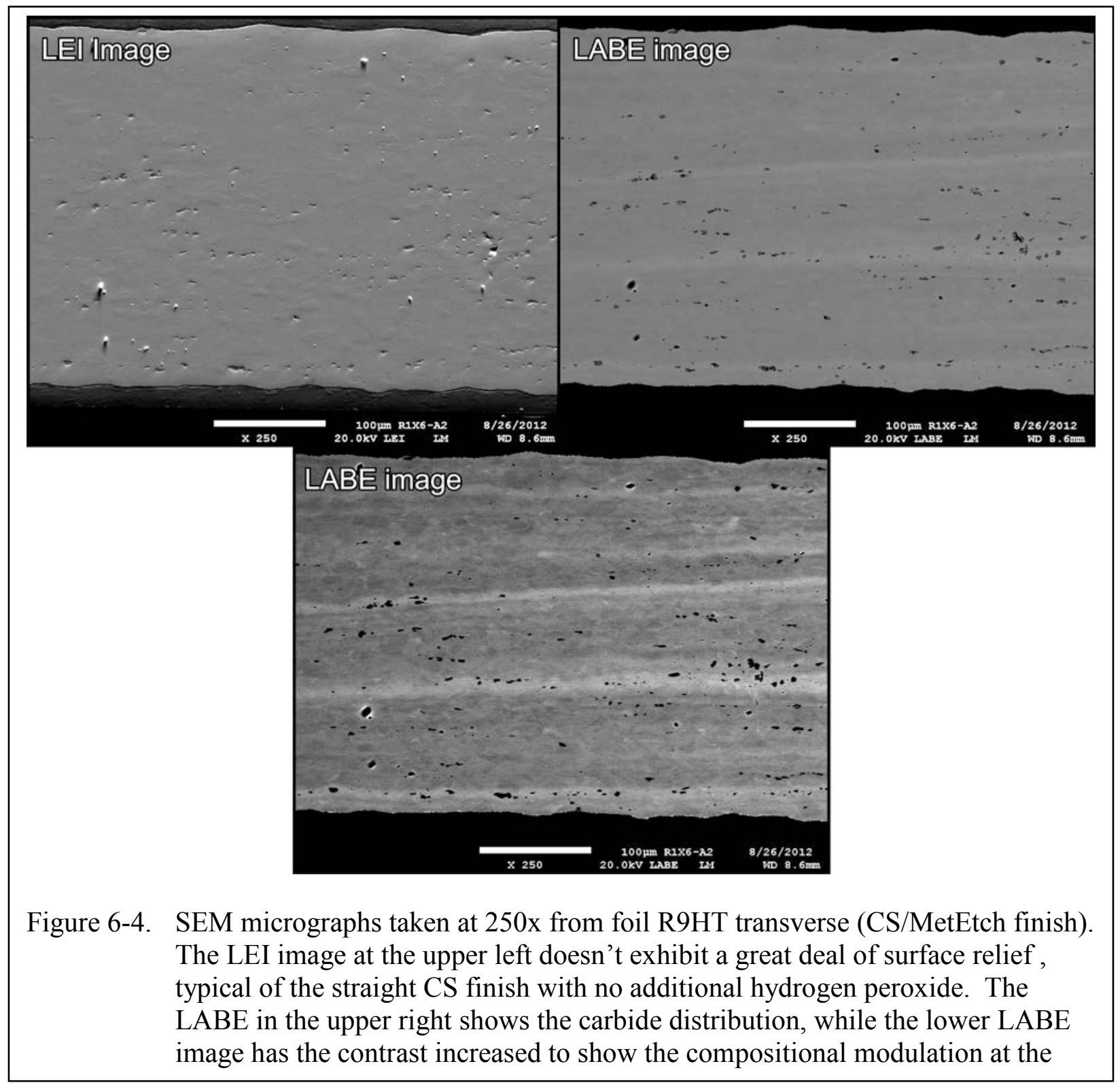

micrographs is that the carbides do not seem to be as closely associated with the low Mo regions as seen in the Y-12 foils, which is the case also for the R1X4 archive. The elemental maps in Figure 6-6 clearly show the variations in the Mo and U, but no clear relationship between the bands and carbides as observed in the Y-12 foils. The carbides in general are not clumped together in stringers as in the case of the Y-12 foils, but more randomly dispersed. One final point to make is that carbides in this foil are not as prone to be fracture as observed in the Y-12 foils. 


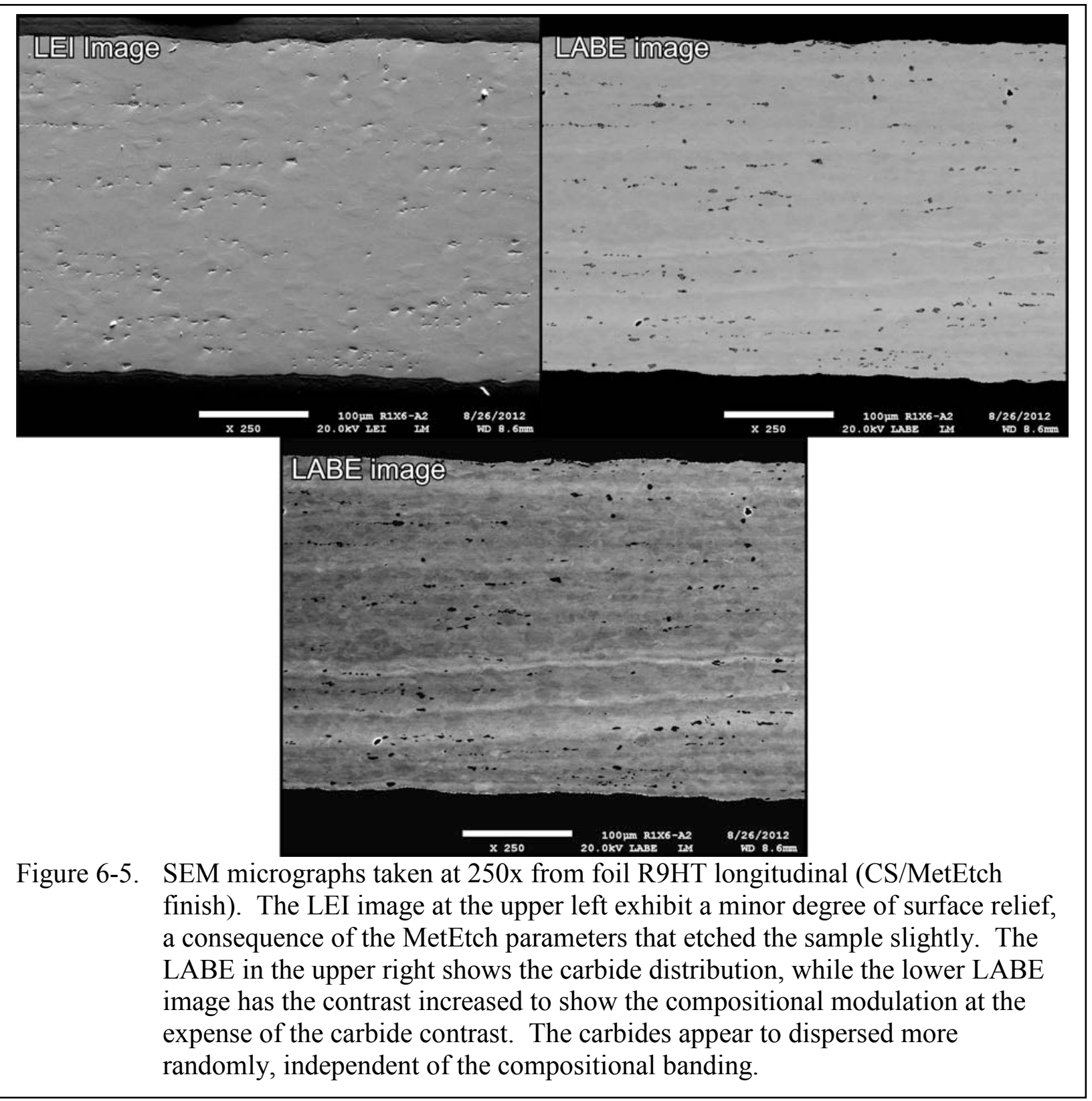




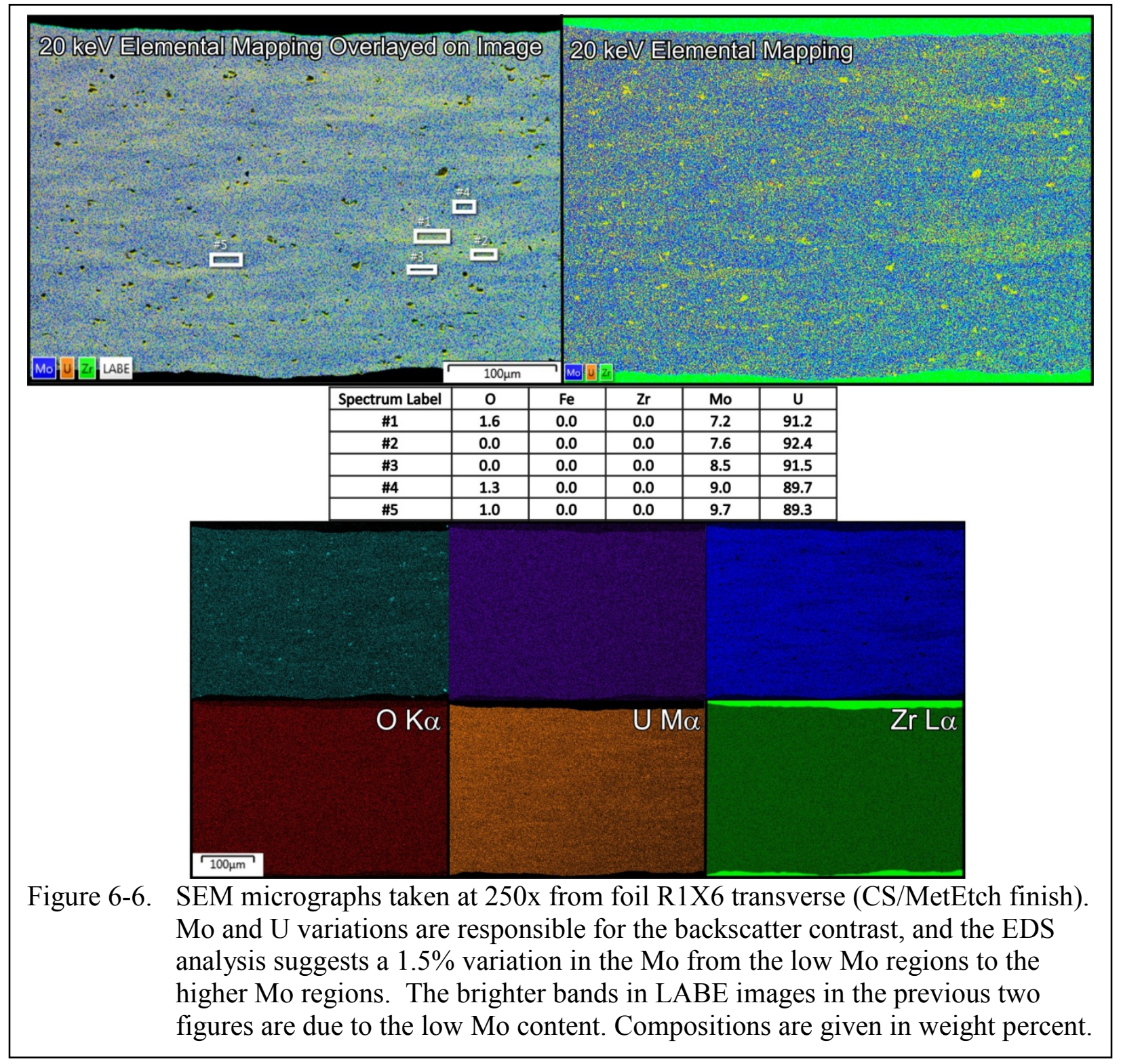




\section{Zirconium/U-10Mo Interaction Layer}

Two examples of the interfacial diffusion zone are provided in Figures 6-7 and 6-8, plus an elemental map in Figure 6-9. The most notable feature that stands out is that the L3 interaction layer where the $\mathrm{Mo}_{2} \mathrm{Zr}$ phase has formed is full of cracks and porosity. The R1X4 exhibit a lower degree of this, but in these two regions in R1X6, it is quite clear that the L3 layer is cracked. It is unlikely that the cracks are the result of sample preparation artifacts, rather, given the nature of the voids between particles, these regions likely result from a volume change between the precipitates and the surrounding matrix, not unlike void shrinkage in casting. Also, whereas the diffusion zone and various interaction layers in the R1X4 archive condition appeared to be fairly uniform and continuous over the observed cross-section of the two pieces, in this foil there are more discontinuities in the interface that are reminiscent of the Y-12 foils, just not as extensive. There is also no evidence of any iron in this regions according to the elemental maps.

\section{Summary of Results for LANL Foil R1X6}

This foil is similar on the macroscopic scale to the R1X4 archive, but there are notable differences at the microscopic scale at the reaction zone between the U-Mo and zirconium. The U-Mo grain structure contains both equiaxed and elongated grains, with the degree of elongation decreasing the finer the grain size. The zirconium layers appear to be more uniform than observed in the Y-12 foils, but there are regions where the thickness decreases to $\sim 10 \mu \mathrm{m}$. It is not clear if this implies that dynamic recrystallization is occurring, but it is worth noting. The reaction zone at the interface between the U-Mo and zirconium has discontinuities, not as extensive as observed in the Y-12 foils, but more than observed in the LANL archive foil R1X4. No iron enrichment was observed in the limited number of regions characterized. 


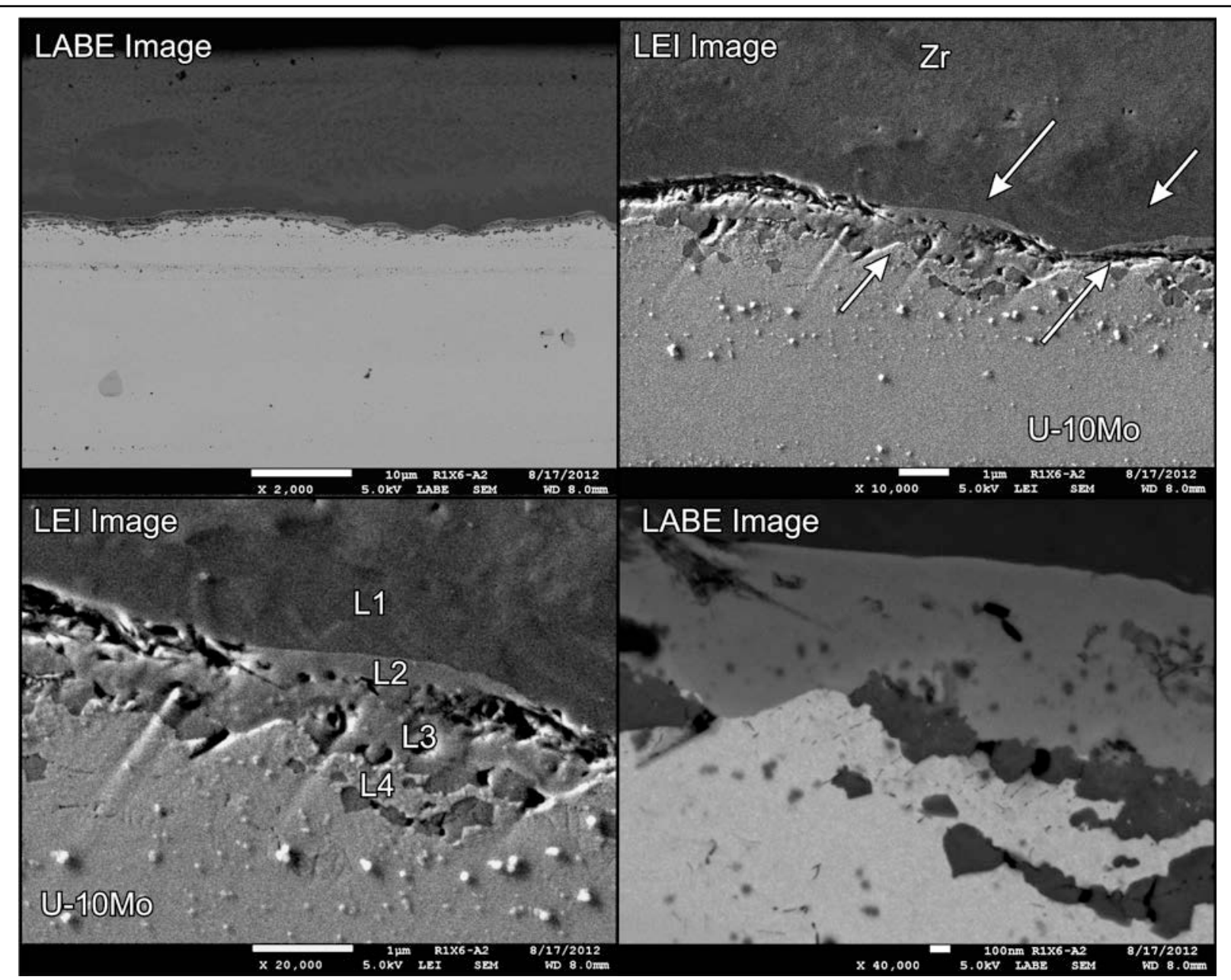

Figure 6-7. SEM micrographs taken at 250x from foil R1X6 transverse (CS/MetEtch finish). The LEI image at the upper left doesn't exhibit a great deal of surface relief, typical of the straight $\mathrm{CS}$ finish with no additional hydrogen peroxide. The LABE in the upper right shows the carbide distribution, while the lower LABE image has the contrast increased to show the compositional modulation at the expense of the carbide contrast. The bright clumps of particles on the surface in the LEI images are colloidal silica residue. 


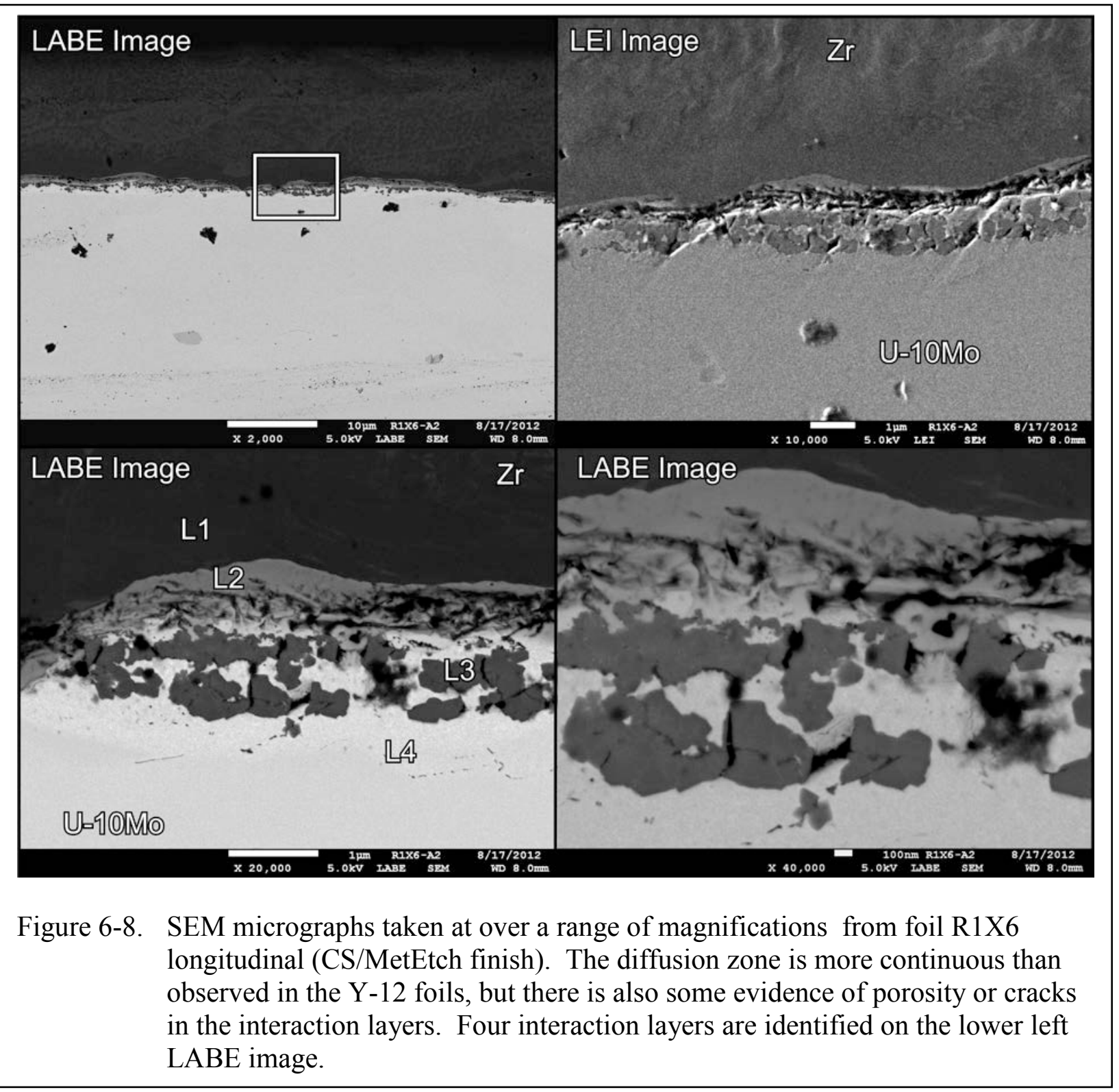




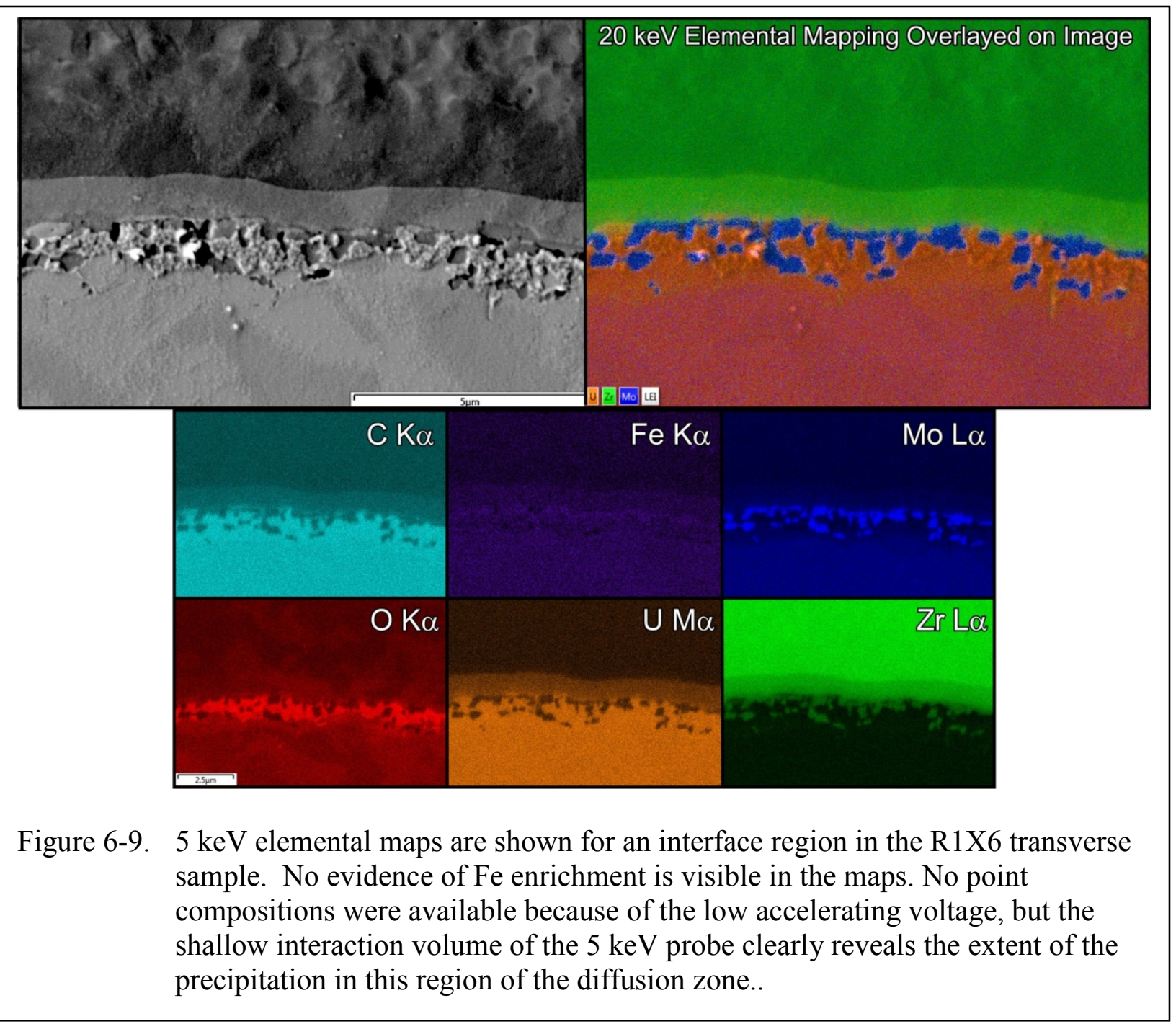




\section{SUMMARY OF RESULTS}

Two sources of U-10Mo foils, one from Y-12 and the other from LANL, have been delivered to PNNL for characterization using optical metallography and field emission gun scanning electron microscopy (FEG-SEM). A total of nine conditions were selected for preparation with the goal of characterizing the transverse and longitudinal orientations of each condition. Some of the samples were sent for irradiations, and some of the samples are archive materials (refer to Table 2-1). Table 7-1 lists the individual samples and the status of what was accomplished from a data acquisition standpoint, and a summary of results is presented in Tables 7-2 and 7-3. For the purposes of this report, we focused on providing an assessment of the one archive material from each source and one foil sent to reactor from each source material.

As described in the earlier sections, considerable time was spent evaluating sample preparation methods that achieved the goal of providing a sample that could be used for both high resolution FEG-SEM imaging for structural information, EDS analysis for chemistry, and electron backscatter analysis if possible. After some experimentation, the goal of preparing samples for high resolution imaging and chemical analysis was readily achieved using a final hydrogen peroxide/colloidal silica (HP/CS) sample preparation approach, but the high degree of cold working prevented a determination of the surface quality for EBSD since diffraction patterns could not be obtained reliably from these materials to acquire full maps. All samples were eventually prepared using the HP/CS method, but only optical metallography could be completed on all samples given the HP/CS final surface polish. For FEG-SEM characterization, samples were either examined in the CS final polish state, which also included a cleaning step in the Gatan MetEtch to remove the silica residue, or the samples were examined after receiving the improved final polish using the HP/CS treatment, which did not leave much in the way of silica residue.

\section{Archives R9HW and R1X4}

With respect to the two sources of materials, archive materials were examined and the results described in the first two sections. There are substantial macroscopic differences between these materials, most notably in that the LANL R1X4 foil doesn't exhibit the noticeable degree of cold work present in the Y-12. This is readily visible in the grain structure as the Y-12 R9HW has a very fine, highly elongated grain structure that gives the appearance of a laminar material. The degree of cold working and inhomogenous grain size distribution precluded the use of the ASTM Standard E112 as requested, so only a range of grain sizes was reported. Both archive foils have very coarse grains that can extend for 100's of microns through the plane of the foil crosssection, however, in the case of the Y-12 foils, this appearance, though present, is suppressed by virtue of the greater degree of deformation. The LANL R1X4 has a more equiaxed grain structure in both orientations compared to the $\mathrm{Y}-12 \mathrm{R} 9 \mathrm{HW}$, but it also possesses more regions with abnormally coarse grains compared to the Y-12 archive foil. This is fairly subjective since the higher degree of cold working produces a less distinct microstructure. 
Table 7-1. Progress on Characterization of Y-12 and LANL U-Mo Foils

\begin{tabular}{|c|c|c|c|c|c|c|c|c|}
\hline Source & Foil ID & $\begin{array}{c}\text { Final } \\
\text { Polish } \\
\text { for SEM }\end{array}$ & $\begin{array}{c}\text { OM } \\
\text { (HP/CS) }\end{array}$ & $\begin{array}{c}200 x \\
\text { Montage } \\
\text { (HP/CS) }\end{array}$ & $\begin{array}{c}\text { SEM SEI, } \\
\text { LEI, LABE } \\
\text { (2-40kx) }\end{array}$ & $\begin{array}{l}\text { SEM Banding, } \\
\text { Structure and } \\
\text { Carbides }\end{array}$ & $\begin{array}{c}\text { EDS } \\
500 X \\
2 \mathrm{kX}\end{array}$ & $\begin{array}{l}\text { EDS } \\
10 \mathrm{kX}\end{array}$ \\
\hline $\mathrm{Y}-12$ & $\begin{array}{c}\text { R9HT-C1 } \\
\text { (Trans) }\end{array}$ & $\mathrm{CS}^{1}$ & $200,500 x$ & Done & Done & Done & Done & Done \\
\hline $\mathrm{Y}-12$ & $\begin{array}{c}\text { R9HT-C2 } \\
\text { (Long) }\end{array}$ & CS & $200,500 x$ & Done & Done & & & Done \\
\hline $\mathrm{Y}-12$ & $\begin{array}{c}\text { R9HV-C1 } \\
\text { (Trans) }\end{array}$ & $\mathrm{HP} / \mathrm{CS}$ & $200,500 x$ & Done & Done & Done & Done & Done \\
\hline $\mathrm{Y}-12$ & $\begin{array}{c}\text { R9HV-C2 } \\
\text { (Long) }\end{array}$ & CS & $200,500 x$ & Done & Done & Done & Done & Done \\
\hline $\mathrm{Y}-12$ & $\begin{array}{c}\text { R9HW-1 } \\
\text { (Trans) }\end{array}$ & CS & $200,500 x$ & Done & & & & \\
\hline $\mathrm{Y}-12$ & $\begin{array}{c}\text { R9HW-2 } \\
\text { (Long) }\end{array}$ & CS & $200,500 x$ & Done & Done & Done & Done & Done \\
\hline LANL & $\begin{array}{l}\text { PVME-JK7- } \\
\text { A1 (Trans) }\end{array}$ & CS & $200,500 x$ & Done & Done & & & Done \\
\hline LANL & $\begin{array}{l}\text { PVME-JK7- } \\
\text { A2 (Long) }\end{array}$ & CS & $200,500 x$ & Done & Done & & & Done \\
\hline LANL & $\begin{array}{l}\text { PVNF-1 } \\
\text { (Trans) }\end{array}$ & $\mathrm{HP} / \mathrm{CS}$ & $200,500 x$ & Done & Done & Done & Done & Done \\
\hline LANL & $\begin{array}{c}\text { PVNF-2 } \\
\text { (Long) }\end{array}$ & $\mathrm{HP} / \mathrm{CS}$ & $200,500 x$ & Done & & & & \\
\hline LANL & $\begin{array}{l}\text { PVMF-12- } \\
\text { B1 (Trans) }\end{array}$ & CS & $200,500 x$ & Done & Done & Done & Done & Done \\
\hline LANL & $\begin{array}{l}\text { PVMF-12- } \\
\text { B2 (Long) }\end{array}$ & CS & $200,500 x$ & Done & Done & & & Done \\
\hline LANL & $\begin{array}{c}\text { R1X9-A1 } \\
\text { (Trans) }\end{array}$ & $\mathrm{HP} / \mathrm{CS}$ & $200,500 x$ & Done & & & & \\
\hline LANL & $\begin{array}{c}\text { R1X9-A2 } \\
\text { (Long) }\end{array}$ & $\mathrm{HP} / \mathrm{CS}$ & $200,500 x$ & Done & Done & Done & Done & Done \\
\hline LANL & $\begin{array}{c}\text { R1X6-A1 } \\
\text { (Trans) }\end{array}$ & CS & $200,500 x$ & Done & Done & Done & Done & Done \\
\hline LANL & $\begin{array}{c}\text { R1X6-A2 } \\
\text { (Long) }\end{array}$ & CS & $200,500 x$ & Done & Done & Done & Done & Done \\
\hline LANL & $\begin{array}{l}\text { R1X4-1 } \\
\text { (Trans) } \\
\end{array}$ & $\mathrm{HP} / \mathrm{CS}$ & $200,500 x$ & Done & Done & Done & Done & Done \\
\hline LANL & $\begin{array}{l}\text { R1X4-2 } \\
\text { (Long) }\end{array}$ & $\mathrm{HP} / \mathrm{CS}$ & $200,500 x$ & Done & Done & Done & Done & Done \\
\hline
\end{tabular}

${ }^{1}$ CS means that the SEM work was completed on samples given a final polish of colloidal silica only. All samples were prepared for optical metallography using the HP/CS process. 
Table 7-2. Summary of Results Obtained from Analyzed Conditions

\begin{tabular}{|c|c|c|c|c|c|c|c|c|}
\hline Foil ID & $\begin{array}{l}\text { U-Mo } \\
\text { Grain Size } \\
\text { Range }\end{array}$ & $\begin{array}{l}\text { Maximum } \\
\text { Aspect } \\
\text { Ratio }\end{array}$ & $\begin{array}{l}\text { Zr Grain } \\
\text { Size Range }\end{array}$ & $\begin{array}{c}\mathrm{Zr} \\
\text { Thickness }\end{array}$ & $\begin{array}{l}\text { Zirconium } \\
\text { Min } \\
\text { Thickness }\end{array}$ & $\begin{array}{l}\text { Zirconium } \\
\text { Max } \\
\text { Thickness }\end{array}$ & $\begin{array}{l}\text { Carbide } \\
\text { Mean } \\
\text { Size }\end{array}$ & General Comments \\
\hline \multicolumn{9}{|c|}{ Y-12 Source Material - R9HW archive \& R9HT (sent to reactor) } \\
\hline $\begin{array}{l}\text { R9HT-1 } \\
\text { (Trans) }\end{array}$ & $\begin{array}{l}5 \text { to } 300 \\
\mu \mathrm{m}\end{array}$ & 15 & 5 to $30 \mu \mathrm{m}$ & 25 & 21 & 37 & 4.9 & $\begin{array}{l}\text { U-Mo grain structure has a few abnormally coarse grains, } \\
\text { mostly a fine elongated grain structure, discontinuous } \\
\text { diffusion layer }\end{array}$ \\
\hline $\begin{array}{l}\text { R9HT-2 } \\
\text { (Long) }\end{array}$ & $\begin{array}{l}5 \text { to } 500 \\
\mu \mathrm{m}\end{array}$ & 30 & 5 to $30 \mu \mathrm{m}$ & 24 & 15 & 34 & 4.2 & $\begin{array}{l}\text { More laminar grain structure, much different than transverse } \\
\text { microstructure, discontinuous diffusion zone }\end{array}$ \\
\hline $\begin{array}{l}\text { R9HW-1 } \\
\text { (Trans) }\end{array}$ & $\begin{array}{l}5 \text { to } 100 \\
\mu \mathrm{m}\end{array}$ & 8 & 5 to $50 \mu \mathrm{m}$ & 22 & 13 & 28 & & $\begin{array}{l}\text { U-Mo grain structure has a few abnormally coarse grains, } \\
\text { mostly a fine elongated grain structure, discontinuous } \\
\text { diffusion layer }\end{array}$ \\
\hline $\begin{array}{l}\text { R9HW-2 } \\
\text { (Long) }\end{array}$ & $\begin{array}{l}5 \text { to } 300 \\
\mu \mathrm{m}\end{array}$ & 30 & 5 to $50 \mu \mathrm{m}$ & 24 & 15 & 33 & 4.3 & $\begin{array}{l}\text { More laminar grain structure, much different than transverse } \\
\text { microstructure, discontinuous diffusion zone }\end{array}$ \\
\hline \multicolumn{9}{|c|}{ LANL Source Material - R1X4 archive \& R1X6 (sent to reactor) } \\
\hline $\begin{array}{l}\text { R1X6-1 } \\
\text { (Trans) }\end{array}$ & $\begin{array}{l}10 \text { to } 250 \\
\mu \mathrm{m}\end{array}$ & 15 & 15 to $100 \mu \mathrm{m}$ & 25 & 20 & 37 & & $\begin{array}{l}\text { Fairly equiaxed fine grain structure, some coarse grains } \\
\text { present . Diffusion layer is discontinuous, more like Y-12 } \\
\text { than the LANL archive R1X4 }\end{array}$ \\
\hline $\begin{array}{c}\text { R1X6-2 } \\
\text { (Long) }\end{array}$ & $\begin{array}{l}3 \text { to } 150 \\
\mu \mathrm{m}\end{array}$ & 15 & 15 to $100 \mu \mathrm{m}$ & 16 & 7 & 23 & 4.2 & $\begin{array}{l}\text { Much more laminar structure than in the transverse } \\
\text { direction. Diffusion layer is discontinuous, more like Y-12 } \\
\text { than the LANL archive R1X4 }\end{array}$ \\
\hline $\begin{array}{l}\text { R1X4-1 } \\
\text { (Trans) }\end{array}$ & $\begin{array}{l}5 \text { to } 300 \\
\mu \mathrm{m}\end{array}$ & 15 & 15 to $100 \mu \mathrm{m}$ & NM & 6.5 est & 30 est & 5.7 & $\begin{array}{l}\text { U-Mo grain structure is moderately cold worked, abnormally } \\
\text { coarse grains mixed with equiaxed and elongated grains of } \\
\text { smaller sizes, continuous diffusion layer }\end{array}$ \\
\hline $\begin{array}{c}\text { R1X4-2 } \\
\text { (Long) }\end{array}$ & $\begin{array}{l}5 \text { to } 300 \\
\mu \mathrm{m}\end{array}$ & 15 & 15 to $100 \mu \mathrm{m}$ & NM & 6.5 est & 30 est & 2.5 & $\begin{array}{l}\text { U-Mo grain structure is moderately cold worked, abnormally } \\
\text { coarse grains mixed with equiaxed and elongated grains of } \\
\text { smaller sizes, continuous diffusion layer }\end{array}$ \\
\hline
\end{tabular}


Table 7-3. Summary of Zr Layer Thickness Measurements and Carbide Characteristics from Analyzed Conditions

\begin{tabular}{|c|c|c|c|c|c|c|c|c|c|c|}
\hline & \multicolumn{4}{|c|}{ Zr Layer Thickness Variation } & \multicolumn{6}{|c|}{ Carbide Distributions } \\
\hline Foil ID & Mean Size & STD & Min Size & Max Size & Mean Size & STD & $\begin{array}{c}\text { Area } \\
\text { Fraction }\end{array}$ & Min Size & Max Size & $\begin{array}{l}\text { Colloidal Silica } \\
\text { Contamination }\end{array}$ \\
\hline \multicolumn{11}{|c|}{ Y-12 Source Material - R9HW archive \& R9HT (sent to reactor) } \\
\hline $\begin{array}{l}\text { R9HT-C1 } \\
\text { (Trans) }\end{array}$ & 25 & 4 & 21 & 37 & 4.9 & 10.8 & 1.6 & 0.14 & 95.7 & \\
\hline $\begin{array}{c}\text { R9HT-C2 } \\
\text { (Long) }\end{array}$ & 24 & 5 & 15 & 34 & 4.2 & 7.4 & 1.6 & 0.03 & 41.4 & \\
\hline $\begin{array}{l}\text { R9HW-1 } \\
\text { (Trans) }\end{array}$ & 22 & 3 & 13 & 28 & $N M$ & $N M$ & $N M$ & $N M$ & $N M$ & \\
\hline $\begin{array}{l}\text { R9HW-2 } \\
\text { (Long) }\end{array}$ & 24 & 6 & 15 & 33 & 4.3 & 11.7 & 2.1 & 0.14 & 161 & \\
\hline \multicolumn{11}{|c|}{ LANL Source Material - R1X4 archive \& R1X6 (sent to reactor) } \\
\hline $\begin{array}{c}\text { R1X6-A1 } \\
\text { (Trans) }\end{array}$ & 25 & 4 & 20 & 37 & $N M$ & $N M$ & $N M$ & $N M$ & $N M$ & \\
\hline $\begin{array}{c}\text { R1X6-A2 } \\
\text { (Long) }\end{array}$ & 16 & 4 & 7 & 23 & 4.2 & 5.9 & 1.4 & 0.14 & 44.4 & \\
\hline $\begin{array}{l}\text { R1X4-1 } \\
\text { (Trans) }\end{array}$ & $N M$ & $N M$ & $N M$ & $N M$ & 5.7 & 10.8 & 2.1 & 0.14 & 68.9 & \\
\hline $\begin{array}{c}\text { R1X4-2 } \\
\text { (Long) }\end{array}$ & $N M$ & $N M$ & $N M$ & $N M$ & 2.5 & 7.8 & 1 & 0.56 & 64.9 & Yes \\
\hline
\end{tabular}

$N M-$ Not measured at the time of report completion using the same technique 
Another difference between the two source archive materials is that the zirconium layer in the LANL foil R1X4 exhibits a coarser grained structure on each side of the foil, with the diameter of the zirconium grains often exceeding the width of the layer itself. The undulation of the zirconium/U-Mo interface was not as great in the LANL archive material in the sense of the periodicity of the undulation, however, there was greater variability in the layer thickness, ranging from $\sim 6 \mu \mathrm{m}$ to upwards of $\sim 35 \mu \mathrm{m}$. The grain structure in the R9HW archive foil usually contained multiple grains through the cross-section of the zirconium layer, and they were clearly more elongated from cold rolling.

The carbide distributions in the LANL archive foil tended to be randomly distributed as isolated particles, whereas in the Y-12 R9HW foil the carbides were not only aligned in stringers, but more often than not the stringers were associated with compositional bands present due to lower Mo in some regions. Both types of source material exhibit the Mo segregation and subsequent chemical banding that shows in both optical and backscatter SEM imaging, but only in the Y-12 foils was it the relationship with the carbides stringers observed.

Table 7-3 lists some preliminary measurements on the carbide sizes and area fraction obtained though automated measurements using the Image J program. The carbide distributions for the two archive materials from each source have similar average sizes of 4- $6 \mu \mathrm{m}$, but carbides up to $160 \mu \mathrm{m}$ were found in the case of the Y-12 R9HW material. Both archive materials were found to have similar area fractions of $\sim 2 \%$ carbides, and the standard deviation of the size distribution was comparable between the two. There wasn't time to check the carbide distribution as a function of position with the foil with respect to the zirconium layers, nor the edges of the foil, but this might be worth pursuing in the future, as well as develop a quantitative method to describe the carbide distribution in stringers versus a more randomized distribution.

The other major difference that exists at the microscopic scale is the reaction zone that forms between the U-Mo matrix and the zirconium layers. In the LANL archive the reaction zone was generally more uniform in both width, continuity, and had the same interaction layers present throughout much of the investigated region, whereas in the Y-12 R9HW material, the reaction was not only discontinuous, but highly variable in the decomposition and precipitation reactions that occurred. Four layers were distinctly noted in the LANL R1X4, each of which was related to some particular feature or average compositional measurement, and these layers were present over much of the reaction zones. In the Y-12 archive, this was not the case, some areas only possessed a limited reaction zone, while colonies formed on one side of the interface undulations. In these colonies usually all 4 of the distinct layers could be identified to one degree or another. Some of the precipitation reactions that occurred as Mo was removed from the U-Mo matrix and formed $\mathrm{Mo}_{2} \mathrm{Zr}$ led to the formation of a highly orientated phase, similar to aligned platelets or fingers of precipitation growing in a particular direction such as one might observe in a material undergoing a cellular-type decomposition. It was also observed that LANL foil R1X4 exhibited evidence of fine-scale precipitation inside the L2 layer, which shows up as fine, spherical particles that are darker than the surrounding matrix. Further confirmation is needed, but this appears to be real since there was no evidence of an etching artifact due to the hydrogen peroxide when the surface is examined with the high resolution In-Lens secondary detector. The identity of these particles may be $\alpha \mathrm{Zr}$ based on their dark contrast and vicinity to the pure $\mathrm{Zr}$, but TEM is likely need to ascertain the phase of the particles. 


\section{Foils sent to Reactor: R9HT and R1X6}

Two foils, one foil from each of the two source materials, that had been polished with either the CS/MetEtch or the HP/CS final surface finish were fully characterized by optical and scanning electron microscopy. The Y-12 foil R9HT was similar in most respects to the archive foil R9HW, particularly in regard to the grain structure of the U-Mo foil and the zirconium layers on either side of the U-Mo foil. One significant observation that distinguishes foil R9HT involves Fe. While there was occasional minor indications of $\mathrm{Fe}$ in the diffusion layer of the archive R9HW and even the other foils from LANL, and even the occasional particle, clear evidence of relatively large Fe-rich discrete particles could be observed in the backscatter images and elemental maps of Y-12 R9HT. Given the size of these particles, it is possible that this could be present in the archive material, but is simply not present at all locations and was missed.

The LANL foil R1X6 was unusual in that while macroscopically it was similar to the archive $\mathrm{R} 1 \mathrm{X} 4$, it differed considerably in the diffusion interface. The reaction zone between the zirconium foil and the U-Mo looked more like the Y-12 foils than the R1X4 in that it was no longer continuous across the visible cross-section, but had small pockets of reaction layers that formed all four of the interaction layers seen in the R1X4 material. Outside these pockets the interaction layers were more simple, with just 1 to 2 layers of zirconium containing uranium at various levels. This raises the issue of whether this exists also in the R1X4 material and was missed due to sampling, or if processing conditions varied substantially between the R1X4 and R1X6 foils.

Both R9HT and R1X6 exhibited the same degree of Mo banding as observed in the archive materials, and like the R9HW archive foil, the carbides in Y-12 R9HT were often associated with the low-Mo levels bands as stringers. The carbides in the R1X6 foil, by contrast, were distributed more randomly as discrete particles or clusters of particles, but not as aligned stringers. 


\section{8}

\section{RECOMMENDATIONS FOR FUTURE WORK}

Beyond this effort, there are issues that beg further investigation, some of which should be addressed using transmission electron microscopy.

1. Sample preparation has reached a useful, consistent stage, but some fine tuning is needed to be able to optimize the sample preparation with respect to time and reduction of any potential artifacts such as preferential etching and contamination on the surface.

2. Some of the LANL materials might be suitable for EBSD, but this wasn't pursued due to the lack of time between the realization that the HP-CS was potential yielding EBSDquality surface finishes versus obtaining a consistent comparison across the right set of samples.

3. Might pursue some stress relieving treatments to relax the dislocation structures in those Y-12 foils, and LANL foils also if necessary, to try and improve the EBSD patterns to the point we can quantify the microstructure and texture.

4. The fine-scale precipitation that appears only in the LANL archive foil R1X4 needs to be investigated using TEM, particularly since it is not present in the LANL foil R1X6, which may have seen a different processing history.

5. The grain size wasn't measured in these materials due to the highly cold worked appearance in many of the foils, particularly the Y-12 foils. Grain size might be evaluated by using a different etching technique to reveal the grain structure more clearly, but it is unlikely given the bimodal distribution and degree of cold work that ASTM grain sizes will apply. While the HP/CS does a great job, it also provides a lot of contrast highlighting the strain contrast within the grains that obscures the actual boundaries in many cases. A chemical etch or electrochemical etch might reveal just the grain boundaries, making it easier to measure the grain size and sub-grain size variation throughout the various materials.

6. As indicated earlier, a more thorough check is needed for the Fe segregation in the Y-12 archive foil R9HW since the foils appear to be very similar in all other aspects. 


\section{9}

\section{APPENDIX}

Data extracted from AFIP-7 Status Report, August 20, 2012.

\subsection{PVME-A1 Transverse}

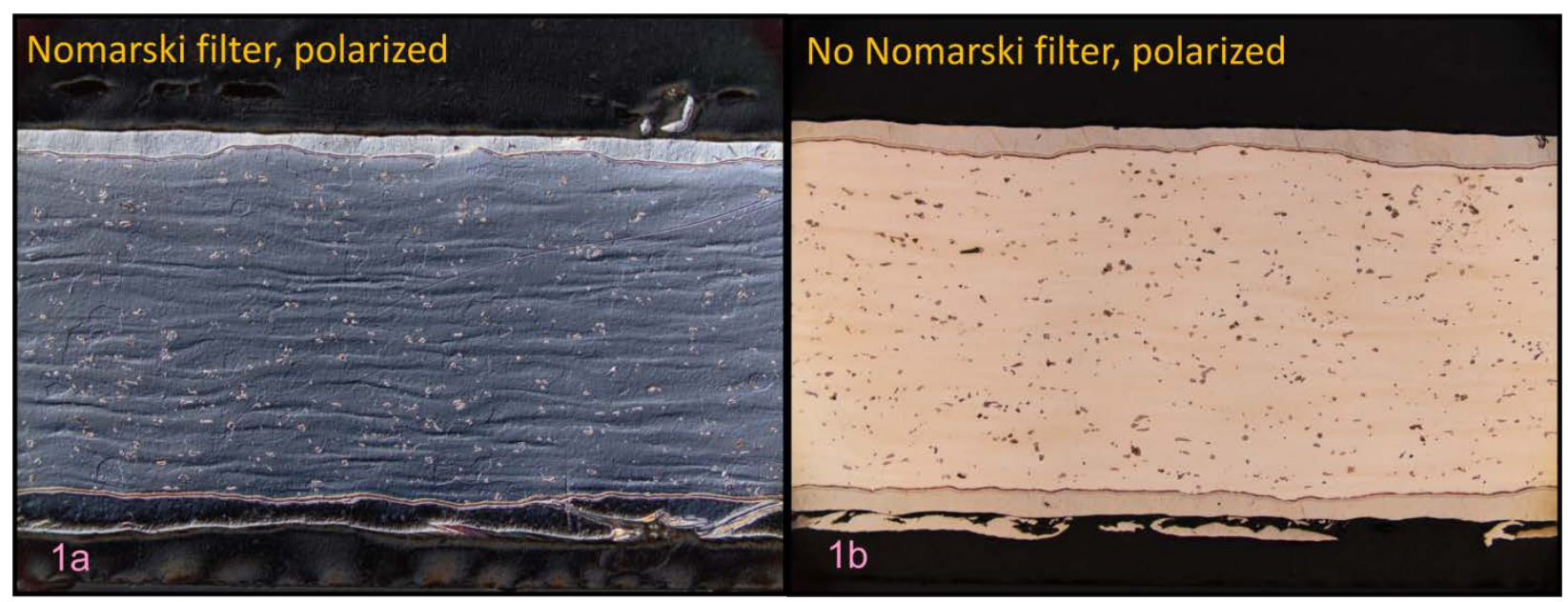

Figure 8.1.1. These images illustrate the effects of electropolishing after the $1 \mu \mathrm{m}$ diamond polish. This technique produced a reasonable surface finish for optical metallography and revealed the overall characteristics of the foil. Figure 1a, with the Nomarski filter in place, shows the uneven surface which could be caused by chemical macrosegregation. The Zirc/U-Mo interface and the U-carbides are also clearly revealed. 


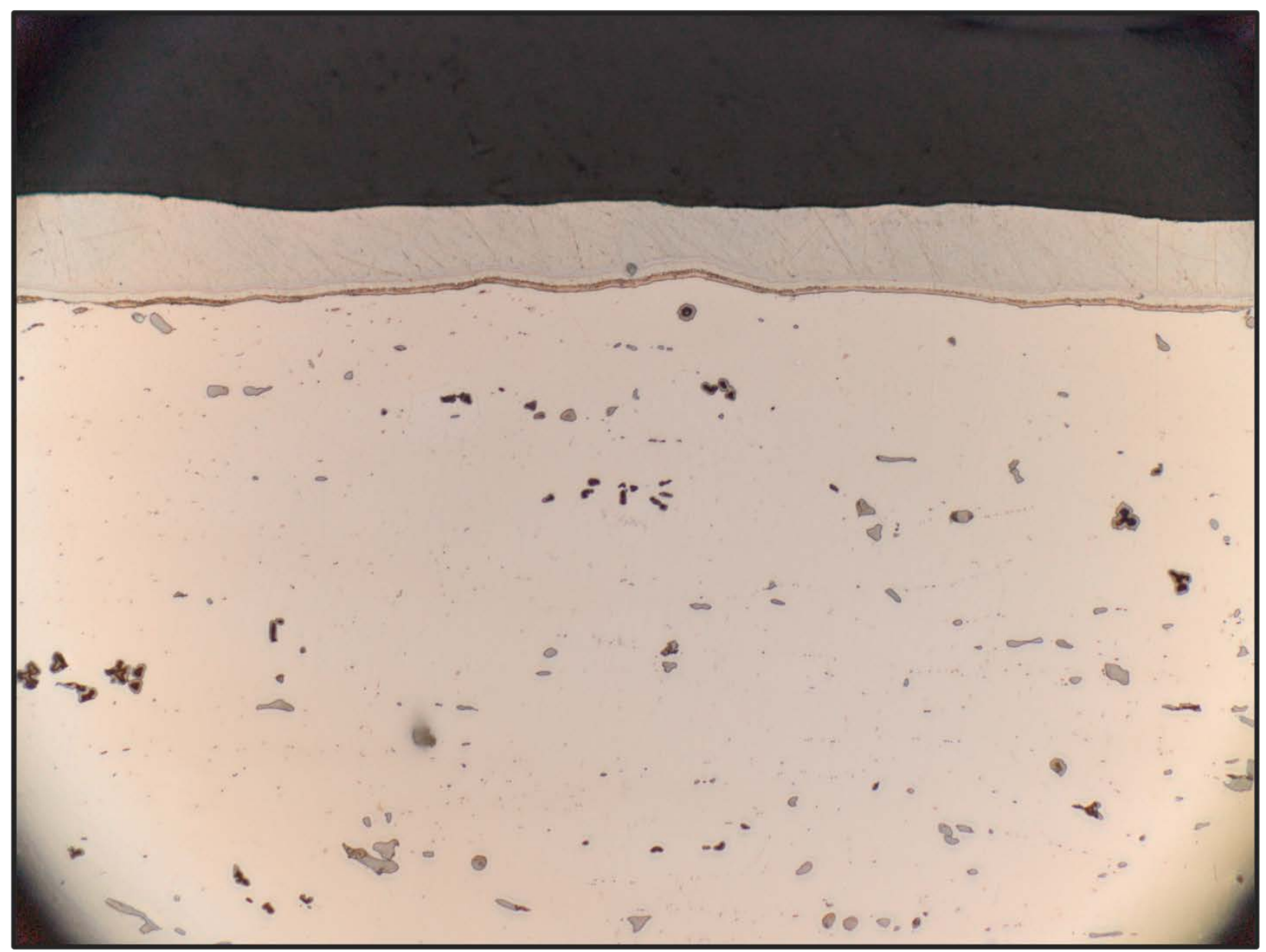

Figure 8.1.2. 500X optical image showing that the zirconium is not polished during the electropolishing process. The diffusion zone, however, is etched and shows clear layers, and electropolishing also reveals different layers in the carbides. 

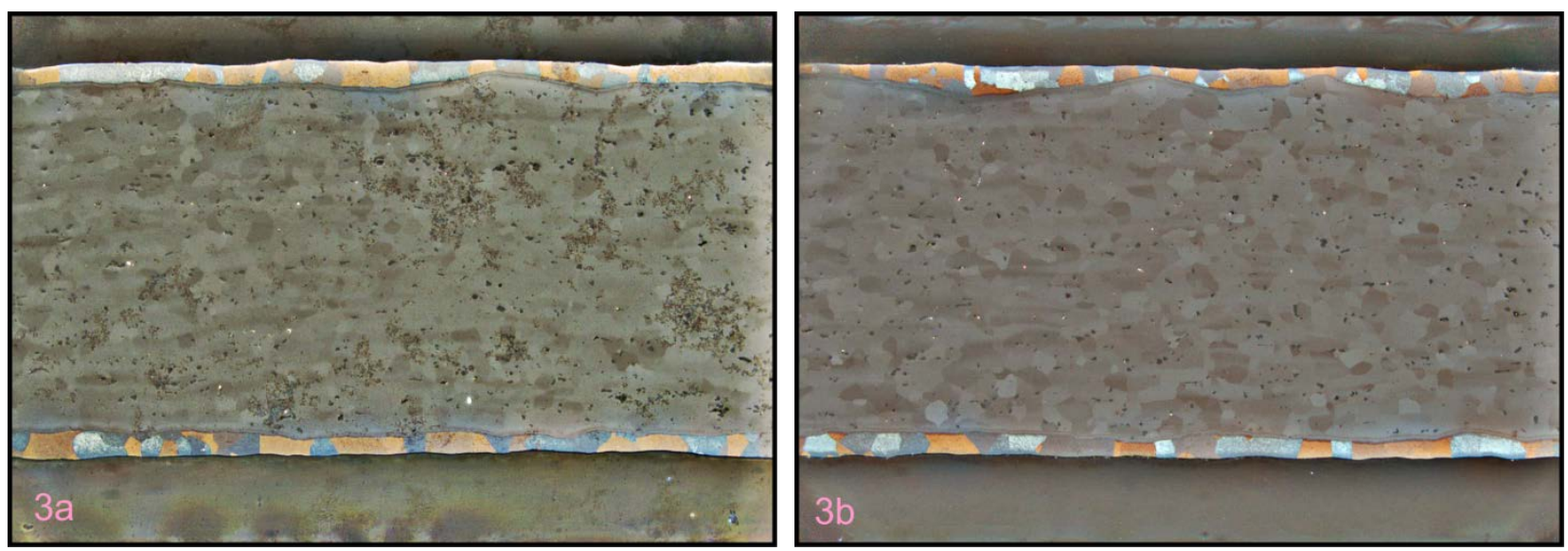

Figure 8.1.3. (a) and (b) 200X Optical images after electropolishing and colloidal silica final polish. The scratches are completely removed after 3.5 hours and a polarized "bamboo" grain structure is now visible in the $\mathrm{Zr}$ layer. We can begin to see the U-Mo grain structure under polarization as well, though oxidation may be inhibiting this effect. Clumps of colloidal silica residue are visible in the optical images.
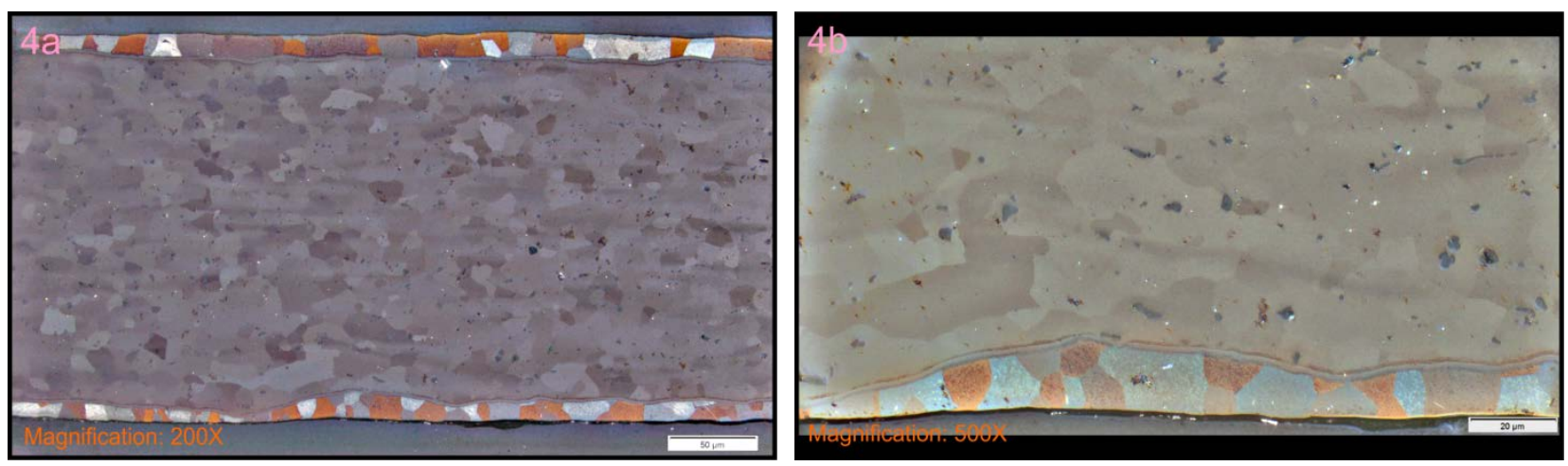

Figure 8.1.4. Optical images after electropolishing and colloidal silica final polish. (a) 200X. (b) $500 X$. The scratches are completely removed after 3.5 hours and a polarized "bamboo" grain structure is now visible in the Zr layer. We can begin to see the U-Mo grain structure under polarization as well, though oxidation may be inhibiting this effect. Clumps of colloidal silica residue are visible in the optical images. 

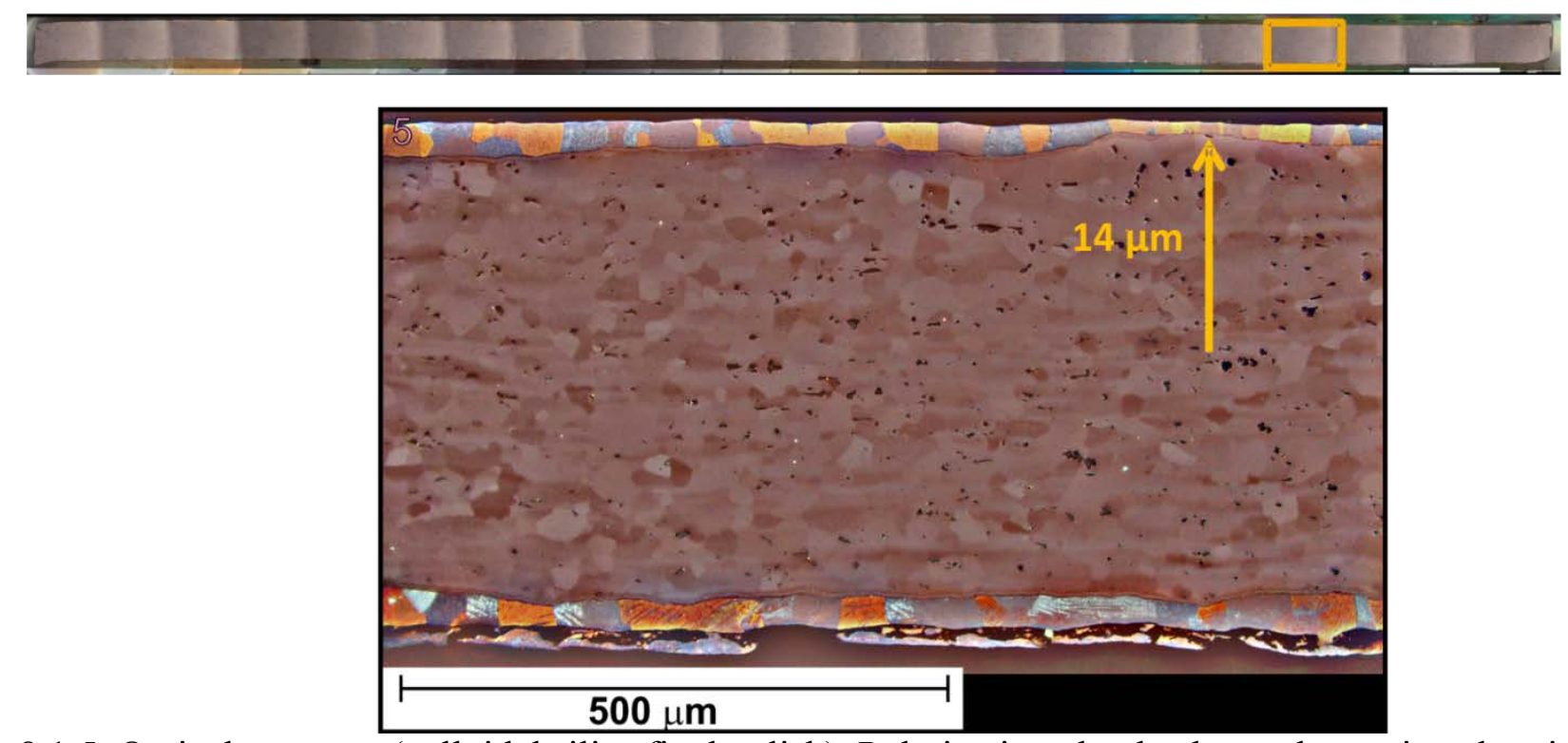

Figure 8.1.5. Optical montage (colloidal silica final polish). Polarization clearly shows the equiaxed grain structure in the U-Mo foil. Carbides, both isolated and in short stringers can be seen throughout the foil. The zirconium layer, as thin as 14 microns in places, displays coase grains with a "bamboo" appearance as described by LANL in previous work.

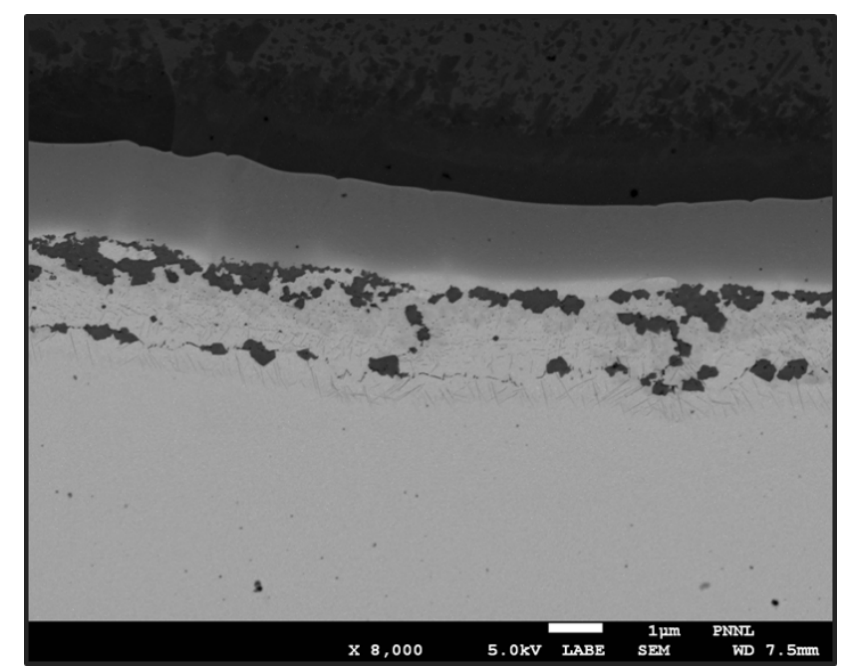

\subsection{6a. LABE SEM image.}

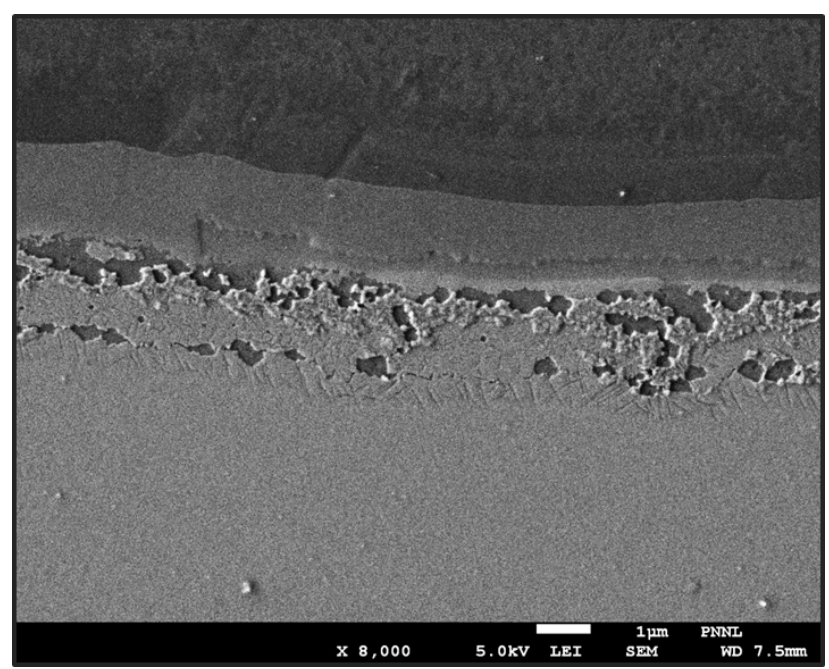

8.1.6b. LEI SEM image.

Figure 8.1.6. SEM image after electropolishing followed by colloidal silica final polish. These images were taken at $8 \mathrm{kX}$ and $5 \mathrm{keV}$. The scratches were completely removed after 3.5 hours on colloidal silica, though the surfaces have already begun to oxidize. Even so, the diffusion layers are clearly visible in both backscattered and secondary electron images. The complicated structure and fine precipitation are both evident inside the diffusion layers. 


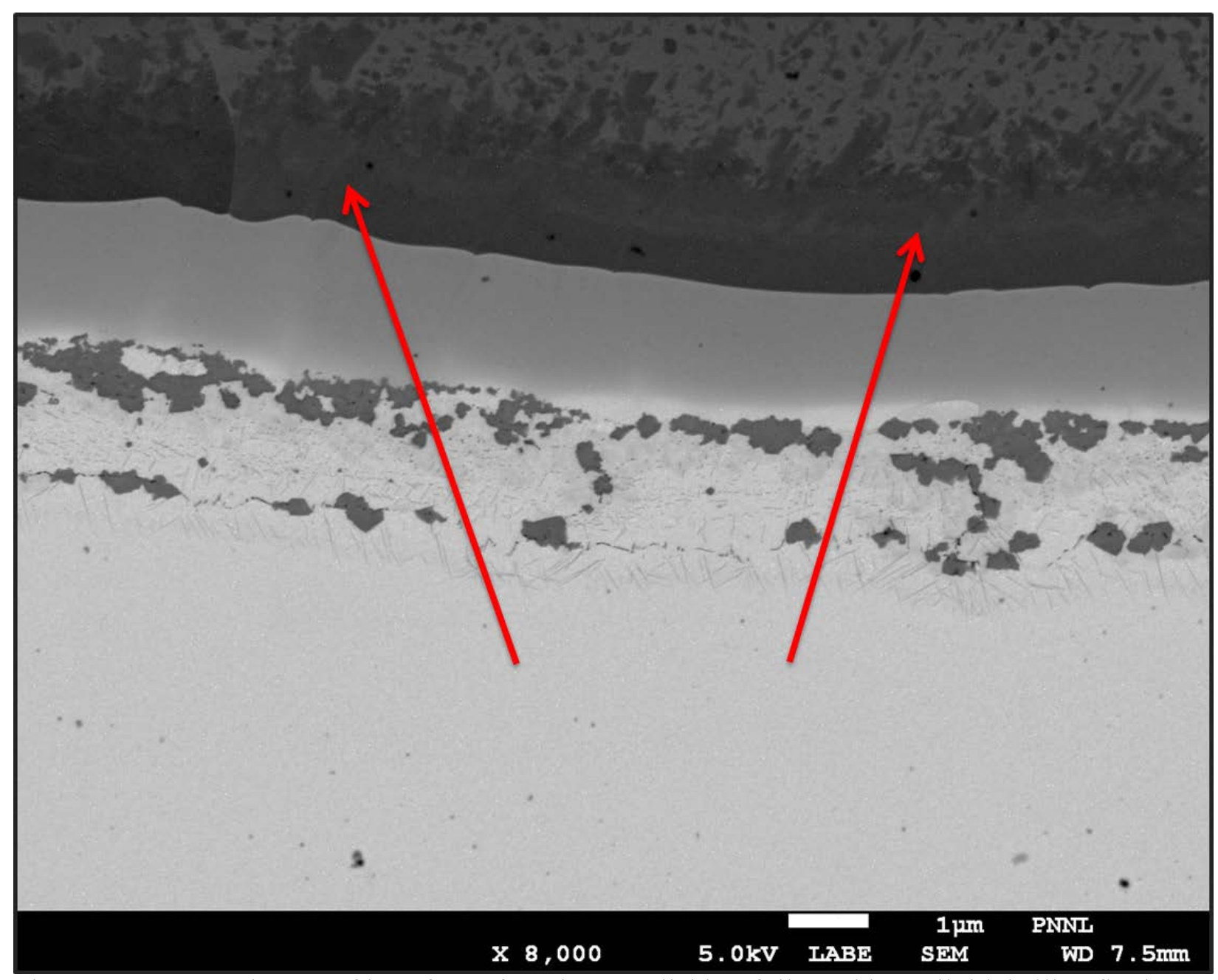

Figure 8.1.7. SEM image of interface after electropolishing followed by colloidal silica final polish. Zirconium region near the Zr-Mo layer appears darker in the backscatter images, Above this oxidized region is pure zirconium with isolated pockets of oxide. 

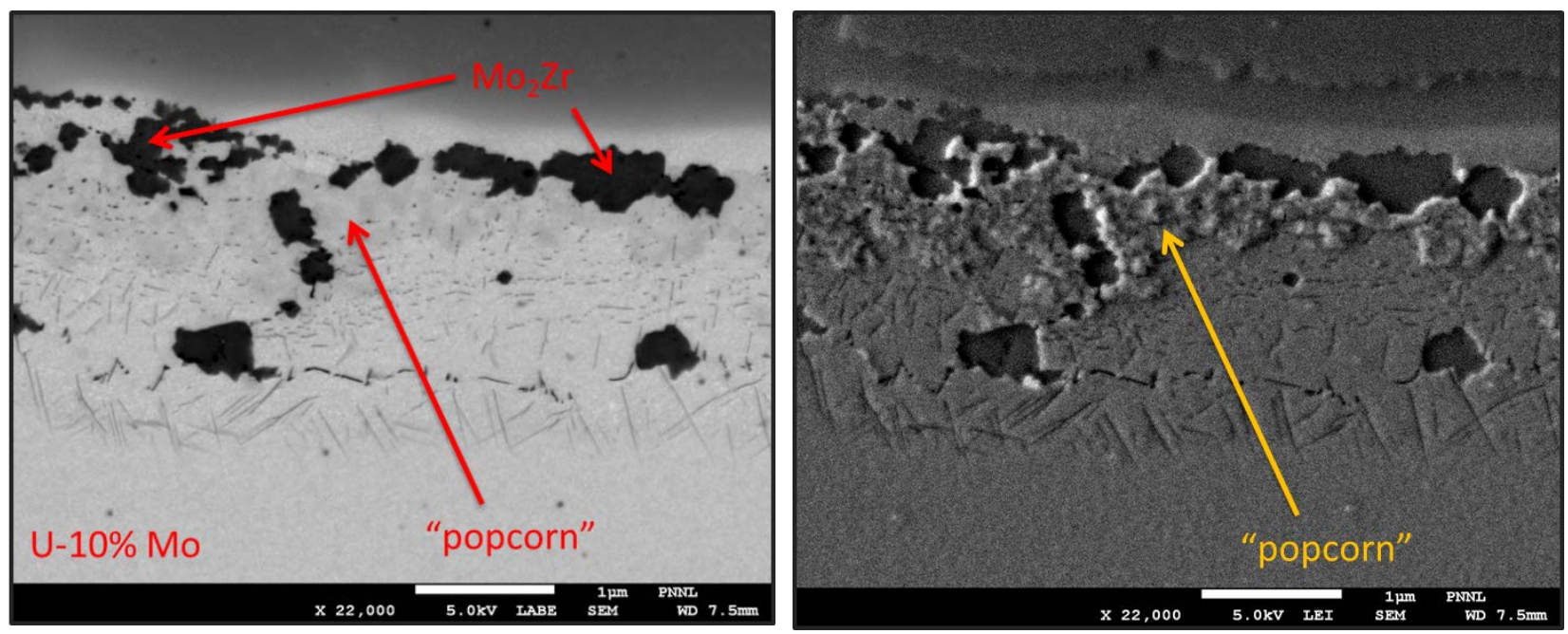

Figure 8.1.8a. LABE Image.

Figure 8.1.8b. LEI Image.

Figure 8.1.8. $22 \mathrm{kx}, 5 \mathrm{keV}$ images after electropolishing followed by a colloidal silica final polish. Note the very fine microstructure and various phases present. While the phases are difficult to analyze compositionally in the SEM, they are easily visible in the images. One phase within the diffusion layer, displaying a "popcorn" appearance, is oxygen-rich according to the EDS map and shows up darker in the backscattered image. The large $\mathrm{Mo}_{2} \mathrm{Zr}$ particles and fine platelets may be the same phase.
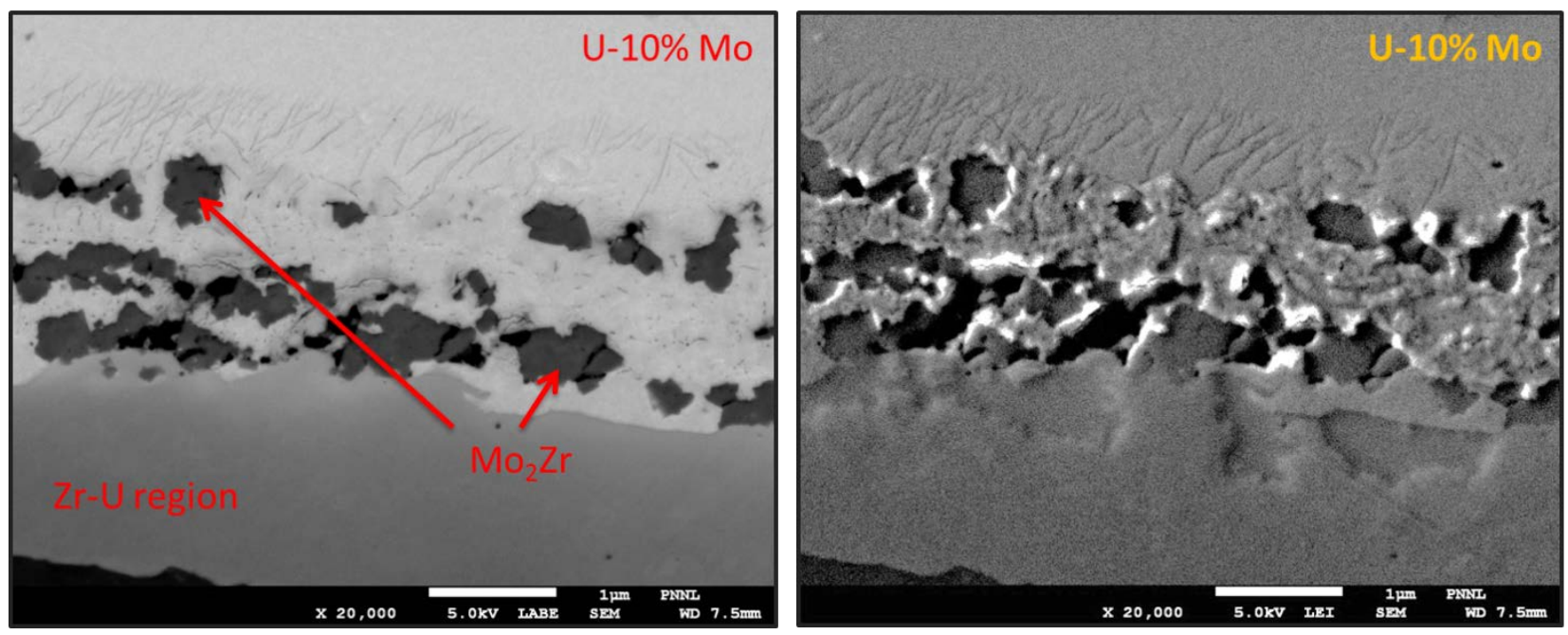

Figure 8.1.9a. LABE Image

Figure 8.1.9b. LEI Image

Figure 8.1.9. $20 \mathrm{kx}, 5 \mathrm{keV}$ images after electropolishing followed by a colloidal silica final polish. These images were taken from the bottom side of the same foil. The same features are common to both sides. 


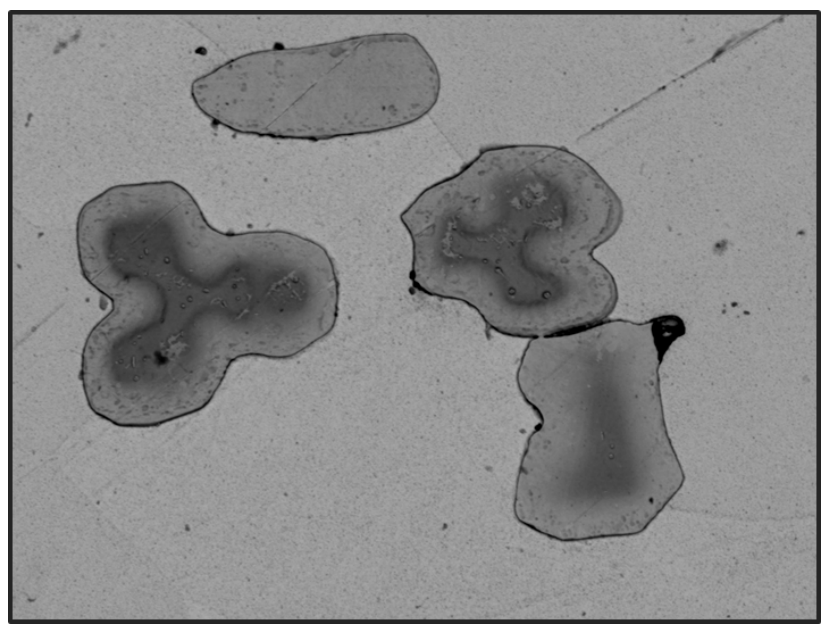

Figure 8.1.10a. LABE Image. Figure 8.1.10b. LEI Image.
Figure 8.1.10. 5keV images after electropolishing. Carbides are present throughout the foil in various shapes and sizes. A shell seems to have formed around the periphery of the particles and we are not completely sure what would cause this appearance.
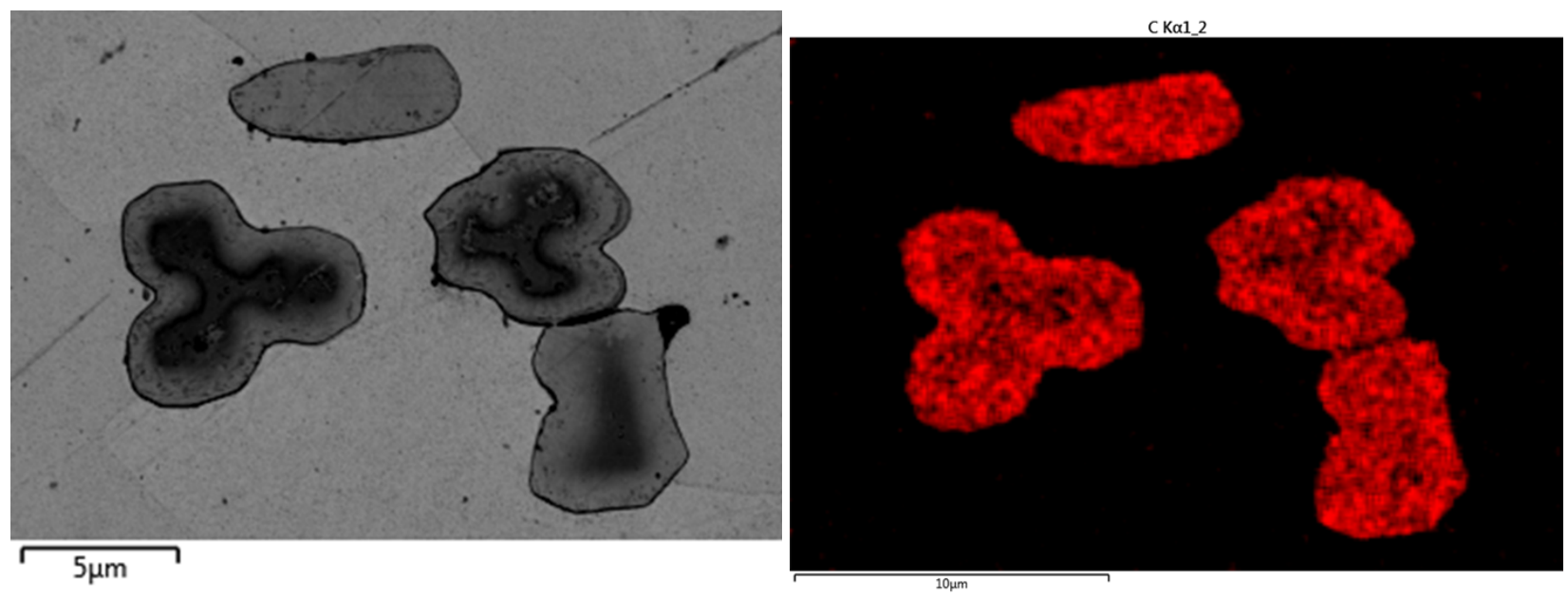

Figure 8.1.11a. LABE Image.

Figure 8.1.11b. Carbon map.

Figure 8.1.11. Carbon map of uranium carbides showing slight enrichment around the outside shell. 


\subsection{PVMF-B1 Transverse.}

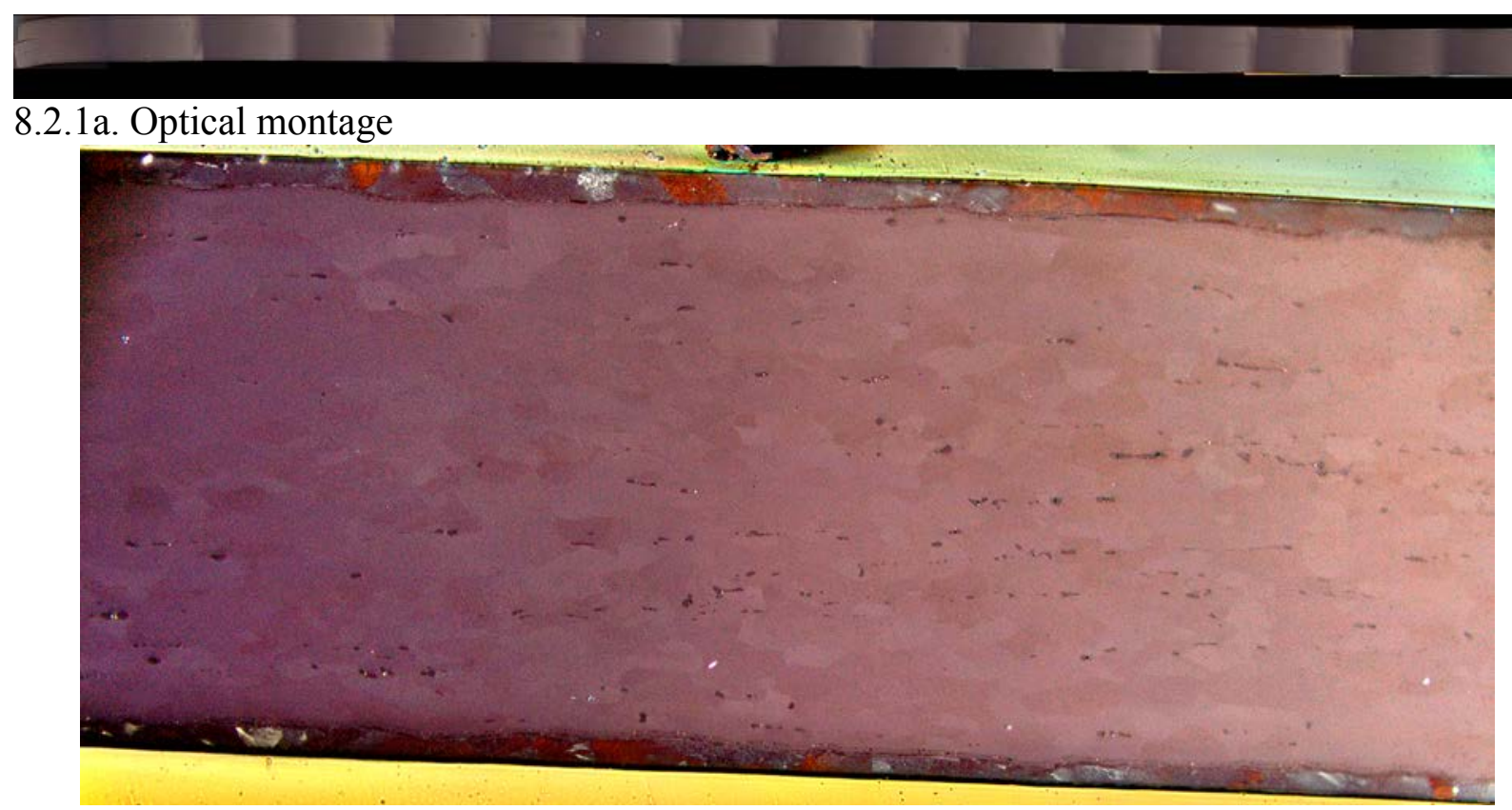

\subsection{1b. Detail.}

Figure 8.2.1. Optical image of bent foil. The U-Mo foil displays an elongated grain structure in this orientation. Again we see carbides present throughout the foil, both isolated and in short stringers. While the zirconium still has the large-grained, "bamboo" appearance as previously described by LANL, the layer is thin in places, as low as 4 to 8 microns.
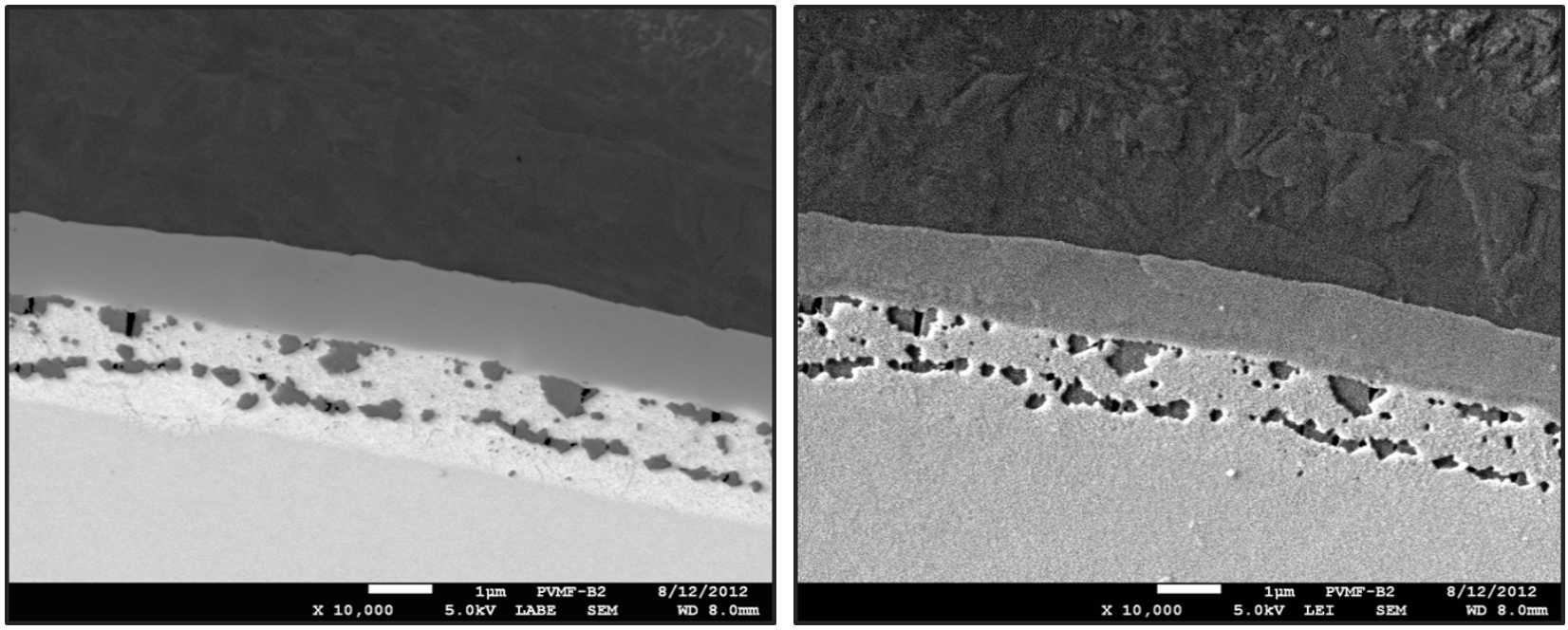

Figure 8.2.2a. LABE Image.

Figure 8.2.2b. LEI Image.

Figure $8.2 .2 .10 \mathrm{kx}, 5 \mathrm{keV}$ SEM images after electropolishing followed by colloidal silica final polish. The diffusion layers are clearly revealed in both backscattered and secondary electron images, showing fine precipitation and very little porosity inside. 

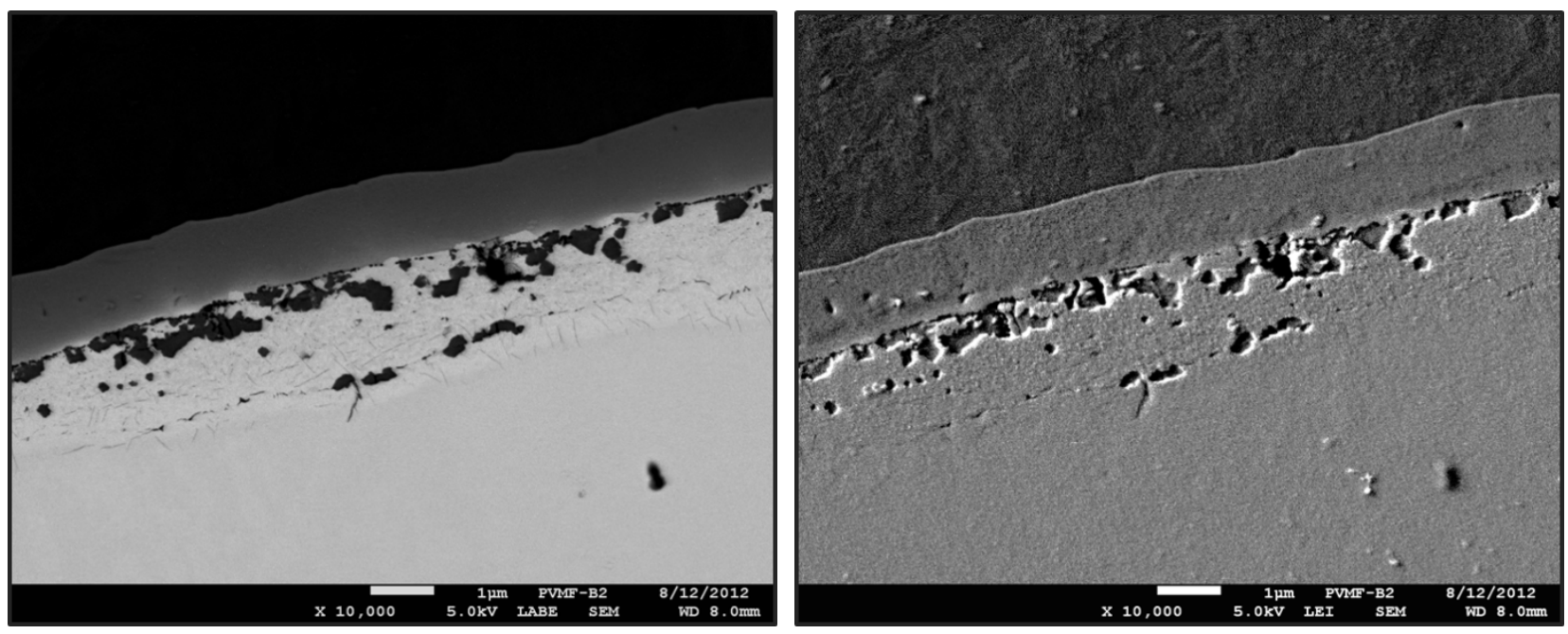

Figure 8.2.3a. LABE Image.

Figure 8.2.3b. LEI Image.

Figure 8.2 .3 . 10kx, 5keV SEM images after electropolishing followed by colloidal silica final polish. The diffusion layers are clearly revealed in both backscattered and secondary electron images, showing fine precipitation and very little porosity inside. 


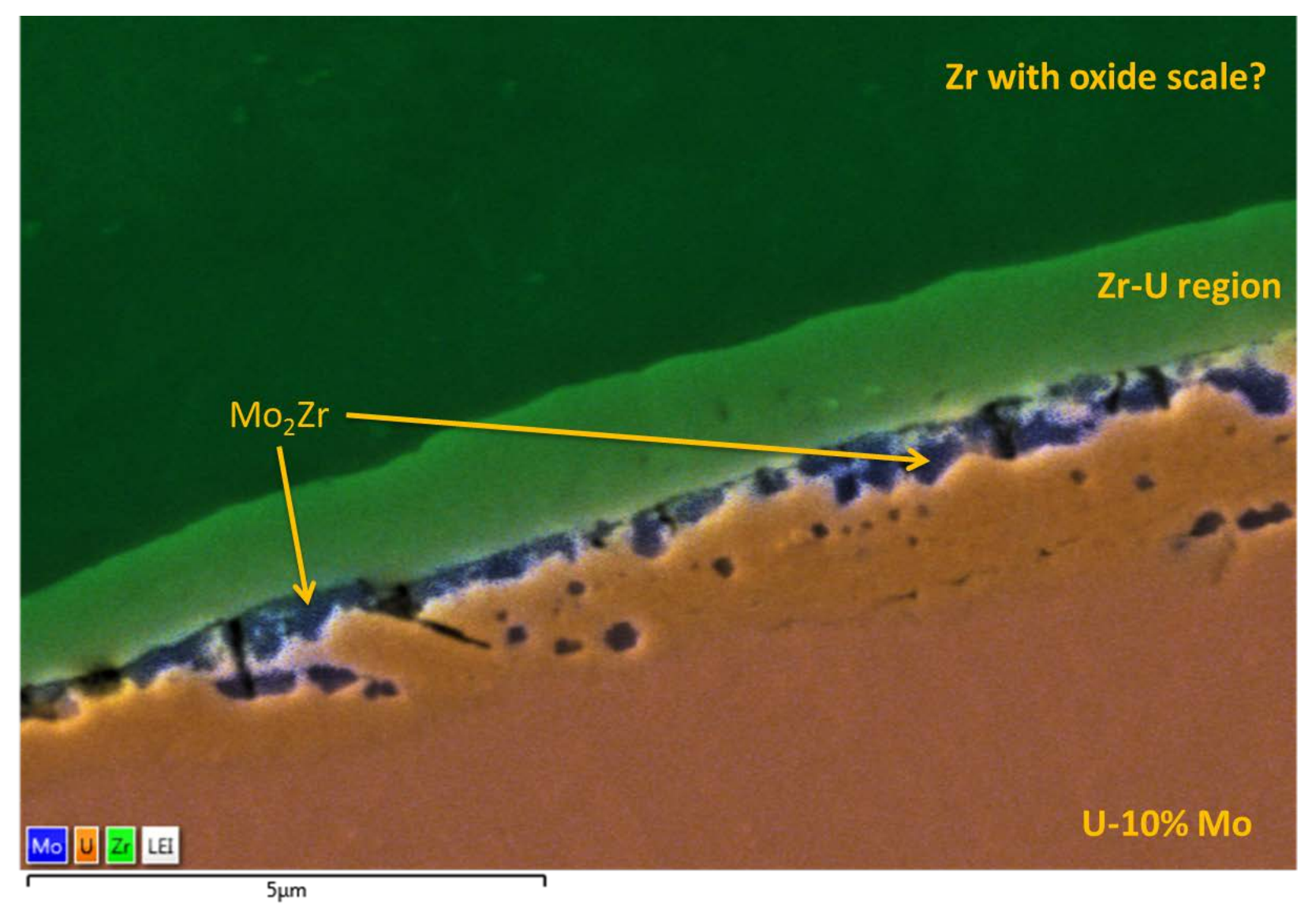

Figure 8.2.4. SEM EDS overlay image after electropolishing followed by colloidal silica final polish. 


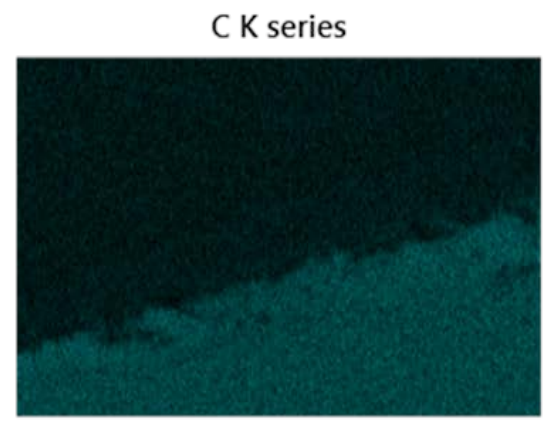

$\longdiv { 2 . 5 \mu \mathrm { m } }$

U M series

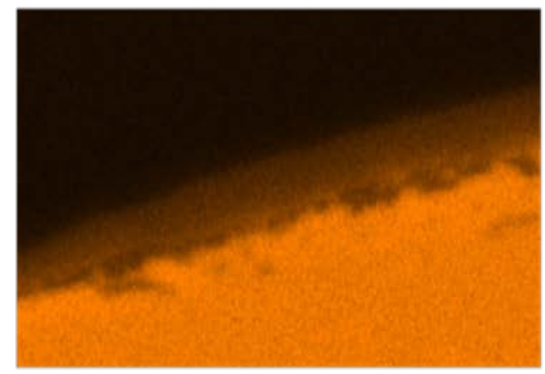

$\longdiv { 2 . 5 \mu \mathrm { m } }$
Mo L series

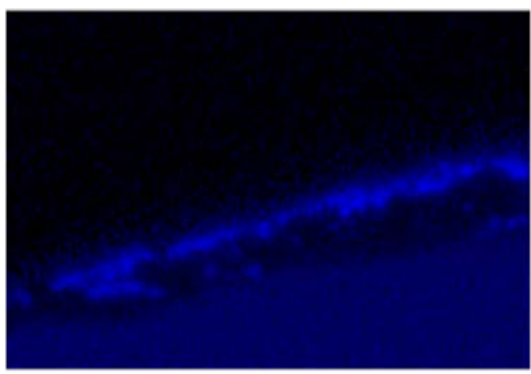

$\longdiv { 2 . 5 \mu \mathrm { m } }$

Zr L series

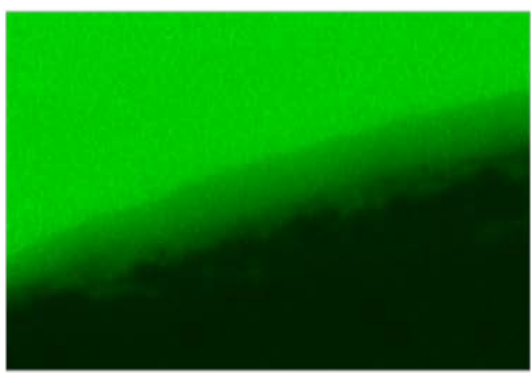

$\longdiv { 2 . 5 \mu \mathrm { m } }$
O K series

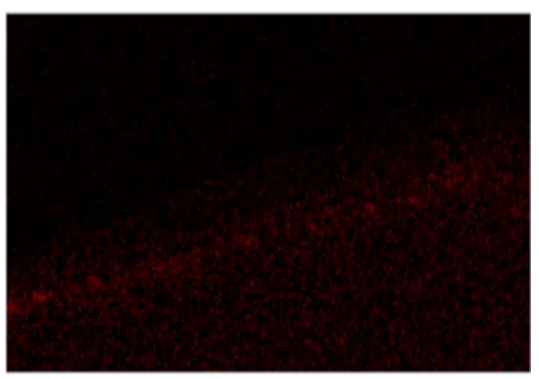

$\longdiv { 2 . 5 \mu \mathrm { m } }$

Figure 8.2.5. $20 \mathrm{keV}$ elemental maps of the interface. The Tru-Map® routine reveals the oxygen enriched region near the $\mathrm{Mo}_{2} \mathrm{Zr}$ precipitate layer. This diffusion zone is approximately 3-4 microns 


Figure 8.2.6a. U and Mo Profiles.




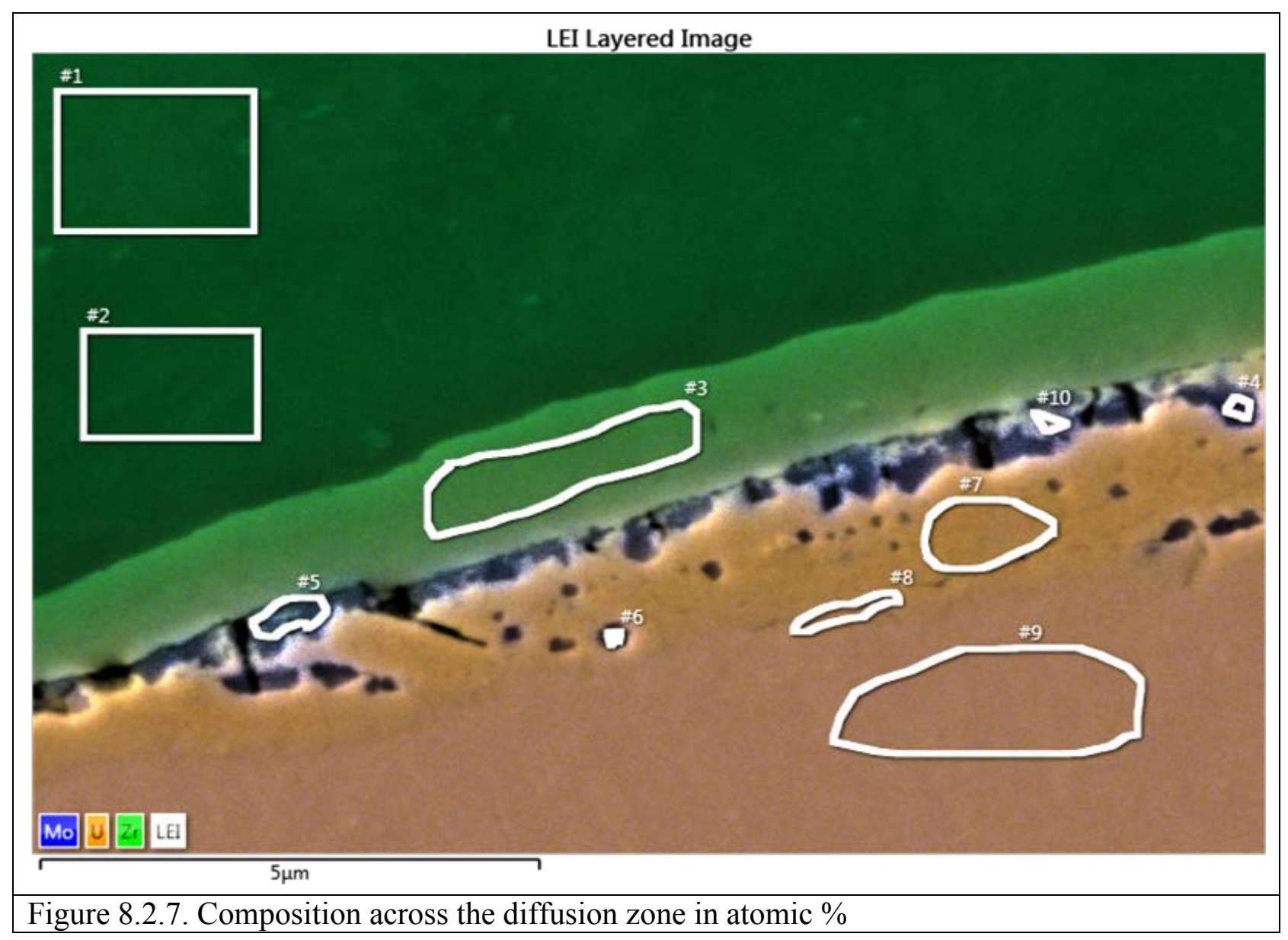

Table 8.2.1

\begin{tabular}{|c|c|c|c|c|c|c|c|c|c|c|}
\hline $\begin{array}{c}\text { Spectrum } \\
\text { Label }\end{array}$ & $\# \mathbf{1}$ & \#2 & \#3 & \#4 & \#5 & \#6 & $\# \mathbf{7}$ & \#8 & \#9 & \#10 \\
\hline $\mathbf{O}$ & 17.6 & 18.3 & 21.0 & 20.7 & 22.7 & 0.00 & 28.3 & 26.0 & 23.8 & 31.8 \\
\hline $\mathbf{F e}$ & 0.0 & 0.0 & 0.0 & 0.0 & 1.2 & 0.0 & 0.0 & 0.0 & 0.0 & 0.0 \\
\hline $\mathbf{Z r}$ & 82.3 & 81.6 & 62.0 & 22.6 & 37.4 & 19.2 & 5.1 & 4.8 & 0.6 & 21.3 \\
\hline Mo & 0.0 & 0.0 & 2.2 & 29.2 & 20.1 & 25.0 & 5.2 & 9.4 & 12.9 & 15.9 \\
\hline $\mathbf{U}$ & 0.0 & 0.1 & 14.8 & 27.5 & 18.7 & 55.8 & 61.5 & 59.8 & 62.7 & 31.1 \\
\hline
\end{tabular}

